Linköping Studies in Science and Technology

Dissertation No. 2164

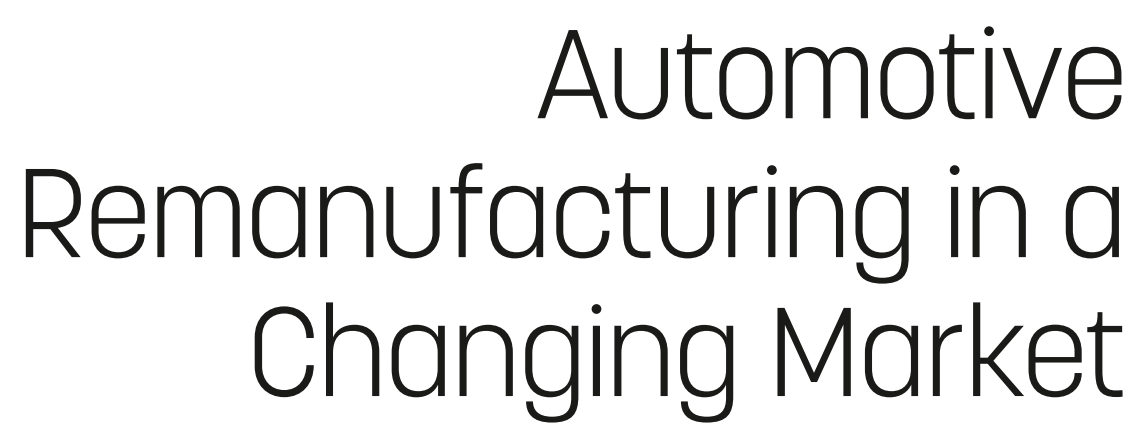

Challenges and Opportunities in a market with a growing share of electric cars

Robert Casper

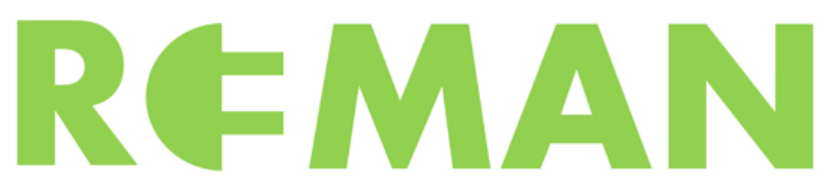

Return 

Linköping Studies in Science and Technology,

Dissertation No. 2164

\title{
Automotive Remanufacturing in a Changing Market Challenges and Opportunities in a market with a growing share of electric cars
}

\author{
Robert Casper
}


(c) $\mathbf{E Y}$ This work is licensed under a Creative Commons Attribution 4.0 International License.

https://creativecommons.org/licenses/by/4.0/

(C) Robert Casper, 2021

Linköping Studies in Science and Technology,

Dissertation No. 2164

ISBN: 978-91-7929-012-2

ISSN: 0345-7524

Printed by: LiU-Tryck, Linköping

Distributed by:

Linköping University

Department of Management and Engineering

SE-581 83 Linköping, Sweden

Tel: +4613 281000, fax: +4613281873 


\title{
Automotive Remanufacturing in a Changing Market
}

Challenges and Opportunities in a market with a growing share of electric cars

\author{
By \\ Robert Casper \\ December 2021 \\ Dissertation No. 2164 \\ ISBN: 978-91-7929-012-2
}

ISSN: 0345-7524
Department of Management and Engineering
Linköping University
SE-581 83 Linköping, Sweden




\section{ABSTRACT}

This doctoral thesis deals with closed-loop supply chains, which include remanufacturing. Remanufacturing can be described as an industrial process to bring back a used good into an "as-good-as-new" condition. Furthermore, focus is put on one of the largest global industry sectors: the automotive industry. The objective of this doctoral thesis is to provide an exploration of the automotive remanufacturing industry and to identify current and future challenges and opportunities with special consideration of a growing share of EVs. This objective is reached by:

- conducting the literature research on automotive part remanufacturing and the latest electric vehicle (EV) technologies,

- performing interviews and questionnaires with experts from the automotive part remanufacturing industry, and

- analyzing and visualizing the processes of automotive part remanufacturing.

Firstly, this thesis brings up an exploration of the challenges this industry is facing today: difficulties in the sourcing and returning of used automotive parts, challenges to identify and disassembly parts, difficulties implementing industrial processes to bring the used parts back into an "as-good-as-new" condition and obstacles to handle and recycle the parts which cannot be reused in an economic and ecological way.

Secondly, this thesis deals with matters resulting from the latest trends in the phase of technical transition towards EVs. This means, for example, new parts (e.g., electric motors, battery packs), new market actors (e.g., Tesla) and different remanufacturing processes (e.g., high-voltage battery remanufacturing) are offering both opportunities and risks: potential for new business, but at the same time, capital-intensive investments into know-how (e.g., schooling, specifications, staff) and machinery and handling new sorts of waste (e.g., hazardous components and materials of batteries).

In a final step, these current and future opportunities and challenges are evaluated, and recommendations for industrial actions are given.

Keywords: Circular Economy, Remanufacturing Process Challenges and Improvements, Process Efficiency, Automotive Part Remanufacturing and Reuse, Internal Combustion Engines (ICE), Battery Electric Vehicles (BEV) 


\section{SAMMANFATTNING}

Denna doktorsavhandling ”Återtillverkning inom bilindustrin på en föränderlig marknad“ utforskar återtillverkning inom cirkulära värdekedjor. Återtillverkning kan beskrivas som en industriell process där använda produkter återförs till nyskick. I avhandlingen läggs vikt vid en av de största globala industrisektorerna, nämligen bilindustrin. Den utförda forskningen i denna avhandling syftar till att förstå dagens utmaningar inom denna industri och till att analysera vilka sorters utmaningar och möjligheter som följer av ett tekniskt skifte mot elektrifiering av fordon. Syftet uppnåddes genom att:

- gå igenom tidigare forskningslitteratur om återtillverkning av bildelar samt om den senaste tekniken inom elbilar

- utföra intervjuer och enkätstudier riktat mot experter från återtillverkningsindustrin för bildelar

- beskriva och visualisera processteg för återtillverkning av olika bildelar

I den första delen av avhandlingen beskrivs utmaningar som industrin står inför idag. Dessa är svårigheter vid anskaffning och insamling av använda bildelar, utmaningar i att identifiera och demontera delar, svårigheter att utföra de industriella processer som återför de använda delarna till nyskick, samt hinder vid hantering och återtillverkning av de delar som inte kan återanvändas på ett ekonomiskt och miljömässigt gynnsamt sätt.

I den andra delen behandlas ämnen som följer av de senaste trenderna inom det tekniska skiftet mot elbilar. Exempelvis betyder detta att nya produkter (såsom elmotorer, batteripaket), nya marknadsaktörer (såsom Tesla) och olika återtillverkningsprocesser (såsom återtillverkning av batteripaket) kan leda till såväl nya möjligheter som risker. Det kan ge potential för nya affärsidéer, men samtidigt kräva kapitalintensiva investeringar inom fackkunskap (t.ex. utbildning, specifikationer och personal), tillverkningsmaskiner, och hantering av nya former av avfall (såsom farligt avfall från batteripaket).

Slutligen, baserat på utvärdering av nuvarande och framtida möjligheter och utmaningar, tas rekommendationer fram riktat mot hur industrin kan agera i pågående teknikskiftet mot elbilar.

Nyckelord: Cirkulär Ekonomi, Återtillverkning, Återtillverkningsprocesser, Processeffektivitet, Bilindustri, Förbränningsmotorer, Elbilar, Elektrifiering 


\section{ACKNOWLEDGMENTS}

With this thesis, my $\mathrm{PhD}$ studies are coming to an end: a project which, all in all, took more than ten very busy but extremely fruitful years. It was a project which was not only the longest in my life so far but also the project which influenced my way of thinking the most.

Projects like this can never be mastered alone. Therefore, I would like to express my sincere gratitude and deepest thanks to all the people who supported me with ideas, input, feedback and motivating words. Particular thanks go to the following persons:

My dear supervisor and "Doktorvater" ${ }^{1}$ Erik. Thank you for your great academic support, patience with me as an Industrial PhD student and for your ever-present kindness. I could never have finished this project without you. In the same way, I would like to thank my dear co-supervisor Mats for his excellent, friendly and helpful feedback and advice.

Furthermore, gratitude is owed to my dear former executives and colleagues Achim, Carsten, Tim, Volker and Willi. You and our common field of work provided the source of inspiration for my research topic. Moreover, you were a rich, precious source of information and motivation.

Finally, my special tribute and deepest thanks to my mother, Lynne, without whom I probably would never have finished this project and my dear father, Herbert, who unfortunately did not live to see the finalization of my studies. To you both, I owe everything I am.

Thank you!

\footnotetext{
${ }^{1}$ German expression for a PhD supervisor; "doctoral father"
} 


\section{APPENDED PAPERS INCLUDING AUTHOR'S CONTRIBUTION}

PAPER I Casper R. and Sundin E. (2018) Addressing Today's challenges in automotive remanufacturing, Journal of Remanufacturing, October 2018, Volume 8, Issue 3, pp 93-102. Presented at the World Remanufacturing Summit (WRS) in Amsterdam, 16 - 17 June, 2015, Amsterdam, The Netherlands.

Robert Casper conducted the literature study. He collected and evaluated the data. Erik Sundin gave feedback and suggested improvements.

PAPER II Casper R. and Sundin E. (2018) Reverse Logistic Transportation and Packaging Concepts in Automotive Remanufacturing, Procedia Manufacturing 25, pp 154-160, Presented at $8^{\text {th }}$ Swedish Production Symposium (SPS), 16 - 18 May 2018, Stockholm, Sweden.

Robert Casper conducted the literature study and the case study and evaluated the data. Erik Sundin gave feedback and suggested improvements.

PAPER III Casper R. and Sundin E. (2021) Electrification in the automotive industry: effects on remanufacturing, Journal of Remanufacturing, Issue 11, pp 121-136. Presented at the International Conference of Remanufacturing (ICoR) 23 - 25 June 2019 in Amsterdam, The Netherlands.

Robert Casper conducted the literature study, executed and evaluated the process of data research and led expert discussions. Erik Sundin created contacts with experts, supported in gaining data and revised the results.

PAPER IV Sundin E., Kurilova-Palisaitiene J and Casper R. (2021) Assessing Automotive Parts for Remanufacturing. Presented at the International Conference of Remanufacturing (ICoR) 24 - 25 March 2021 online.

Erik Sundin collected data for this paper with the support of Robert Casper and Jelena Kurilova-Palisaitiene. Robert Casper conducted information about EV remanufacturing and criteria for market evaluations for remanufacturing companies. 


\section{OTHER PUBLICATIONS}

i. Casper R. (2013). Technical and economic criteria and methods for an evaluation of core in the Automobile Remanufacturing Industry International Conference of Remanufacturing (ICoR) 14 - 16 June 2015 in Amsterdam, The Netherlands, Poster

ii. Casper R. (2015). Predictive Maintenance in Passenger Cars. ReMaTecNews; December 2015;No 6; Volume 15; pp. 28 to 29, Popular science article

iii. Casper R. (2018). Recycling in Thailand "A Paradise between Ambition and Reality - Recycling in Thailand." Internet publication, Popular science article 


\section{TABLE OF CONTENTS}

1. INTRODUCTION ……........................................................................................................

1.1 BACKGROUND......................................................................................................

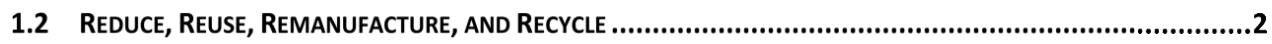

1.3 AUTOMOTIVE REMANUFACTURING ......................................................................................

1.4 TECHNOLOGY TRANSITION TOWARDS ELECTRIC VEHICLES .............................................................6

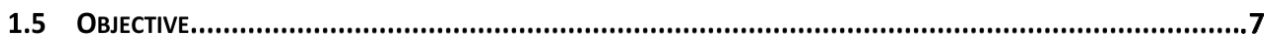

1.6 RESEARCH QUESTIONS .................................................................................................

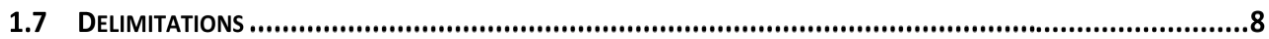

1.8 RESEARCH ETHICS ....................................................................................................

1.9 THESIS STRUCTURE.......................................................................................................

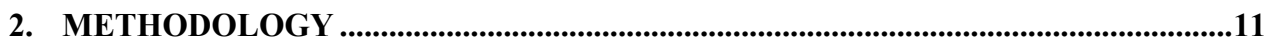

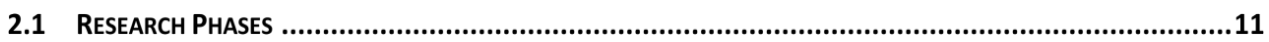

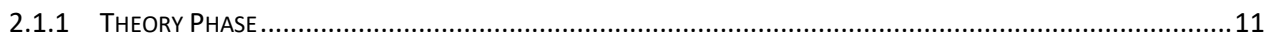

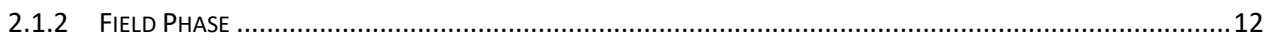

2.1.3 EXPLORATION AND VALIDATION PHASE ………………………………………………….....12

2.1.4 DeVelopment Phase of OVerview About Remanufacturing Challenges .......................................12

2.2 RESEARCH METHODS …..................................................................................................13

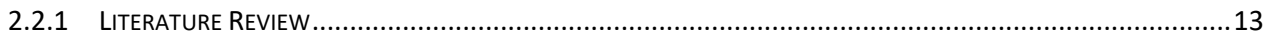

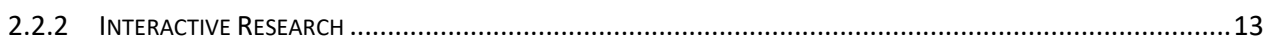

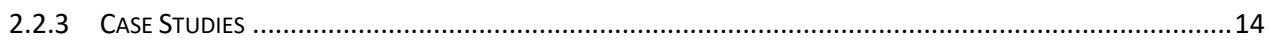

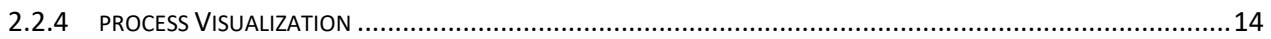

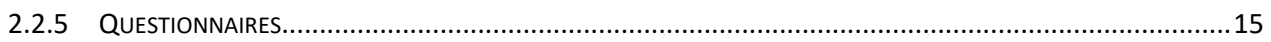

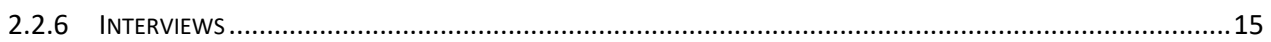

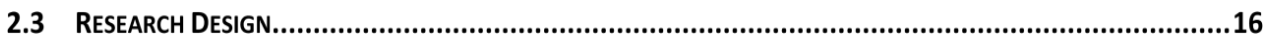

2.4 RESEARCH PROCESSING …………….......................................................................18

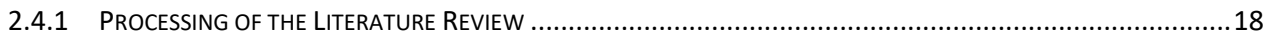

2.4.2 PROCESSING OF INTERACTIVE RESEARCH............................................................................18

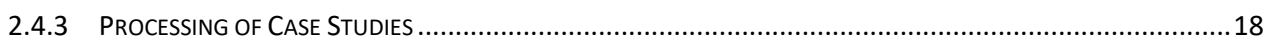

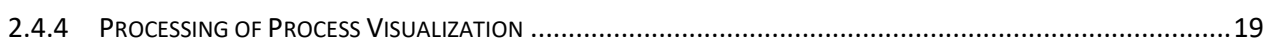

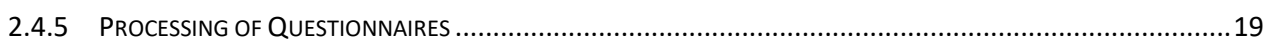

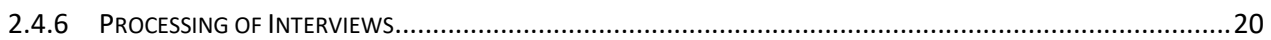

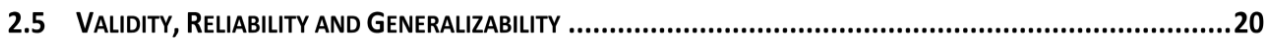

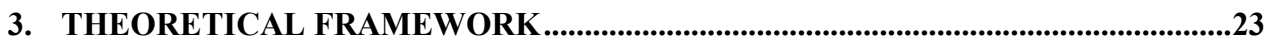

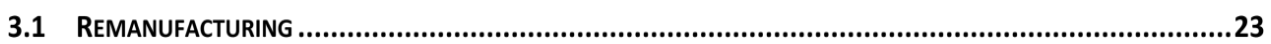

3.2 AUTOMOTIVE REMANUFACTURING ........................................................................................26

3.2.1 MOTIVATION - BENEFITS FROM AUTOMOTIVE REMANUFACTURING ...................................................26

3.2.2 ISSUES—TECHNICAL REASONS FOR AUTOMOTIVE REMANUFACTURING ................................................31

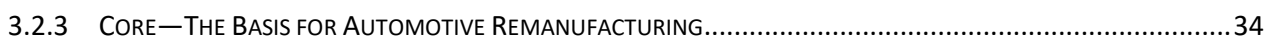

3.3 AUTOMOTIVE REMANUFACTURING PROCESSES .......................................................................

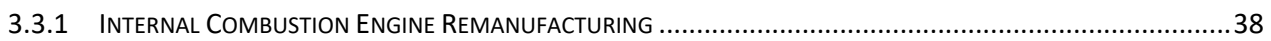

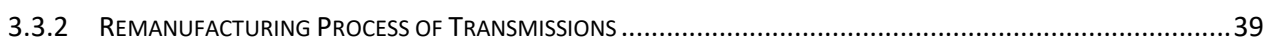

3.3.3 INJECTION SYSTEM REMANUFACTURING .................................................................................

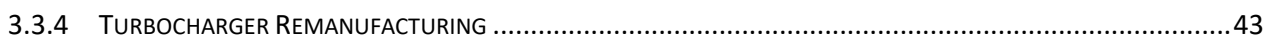

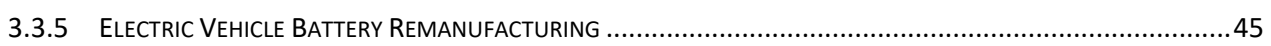

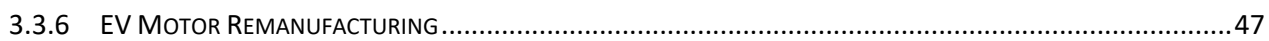


4. TODAY'S CHALLENGES IN AUTOMOTIVE REMANUFACTURING .049

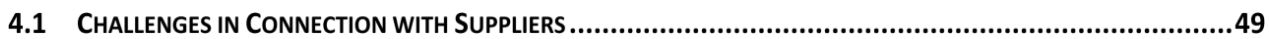

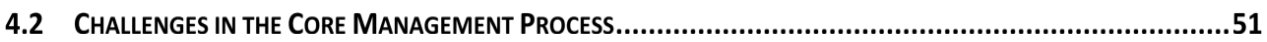

4.3 Challenges in the Identification, Visual CheCKing, Disassembly and Cleaning ............................52

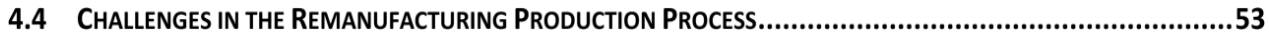

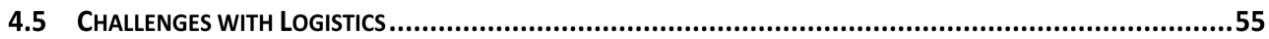

5. FUTURE CHALLENGES AND OPPORTUNITIES IN THE TECHNOLOGY TRANSITION TOWARDS ELECTRIC VEHICLE PART REMANUFACTURING .....59

5.1 CHARACTERISTICS OF THE TRANSITION PHASE

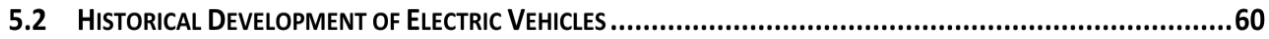

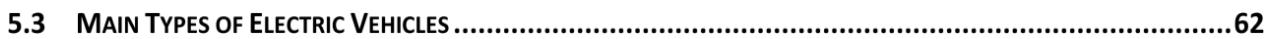

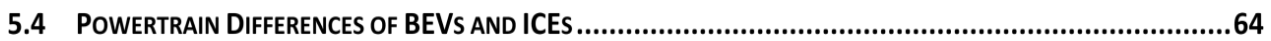

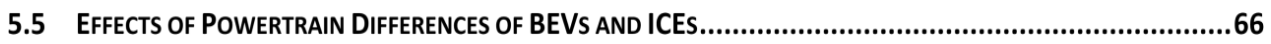

5.6 OpPortunities ANd Challenges in the Remanufacturing of Automotive PARTS for EVs..................70

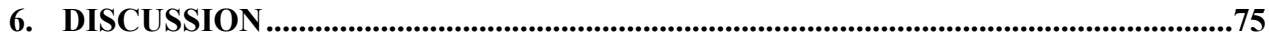

6.1 TODAY'S CHALLENGES IN THE AUTOMOTIVE REMANUFACTURING INDUSTRY .........................................75

6.2 CHALLENGES AND OPPORTUNITIES FOR THE AUTOMOTIVE REMANUFACTURING INDUSTRY IN A PHASE OF

TECHNOLOGY TRANSITION TOWARDS ELECTRIC VEHICLE PART REMANUFACTURING .......................................78

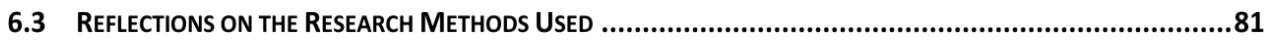

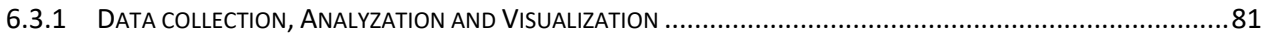

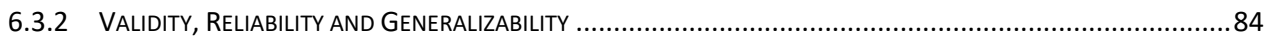

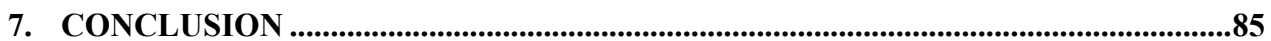

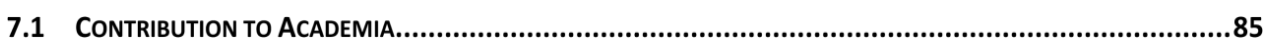

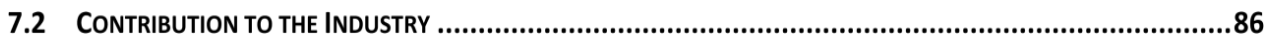

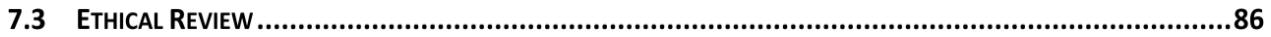

7.4 FUTURE RESEARCH

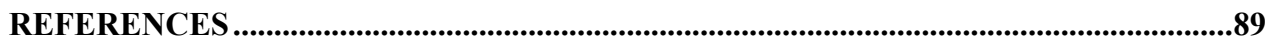

\section{APPENDIX A; APPENDED PAPERS}

Paper I Addressing Today's challenges in automotive remanufacturing Paper II Reverse Logistic Transportation and Packaging Concepts

Paper III Electrification in the automotive industry: effects on remanufacturing Paper IV Assessing Automotive Parts for Remanufacturing

$\begin{array}{ll}\text { APPENDIX B; SUPPORTING FILES } \\ \text { B1 } & \text { Remanufacturing processes visualized with BPMN } \\ \text { B2 } & \text { Expert list } \\ \text { B3 } & \text { Questionnaire } \\ \text { B4 } & \text { Answers from experts }\end{array}$




\section{LIST OF FIGURES}

Figure 1: The Waste Management Hierarchy ................................................................ 4

Figure 2: Reuse, remanufacturing and recycling in a closed-loop supply chain .............. 5

Figure 3: Research phases on a timeline, including their main elements ....................... 11

Figure 4: Visualization of the distribution of new parts and demand for spare and

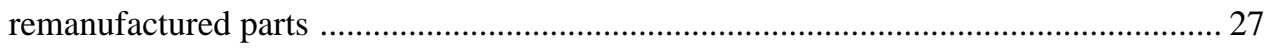

Figure 5: Internal and external sources for core parts ................................................ 35

Figure 6: Forecast of annual share of sales of EVs and ICEs....................................... 62

Figure 7: Simplified illustration of the main parts of cars with internal combustion engines (ICE) (left) and battery electric vehicles (BEV) (right). Parts that have the potential for

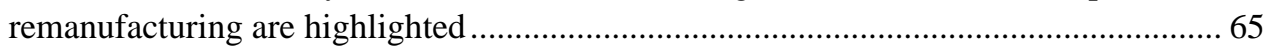




\section{LIST OF TABLES}

Table 1: Structure of dissertation and content per chapter.... 10

Table 2: Overview of research questions and relevant publications focusing on each

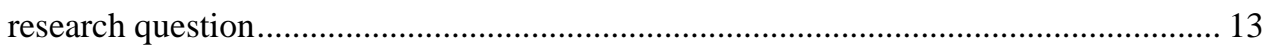

Table 3: Motivation of usage for the research methods used ........................................ 16

Table 4: Summary of sent and received questionnaires for Paper III............................. 19

Table 5: Interview partner with experts from the industry ………………………........ 20

Table 6: Reliability techniques and their usage in the thesis ........................................ 21

Table 7: Forms of generalization and their usage in this thesis..................................... 22

Table 8: Industrial sectors performing remanufacturing in Europe................................ 23

Table 9: Challenges of remanufacturing effecting process lead times ........................... 25

Table 10: Distribution channels and business concepts of remanufactured parts .......... 28

Table 11: Distribution channels for core parts for OEM/OES and IAM......................... 35

Table 12: Remanufacturing processes of injectors and injection pumps ....................... 42

Table 13: EV strategy of prominent OEMs (Deloitte, 2020) .......................................... 61

Table 14: Main types of today's electric vehicles ........................................................... 63

Table 15: Simplified process flows of the remanufacturing procedure of mechanical parts from internal combustion engines and parts from an electric motor ................................. 66

Table 16: Effects based on the main differences between the remanufacturing procedure

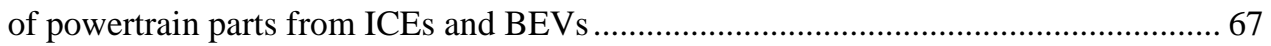

Table 17: Evaluation of statements made by industry experts $(\mathrm{N}=20)$...........................69

Table 18: SWOT analysis reflecting the usage of questionnaires in this thesis ............. 82

Table 19: SWOT analysis reflecting the usage of interviews in this thesis................... 83 


\title{
ABBREVIATIONS \& TERMINOLOGY
}

\section{ACEA (EUROPEAN AUTOMOBILE MANUFACTURERS' ASSOCIATION)}

The European Automobile Manufacturers' Association (ACEA) is an organization of the automobile industry representing 16 OEMs in Europe (ACEA, 2021).

\begin{abstract}
AFTERMARKET
Aftermarket parts are for service and repair, whereas original equipment parts are for the production of new vehicles. If aftermarket parts are sourced via the manufacturer, they are called Original Equipment Service ( $\rightarrow$ OES) parts; if not, they are called Independent Aftermarket ( $\rightarrow$ IAM) parts (Subramoniam, 2012).
\end{abstract}

ANSI (AMERICAN NATIONAL STANDARDS INSTITUTE)

Institute with the aim to set "standards and conformity assessment activities in the United States" (ANSI, 2021).

\section{APRA (AUTOMOTIVE PARTS REMANUFACTURERS ASSOCIATION)}

Association of about worldwide 1,000 member companies of the remanufacturing industry according to its own statements (APRA, 2020).

\section{BEV (BATTERY ELECTRIC VEHICLE)}

Vehicle exclusively using energy stored in rechargeable batteries (Ning et al., 2017).

BPMN (BUSINESS PROCESS MODELLING NOTATION)

Software-based technique to model business process (Kluza et al., 2017).

\section{CEO (CHIEF EXECUTIVE OFFICER)}

\section{CLSC (CLOSED-LOOP SUPPLY CHAIN)}

Efforts to manage production residues to decrease waste. Closed-loop supply chains consist of a return process to integrate additional value (Szmelter, 2016). A closed-loop supply chain focuses "on taking back products from customers and recovering added value by reusing the entire product, and/or some of its modules, components and parts." (Guide and van Wassenhove, 2009). Integration of forward and reverse logistics in a supply chain (Amin, 2012). CLSCs refer to a complete life cycle and which consist of forward as well as reverse logistics processes through remanufacturing or other recovery processes (Xia et al., 2011).

\section{CORE}

Used part intended for reuse, for example, remanufacturing (Wei et al., 2015). "A core is a previously sold, worn or non-functional product or part, intended for the remanufacturing process. During reverse logistics, a core is protected, handled and identified for remanufacturing to avoid damage and to preserve its value. A core is not waste or scrap and is not intended to be reused before remanufacturing" (APRA, 2016). 
CR (CONTRACTED REMANUFACTURER)

Company conducting the remanufacturing for the OEM/OES and supplying to its supply chain (Oestlin, 2008).

CRADLE-TO-CRADLE ATTITUDE

Approach to create products and processes sustainable (Bakker et al., 2010).

CRHA (CENTER ROTATING HOUSING ASSEMBLY)

Part of a turbocharger. "An exemplary center housing for a turbocharger includes a compressor end and a turbine end and a through bore that includes a turbine end opening for receiving a bearing cartridge and shaft subassembly" (EPO, 2009).

CRM (CUSTOMER RELATIONSHIP MANAGEMENT)

"CRM is a philosophy, process, concept of development and management of customer relationships" (Laketa et al., 2015).

\section{DfE (DESIGN FOR ENVIRONMENT)}

"The Design for the Environment (DfE) Program began in the early 1990s as an innovative, non-regulatory initiative to help companies consider human health, environmental and economic effects of chemicals and technologies, as well as product performance, when designing and manufacturing commercial products and processes" (EPA, 2021).

\section{DfRem (DESIGN FOR REMANUFACTURING)}

Approach to respect requirements for remanufacturing in the product design phase in order to improve the remanufacturing feasibility and efficiency (Hatcher et al., 2011).

\section{DRESS LEVEL}

The dress level of an engine defines its delivery scope. Each dress level indicates what kinds of engine parts are part of the scope. Typical dress levels are the "short block engine" (consisting of the engine block, including crankshaft, pistons and connecting rods), the "long block engine" (consisting of all parts of a "short block engine" plus cylinder-head with camshaft, lifters and valves) and the "full dress level" (consisting of all parts of a "long block engine" plus auxiliary parts, e.g., starter motor, alternator fuel injection equipment) (Ridley and Ijomah, 2021; Walton, 2021).

\section{ECU (ELECTRONIC CONTROL UNIT)}

Information measured by sensors is processed in electronic control units (ECU) and is dependent on the sensor information giving commands to actuators. In addition to other appliances, ECUs have an important role in the functionality of modern vehicles, for example, for built-in diagnosis, safety, security and comfort (Kleylein-Feuerstein et al., 2015). 


\section{EDO (END OF DELIVERY OBLIGATION)}

"Machine and plant manufacturers are obligated to supply their customers with spares. Legal and voluntary obligations determine the duration and extent of spares provision. "Legal obligations" are triggered by the customer's rights in the event of a defect, and "voluntary obligations" are triggered by contractual agreements or warranty obligations"

(Wagner et al., 2017b). The point in time when this obligation ends is called the "end of delivery obligation," or EDO.

\section{EOP (END OF PRODUCTION)}

Closing production activities of a certain product or certain program after producing the last item (Wagner, 2017a).

\section{EPR (EXTENDED PRODUCER RESPONSIBILITY)}

In this thesis: Making car manufacturers responsible for battery recycling by assuring the collection, efficient recycling processes and a design respecting the requirements for recycling (Murphy, 2017).

\section{EOQ (ECONOMIC ORDER QUANTITY)}

"In inventory management, Economic Order Quantity (EOQ) is the quantity of orders that minimize the total cost of containment and booking fees (...). The booking fee is the cost to order and receive the stockpile. This includes determining how much is needed, preparing invoices, transportation costs and inspection fees" (Riza and Purba, 2018).

\section{EREV (EXTENDED-RANGE ELECTRIC VEHICLES)}

Electric vehicles running mostly on battery but consisting of a combustion engine in order to recharge the battery when this runs low (Yatheesha et al., 2014).

\section{ERP (ENTERPRISE RESOURCE PLANNING)}

"Enterprise resource planning systems or enterprise systems are software systems for business management, encompassing modules supporting functional areas such as planning, manufacturing, sales, marketing, distribution, accounting, financial, human resource management, project management, inventory management, service and maintenance, transportation and e-business" (Hossain et al., 2003).

\section{EU (EUROPEAN UNION)}

\section{EUROPEAN GREEN DEAL}

A package of activities initiated by the European Commission with the overall aim to become climate-neutral in the European Union (EU, 2019a).

\section{EV (ELECTRIC VEHICLE)}

In this thesis: Car powered completely or partly by electricity

FCEV (FUEL CELL ELECTRIC VEHICLE)

Electric vehicle fed by hydrogen (Briguglio et al., 2011). 


\section{GDP (GROSS DOMESTIC PRODUCT)}

GMI (GÜTEGEMEINSCHAFT DER MOTORENINSTANDSETZUNGSBETRIEBE E.V)

Association of German engine remanufacturing companies with aim to set quality standards (GMI, 2020a).

\section{GREEN BUSINESS}

Synonym for sustainable business.

\section{GWP (GLOBAL WARMING POTENTIAL)}

"The global warming potential index (GWP) has been proposed to quantitatively compare the integrated greenhouse effect of different gases” (Rosa and Schaeffer, 1995).

\section{HEV (HYBRID ELECTRIC VEHICLE)}

Vehicle in which propulsion relies on both the (diesel/gasoline) engine and the electric motor (Ning, 2017).

\section{IAM (INDEPENDENT AFTERMARKET)}

The market for parts and services not controlled by the OEM (->). Stakeholders can be, for example, automotive suppliers, generic manufacturers, independent distributors, garages or buying groups (McKinsey, 2017).

\section{ICE (INTERNAL COMBUSTION ENGINE)}

Vehicle consisting of a conventional combustion engine using diesel or gasoline (Briguglio et al., 2011).

\section{IR (INDEPENDENT REMANUFACTURER)}

Company implementing remanufacturing without being controlled or contracted by the OEM/OES (Oestlin, 2008).

\section{MOQ (MINIMUM ORDER QUANTITY)}

"Minimum order quantities or MOQs are the minimum order size that the supplier is willing to accept. This is often expressed as the minimum number of units. However, suppliers may also set the minimum order quantity in terms of order value" (Slimstock, 2019).

\section{OBD (ON-BOARD DIAGNOSIS)}

"Parameters observed and diagnosed by OBD system are used by the Electronic Control Unit (ECU, also see -> ECU) of vehicle which in turn controls the engine's main operation (like spark timing control, air fuel mixture, fuel injectors spraying period etc.). Combination of these two systems ensures safety and efficient vehicle operation" (Nandhini et al., 2014). 
OEM (ORIGINAL EQUIPMENT MANUFACTURER)

Automotive company providing a value chain of product development, logistics, manufacturing and sales of new cars (Capgemini, 2010).

OER (ORIGINAL EQUIPMENT REMANUFACTURER)

Remanufacturing performed and distributed by the OEM/OES (Oestlin, 2008).

\section{OES (ORIGINAL EQUIPMENT SUPPLIER)}

Network of OEM (->) providing parts and services in the aftersales phase (Capgemini, 2010).

\section{PART/CAR PART}

A part or car part, as it is defined in this thesis, is a piece of a car that is manufactured and distributed to build or repair a car (Cambridge, 2021a). A part (e.g., a combustion engine) can therefore consist of several pieces (e.g., cylinder head, pistons, crankshaft, etc.). Different terms are "components," "products," "assemblies" or "subassemblies." For this thesis, these terms are covered by the term "(car) part."

\section{PCV (POSITIVE CRANKSHAFT VENTILATION)}

"Positive Crankcase Ventilation is a system that was developed to remove harmful vapors from the engine and to prevent those vapors from being expelled into the atmosphere (...). PCV systems have been standard equipment on all new cars since the early sixties" (FMC, 2020).

\section{PHEV (PLUG-IN HYBRID ELECTRIC VEHICLE)}

Electric vehicle consisting of a conventional combustion engine using diesel or gasoline and an electric motor. As it can be charged by connecting it to external 110/230-volt electric systems, it can reduce the consumption of fuel (Björnsson et al., 2018).

\section{POWERTRAIN}

"(in a motorized vehicle) the whole mechanism by which power is generated and transmitted to the road (...)" (Collins, 2021). The main parts of an ICE powertrain are the engine, the transmission and the exhaust system. The main parts of a BEV powertrain are the motor and the battery system (McKinsey, 2021a).

QM (QUALITY MANAGEMENT)

R\&D (RESEARCH AND DEVELOPMENT)

REEV (RANGE EXTENDED ELECTRIC VEHICLES)

$\rightarrow$ EREV

RQ (RESEARCH QUESTIONS) 
SEV (SOLAR ELECTRIC VEHICLE)

Electric vehicles consisting of solar panels feeding the rechargeable batteries (Mohammadia, 2018).

SWOT (STRENGTHS, WEAKNESSES, OPPORTUNITIES, AND THREATS ANALYSIS)

TIER-1, TIER-2, and TIER-N

"Tier-1s" are companies supplying the car manufacturer directly. "Tier-2s," "Tier-3s," and "Tier-ns" supply to the company that follows them in the relevant supply chain. Example: A "Tier-2" is supplying a "Tier-1" that is eventually supplying the OEM/car manufacturer (ILO, 2005).

VTG (VARIABLE TURBINE GEOMETRY)

Turbocharger using a regulated turbine. The goal is "to expand the usable flow rate range in practical applications while maintaining a high level of efficiency. To accomplish this, the turbine output is regulated by changing the inflow angle and inflow speed at the turbine wheel inlet" (BW, 2021). 


\section{INTRODUCTION}

This chapter describes the growing global demand for resources and the attempts to cover these demands by reducing, reusing, remanufacturing and recycling parts. It portrays the changing attitudes over time towards waste and used goods and what kinds of methods were and are used to prevent the usage of new materials. The latest relevant political, economic and technical developments (e.g., the European Green Deal, the rise of electric vehicles) are presented. Finally, the goal of this thesis-analyzing and evaluating today's and future challenges in the automotive remanufacturing industryis outlined.

"To waste, to destroy our natural resources, to skin and exhaust the land instead of using it so as to increase its usefulness, will result in undermining in the days of our children the very prosperity which we ought by right to hand down to them amplified and developed."

Theodore Roosevelt, 1858-1919,

26th President of the United States

From his Seventh Annual Message, December 3, 1907

(USA, 2020)

\subsection{BACKGROUND}

The world is changing rapidly. In the last fifty years, the global gross domestic product (GDP) has doubled, a circumstance that has freed billions of people from poverty. But this growth has also had serious, irreversible and evident consequences, resulting from the steadily and strongly increasing need for resources (UN, 2019). These resources, which are the essential basis for this growth, are finite. The hunt for them has led to environmental damage, climate change, wars and drivers of negative impacts on people. The negative impacts are especially endured by the poorest people, who initially should have benefited from the increase in global GDP (Oxfam, 2020).

Resources, in the context of this thesis, are "stocks of materials that exist in the natural environment that are both scarce and economically useful in production or consumption, either in their raw state or after a minimal amount of processing" (WTO, 2011). In particular, natural resources such as oil, gas, minerals and timber are of high economic significance for companies, while natural resources like water, air, soil and salt are of the greatest importance for the life of people (OECD, 2011; RRC, 2020). In the last few 
decades alone, the demand for oil has increased constantly, with a short-term decrease during the COVID-19 pandemic situation in 2019 and 2020. This decrease is foreseen to recover by late 2021 or early 2022 and to return to pre-pandemic levels and growth rates (McKinsey, 2021b; Statista, 2021a; Qasem, 2010).

But the need for resources and managing their scarcity is not a new phenomenon. At any time, people have tried to develop concepts to keep the gap between the needed resources and the available resources as small as possible. The attitude towards things that have subjectively or objectively no practical value anymore has often changed over time. There have always been certain periods, particular fields or regions or specific societies that have invested more effort in ways and procedures of keeping the amount of non-usable goods low and reusing goods as well as possible (BUWAL, 2000; Barles, 2014; NGD, 2011; TBR, 2010; ZKR, 2013).

\subsection{Reduce, Reuse, Remanufacture, AND Recycle}

Even in ancient times, an early form of recycling was already common: Excrements were collected by retailers and sold to farmers to fertilize their fields. Later, rag-and-bone men joined the process that collected, sorted and reused items. In those days, waste consisted mainly of excrement from humans and animals, food leftovers and broken pieces of glass and clay. Food leftovers were reused as food for animals. Hair and bones were used for clothes or other household items (ZKR, 2013). Archaeological excavations from Roman settlements from the 3 rd and 4 th centuries found more than 500 bottles, from which half were made of recycled glass (NGD, 2011).

In medieval times, this development stagnated. On the one hand, the consciousness declined; on the other, the size of the cities abruptly grew at the same time. Any kind of dirt and waste was literally thrown out of the window and stayed on the street. These terrible conditions are today seen as one reason for the plague and led to the fact that people later were paid to take the waste out of the cities. Thus, the profession of the “dustman" was invented (BUWAL, 2000).

In the phase of industrialization and urbanization, the value of raw materials either for agricultural purposes (as fertilizer) or for industry (as raw material) increased and led to improved collection and recovery systems. Bones, organic waste, paper, rags and metal were no longer seen as scrap or waste but as a valued raw material to support the fastgrowing economy (Barles, 2014).

In both World Wars, all countries involved saw the collection of metals, glass and textiles as "decisive for the outcome of the war" (Scherner, 2018; UniRegensburg, 2010; TBR, 2010). In the post-war era, which was characterized by a lack of all kinds of goods, the reuse of materials became an important basis and start impulse of the growing wealth and the so-called German "Wirtschaftswunder" ("The German Economic Miracle") (TBR, 
2010; VW, 2011). The economy of scarcity in the communist states of the Warsaw Treaty Organization was highly dependent on the state-organized collection and reuse of materials until its final breakdown in the late 1980s (Calice, 2005). Also in the 1980s, a growing public concern was leading to new policies to reduce landfills and implement systems of sorting and recycling (Buclet and Gordard, 2000).

In the time before the 1980 s, the willingness to reuse material mainly resulted from a lack of raw materials and the will to keep up the production. This attitude towards resources generally changed after the 1980s: The oil crisis, the forest dieback and a growing consciousness of the finiteness of raw materials led to state actions trying to take countermeasures. The German government adopted the "German Life-Cycle Resource Management Act." This, for the first time, avoided the term "waste" and defined that "the main result of waste management must be the substitution of raw materials" (FRG, 2012). As a result of this changing attitude within society and a more environmentally orientated legal framework, a hierarchy of resource management slowly but steadily arose (Cave, 2017; FRG, 2018; Reynolds, 1995).

This change in attitude received additional support from the "European Green Deal," a bundle of actions and programs to facilitate becoming climate-neutral in the European Union by 2050 (EU, 2019a; EU, 2019b). Aside from a conventional approach to reducing $\mathrm{CO}_{2}$ emissions, alternative powertrains are an essential part of the EU's strategy for clean mobility. These powertrains are operated mainly on gas, electricity and hydrogen (EUROWAG, 2020). The European Automobile Manufacturers' Association (ACEA) has declared that the aim of achieving carbon-neutral road transport by then is possible and is defining a 10-point plan to reach this achievement (ACEA, 2020a).

One element of the actions is the optimized management of waste. Different approaches are followed to reach this goal: Apart from the approaches to reduce the amount of used resources, to reuse objects again and to recycle materials, a fourth approach is defined, Remanufacturing, "reman" for short. The Berkshire Encyclopedia of Sustainability defines remanufacturing as "the process of disassembling, cleaning, restoring, replacing, and reassembling the components of a part or product to return it to like-new condition" (Berkshire, 2010). The basis of remanufacturing is a "previously sold, worn or nonfunctional product or part," the so-called core part or just "core" (APRA, 2016).

By classifying the different approaches to decrease the demand for new material from the least beneficial to the most beneficial process from an environmental point of view, a hierarchy of waste management can be created, as illustrated in Figure 1. (UN, 2011; WSA, 2016). 


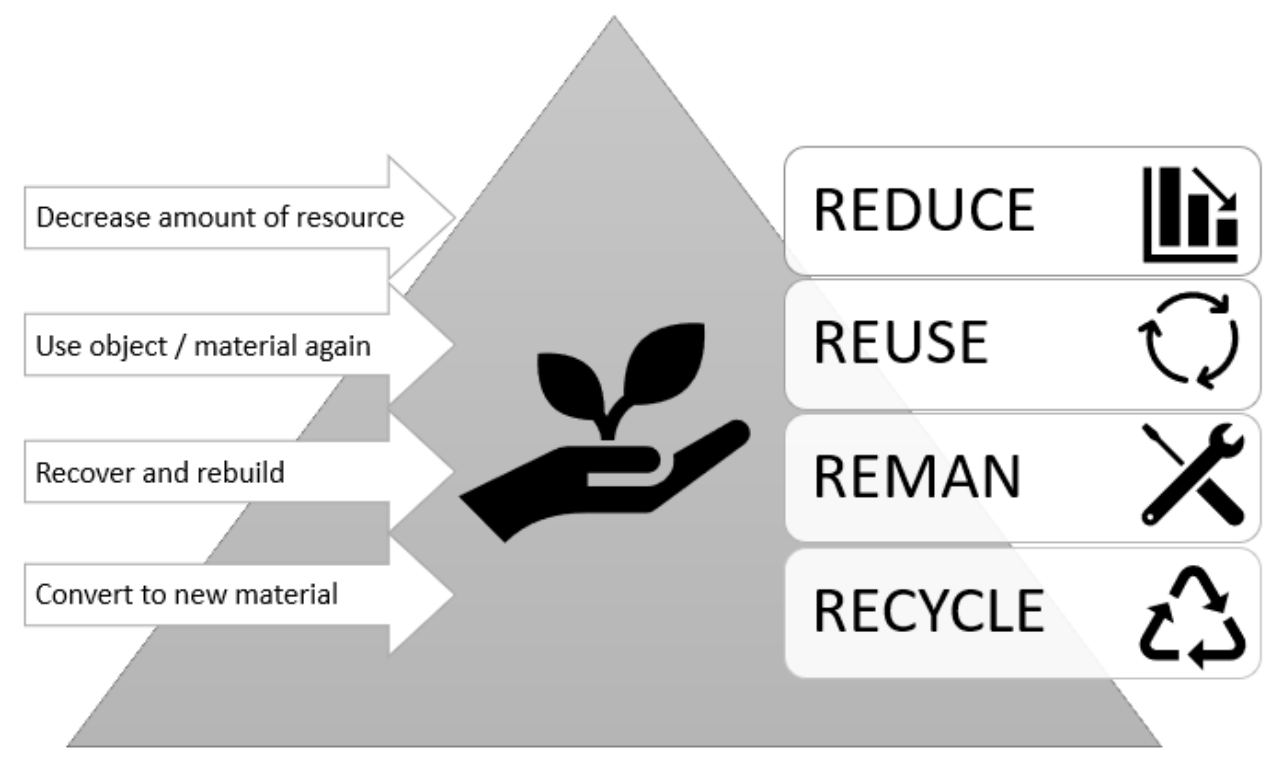

Figure 1: The Waste Management Hierarchy (UN, 2011; WSA, 2016)

The material flow in a classical supply chain directs from the raw material extraction to the production to the end-user: a forward flow. Remanufacturing and recycling add additional concepts of usage and add an additional direction of material flow: a return flow. After the recovery operation, the parts are re-integrated into the forward flow of the supply chain (Seitz, 2005).

The latest disruptions within supply chains have shown their vulnerability and fragility. Natural disasters (for example, earthquakes or flooding), global pandemics (for example, COVID-19) or material shortages (for example, semiconductors) were leading to major negative effects within the global production. The awareness about this issue lately grew within the decision makers in the industry and was leading to increasing investments to manage them (MHI, 2021).

Supply chains, which refer to a complete life cycle and which consist of forward as well as reverse logistics processes through remanufacturing or other recovery processes, can be described as a closed-loop supply chain concept (CLSC) (Xia et al., 2011). Since the beginning of the century, the term has been used in the literature and has not been defined clearly since then. Seitz (2005) states that "all these closed-loop supply chains have common features, such as product acquisition, reverse logistics, inspection, disposition and reconditioning, amongst others." Rashid et al. (2020) classifies systems "designed intentionally for closing the loop of products for reuse, maintaining their original performance at the least, through multiple lifecycles are indispensable for sustainable development." Processes of reusing, remanufacturing and recycling within a CLSC are illustrated in Figure 2 (ERN, 2020a). 


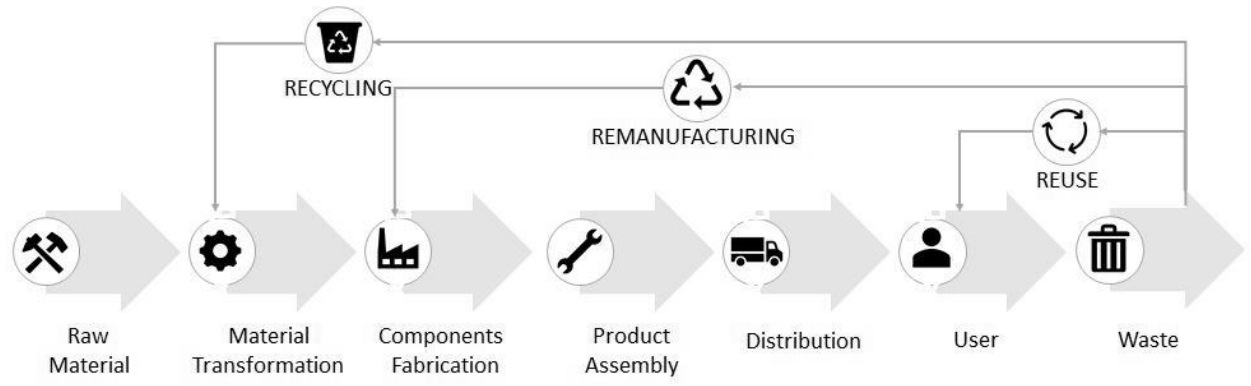

Figure 2: Reuse, remanufacturing and recycling in a closed-loop supply chain (ERN, 2020a)

\subsection{Automotive RemanUfacturing}

The trend of increasing sustainability can also be observed in one of the most important industrial branches: the automotive industry. This industry produces about 90 million units per year, representing $4 \%$ of the global GDP and employing directly and indirectly 13.8 million Europeans, which represents $6 \%$ of the total EU employment with one local focus in Germany (Statista, 2020; Saberi, 2018; ACEA, 2020b; ACEA, 2020c). Three out of four executives in the automotive industry see the demand for a more responsible and sustainable use of resources as a global megatrend in this industry branch (KPMG, 2018).

Resource scarcity gained great importance for the first time in World War II. Besides the leak of raw material for weapons like guns and bombs, the need to reuse automotive and truck parts increased. The chance of reusing parts led to the first automotive remanufacturing in 1940, both in the USA and GB (APRA, 2013a; APRA, 2013b).

German car manufacturers followed, facing the huge scarcity of materials directly after the end of the war. Mercedes-Benz started its remanufacturing in 1945: After clearing up the damage in the factory in Gaggenau, the remanufacturing of engines, gearboxes and axles commenced (Daimler, 2012). Volkswagen followed shortly thereafter and started its program for remanufactured products. Just a few years later, it had a program consisting of remanufactured engines, cylinder heads, cylinders, crankshafts and fuel pumps and was selling several thousand units per year (Graef et al., 2002). Most other car manufactures and Tier-1s, which are suppliers directly supplying the manufacturer (ILO, 2005), set up similar programs.

The definition of what constitutes "remanufacturing," though, was very unclear in the beginning and sometimes still is today. Processes and product features are not always consistent. Frequently used synonyms such as rebuilding, reconditioning, refurbishing and overhauling increase that problem. 
Steinhilper (1998) defines remanufacturing as the process of restoring used durable parts to a "like new" condition. In 2016, six leading associations with members in the automotive sector agreed on a common definition: "Remanufacturing is a standardized industrial process by which cores are returned to same-as-new, or better, condition and performance. The process is in line with specific technical specifications, including engineering, quality and testing standards. The process yields fully warranted products" (APRA, 2016). The American National Standards Institute (ANSI, 2017) defines remanufacturing in a very similar way and adds that remanufacturing is using comprehensive, rigorous, reproducible and sustainable industrial processes (ANSI, 2017). At the same time, the Automotive Parts Remanufacturers Association (APRA) differentiates between certain terms which sometimes are being used synonymously: "A remanufactured part is different from a reused, repaired, rebuilt, refurbished, reworked or reconditioned part. These categories are not subject to this definition and the process of remanufactured parts" (APRA, 2014).

Dr. Nasr from the Rochester Institute of Technology adds: "Remanufactured products or modules can be better than new ones because problems found during the product usage are not duplicated. Parts that prove less durable or that may degrade the performance are replaced with more durable ones" (Nasr, 2010).

\subsection{TeChnology Transition Towards Electric Vehicles}

\section{"I believe the auto industry will change more in the next 5 to 10 years than it has in the last 50." \\ Mary Barra \\ Chair and CEO of General Motors (Forbes, 2016)}

In addition to the changes in the attitude towards sustainability mentioned in the previous chapters, the automotive industry is undergoing major technological changes. This key European industry is now going through major changes with respect to powertrain technology for cars. Up to now, cars using combustion engines (ICE) were globally the technical "state of the art," a trend which has lately changed. In 2017, the number of registered electric vehicles (EVs) hit 1,000,000. With $60 \%$ of these registered EVs, the local focus was on China (Bloomberg, 2016). Future development is vague and controversial, but several studies have concluded that within ten years, $20 \%$ of all sold new cars will be EVs. In twenty years, this number could increase to 25\% (Deloitte, 2019; Sanderson, 2017).

This development is carefully followed by political leaders and the industry. Politicians, for example, German Chancellor, Angela Merkel, see the transition towards EVs as one part of their strategy to reduce emissions and meet their $\mathrm{CO}_{2}$ targets (Spiegel, 2017). The European Union (EU) has defined targets to reduce the pollution of air by emissions of up to $40 \%$ compared with that of 2007 (EU, 2019a). In a radio interview, the German 
automotive industry specialist Professor Ferdinand Dudenhöfer stated: "The combustion engine is dead!"

These changes have direct and major effects on the automotive industry and the supply chain for automotive parts. The design and production processes are a matter of fundamental alterations. Consequently, there is a need for manufacturers to place major investment sums into efforts for research and development (R\&D) and the change of production facilities. A part of these investments is supported by governmental support programs (Gruening and Witte, 2011). But not only the tasks and issues of the industry will change. There will also be a change within the market actors: As EVs consist of many different parts compared to ICEs, the suppliers and supply chains often differ. All these changes offer challenges and opportunities that need to be explored, organized, implemented and monitored carefully.

Alongside the direct effects mentioned above, there will also be indirect effects resulting from this transition phase. This indirect effect will occur with a certain postponement: Following the production of the EVs, the request for spare parts for these new cars will occur. With an increasing share of EVs, the request for spare parts will also strongly rise (Aleksandr and Ashraf, 2017).

The changing attitude towards sustainability, the remanufacturing of automotive parts and the challenges resulting from EVs have been described in the literature by the aforementioned authors (e.g., Aleksandr and Ashraf, 2017; Buclet and Gordard, 2000; Cave, 2017; FRG, 2018; Reynolds, 1995). The interaction of these three developments and the effects from their interaction have not been explored in one overall, coherent study. This thesis aims to decrease this scientific gap.

\subsection{OBJECTIVE}

The objective of this doctoral thesis is to provide an exploration of the automotive remanufacturing industry and to identify current and future challenges and opportunities with special consideration of a growing share of EVs.

\subsection{RESEARCH QUESTIONS}

The market conditions for automotive remanufacturing are changing. From these changes of market conditions and the effects resulting from them, the following research questions have been derived to meet the research objectives:

\section{RQ1: What are today's challenges in the automotive remanufacturing industry?}

In order to find answers to this research question challenges within the main actors need to be explored and highlighted. The focus will be on challenges for companies producing remanufacturing parts. 


\section{RQ2: What are the challenges and opportunities for the automotive remanufacturing industry in a phase of technology transition towards electric vehicle part remanufacturing?}

In order to find answers to this research question the two different powertrain concepts for ICE and EV concepts need to be investigated. The focus is on the major differences, which have effects on remanufacturing processes.

\subsection{DELIMITATIONS}

The following delimitations are defined by the research to choose an adequate focus within the wide research range. Therefore, the following certain regional and supplychain related research restrictions have been defined:

- The research field is strictly limited to the automotive industry. Broader perspectives are partly regarded to explain a circumstance and to compare automotive-related results with other industries.

- The regional focus of the investigation lies on Europe, and here specifically on Germany. Due to the global character of the automotive industry and the global relevance of the topic, the international perspective is used when it is suitable to answer the research questions.

- This thesis explores the macroeconomic as well as microeconomic perspectives. The focus is on the last-mentioned perspective, as most challenges and opportunities have been found at the producing companies in the industry sector.

- Within the microeconomic perspective, the supply chain is explored from companies supplying parts, going over to remanufacturing production companies and ending at the customer.

- Within the management of CLSCs, it is limited to matters related to remanufacturing. The focus will be on remanufacturing companies, their products and their processes of production. Suppliers of these companies will only be explored if they supply the remanufacturing company directly (Tier-1, which are directly delivering to the manufacturer, but not Tier-2 or Tier-n, which are following Tier-1 in the supply chain). From the perspective of the customer, the company level is respected. Here, original equipment manufacturers (OEMs) and companies of the independent aftermarket (IAM) are considered. The perspective of the end customer is not in focus.

- Other perspectives of supply chain management (e.g., reusing and recycling) will only be discussed if they are relevant to answering the research questions.

- Hybrid electric vehicles (HEVs) and plug-in hybrid electric vehicles (PHEVs), besides their electrical parts, also have a classical combustion engine and transmission. The electrical parts are also in a battery electric vehicle (BEV). Therefore, this thesis focuses on BEVs. 


\subsection{RESEARCH ETHICS}

As shown in the RQs, many different parties, such as persons or companies, are in the focus of exploration and evaluation. Data from these parties are generated and used for this thesis. This fact leads to potential ethical and moral conflicts. Taking this into consideration, the following statements shall be made, which reflect the approach in which way data has been generated from these parties:

- As far as there was new data generated for this thesis (e.g., by interviews or questionnaires), the involved parties have been clearly informed of the fact that they are taking part in such an event (e.g., an interview series or a questionnaire evaluation process).

- In no case have there been persons involved in this thesis who would require specific protection or guidance from an ethical point of view (e.g., children, patients, animals or other vulnerable groups).

- The data generated to work on the RQs and the private data of the persons involved (e.g., names of persons, names of companies, etc.) has been strictly separated to retain the privacy of the people and institutions involved. All information given in this thesis is anonymous. Personal data is only accessible for the researchers involved in this thesis.

Applying the "Uppsala Code of Ethics for Scientists" (Gustafsson et al., 1984), a code which was created in the early 1980s by a group of scientists to assure ethical aspects in research work, the following can be stated for these two RQs:

- This research and its RQs are not causing ecological damage. The opposite is the case: This research work shall serve future ecological improvements.

- This research does not have any negative impact on future generations. Again, the opposite is the case: This research aims to improve future generations' lives by having a positive impact on the global $\mathrm{CO}_{2}$ footprint by implementing industrial processes to reduce $\mathrm{CO}_{2}$ emissions.

- This research does not explore any item or knowledge aimed to be used in war or any other way contributing to cruelty or injustice.

- This research is not in any form in conflict with humanity and with human rights as defined in international laws and agreements.

- This research is freely and openly shared with the public using many of today's available channels.

- This research has been carried out in a surrounding and atmosphere that allowed it to announce and claim potential ethical conflicts.

\subsection{ThEsis Structure}

The first chapter introduces the topic and research area. It gives an overview of the changing attitude towards reducing, reusing, remanufacturing and recycling with a 
special focus on automotive changes and trends. From this, it derives the research objectives and research questions. It then highlights the delimitations and presents the structure of the work. The second chapter provides information about the research design, broken down into its research phases. Furthermore, it informs about research techniques and the forms their usage in this thesis. The third chapter contributes the theoretical framework of this work. It maps the research area and provides all information to understand automotive remanufacturing. Moreover, it presents the most important product groups and explores the remanufacturing processes for each group. The fourth chapter presents and evaluates today's challenges and opportunities of the automotive remanufacturing industry. The fifth chapter, in contrast, focuses on future challenges and opportunities resulting from new EV technologies. The sixth chapter summarizes all findings and answers the research questions. Finally, the seventh chapter offers a conclusion and provides an outlook for the future. Table 1 summarizes the structure of this thesis.

Table 1: Structure of dissertation and content per chapter

\begin{tabular}{|l|l|}
\hline Chapter & Content \\
\hline Chapter 1 & Introduction into topic and research area \\
\hline Chapter 2 & Methodology \\
\hline Chapter 3 & Theory of automotive remanufacturing \\
\hline Chapter 4 & $\begin{array}{l}\text { Today's challenges and opportunities of the automotive } \\
\text { remanufacturing industry }\end{array}$ \\
\hline Chapter 5 & $\begin{array}{l}\text { Future challenges and opportunities resulting from the transition phase } \\
\text { towards electric vehicles }\end{array}$ \\
\hline Chapter 6 & A summary of all findings and answers to the research questions \\
\hline Chapter 7 & Final conclusion and outlook \\
\hline
\end{tabular}




\section{METHODOLOGY}

This chapter describes the methodological approach of this thesis. It gives a chronological overview of the different research phases as well as their main milestones. In a second step, the research methods used in this thesis are presented, and an explanation is given for why each method was chosen. Finally, it describes how each method was used and how validity, reliability and generalizability were considered during the research.

\subsection{RESEARCH PHASES}

This thesis can be divided into four main phases, as demonstrated in Figure 3. The phases partly overlap and build upon one another. In the following subchapters, the aim, procedure and results of each phase are described.

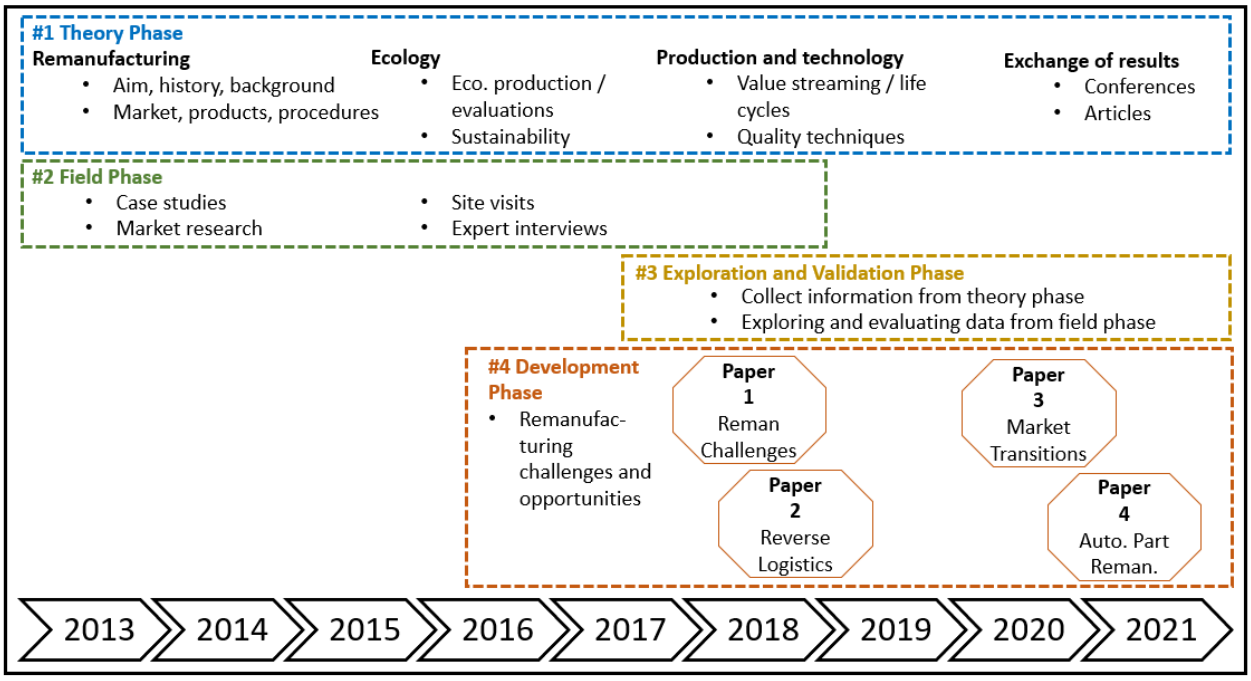

Figure 3: Research phases on a timeline, including their main elements

\subsubsection{THEORY PHASE}

In the first phase of the research, theoretical knowledge and major research techniques were acquired. The literature about remanufacturing was reviewed with a particular focus on the literature related to automotive remanufacturing. History, development and the state of the art are described to gain a better picture of the research topic. In a second step, more specific literature has been identified and reviewed, which is more focused on specific aspects of the research topic. This focused literature deals especially with 
technology, logistics and the latest trends in the automotive remanufacturing industry, as well as new concepts of powertrains of passenger cars.

In parallel to the content-related research, knowledge about the research techniques has been gained. Through academic courses and literature reviews, a solid knowledge basis for research methodology in general, surveys, case studies, papers and interviews were built up. Moreover, the ethical questions of the research were discussed.

\subsubsection{FIELD PHASE}

In the second step, the field phase, the knowledge and techniques acquired in the first phase were applied and deepened. Case studies were executed to gain a deeper understanding of the remanufacturing market, including the major market actors and main products. Remanufacturing companies were visited to magnify the understanding of specific production technology, equipment and procedures. Using the opportunity to have this inside view into practical remanufacturing, technical and logistics issues were investigated on-site. Moreover, specific conferences were visited to present initial findings and enlarge the network of professionals in the remanufacturing business, for example, the World Reman Summit (WRS) and the International Conference on Remanufacturing (ICoR). In addition, the first results were discussed and verified in expert interviews. Furthermore, popular articles were written to receive broader feedback and to gain knowledge about the technique of academic writing and publishing.

\subsubsection{EXPLORATION AND VALIDATION PHASE}

In the phase of exploration and validation, the results from the theory and field phases were gathered. The findings were combined and again discussed with industry experts, and their feedback was taken into account. First, findings were compiled in articles and drafts of papers, which were again reviewed by experienced persons, and their comments and opinions led to revised drafts. Interim results were presented at conferences to get the results validated and evaluated. All feedback and additional input were used as a basis for the papers. With the work on the appended papers, the development phase was started.

\subsubsection{Development Phase of Overview About Remanufacturing Challenges}

With all information and data gained in the previous three phases, the four papers were written and published. The topics of the papers were chosen in a way that they covered the most varied facets of the research topic. Paper I explores today's challenges of remanufacturing. Paper II, in contrast, dealt with one specific challenge, and Paper III highlighted future trends and potential challenges resulting from these trends. In Paper IV, these findings were gathered, compared and evaluated. The feedback from the experts was taken into account and has been respected in this thesis. Using the theory from $\mathrm{PhD}$ 
courses, the information from the case studies, and finally, the results from the four papers, this thesis was created.

Table 2: Overview of research questions and relevant publications focusing on each research question

\begin{tabular}{|l|l|l|l|l|}
\hline Research question & I & II & III & IV \\
\hline $\begin{array}{l}\text { RQ1: } \\
\text { What are today's challenges in the } \\
\text { automotive remanufacturing industry? }\end{array}$ & X & X & & X \\
\hline $\begin{array}{l}\text { RQ2: } \\
\text { What are the challenges and } \\
\text { opportunities for the automotive } \\
\text { remanufacturing industry in a phase of } \\
\text { technology transition towards electric } \\
\text { vehicle part remanufacturing? }\end{array}$ & & & $\mathbf{X}$ & $\mathbf{X}$ \\
\hline
\end{tabular}

\subsection{RESEARCH METHODS}

In the following subchapters, the research methods used in this thesis are described.

\subsubsection{LiTERATURE REVIEW}

Existing knowledge is the basis of any academic activity. Because of its fundamental character and its great significance, priority and a high level of accuracy should be invested in this matter (Snyder, 2019). This knowledge can result from two different sorts of sources: the first is a primary data source, for example, resulting from fieldwork, surveys and observation. This data is often called raw material. The second source is secondary data, for example, journals, textbooks, magazines, books and encyclopedias (Sileyew, 2019). In a systematic literature review process, there is the need to define one or more research questions. Data is selected following transparent rules and defined restrictions (Zawacki-Richter et al., 2020).

\subsubsection{INTERACTIVE RESEARCH}

In an interactive research approach, learning and analyzing are joined (Svensson et al., 2007a). This is gained by a very strong interaction between participants and researchers (Svensson et al., 2007b). By increasing the collaboration between the researcher and his research subjects, the potential gap between research and practice is bridged (Ellström et al., 2020). Interactive research is not one singular method but rather a research approach 
consisting of, combining and using different methods to reach its aim. Methods used can be, for example, interviews, questionnaires or seminars (Svensson et al., 2007c).

\subsubsection{CASE StUdies}

Case studies are deep investigations of individuals, groups, occasions or situations (Kabir, 2016). This wide range of different approaches makes a general definition difficult, as Starman (2013) describes in his paper. VanWynsberghe (2007) even raises the question of whether case studies can be referred to as a method, strategy, research design or methodology. Baxter (2008) summarizes and tries to simplify, saying that qualitative case studies are approaches to research a phenomenon respecting its context while using a variety of data sources.

\subsubsection{PROCESS VISUALIZATION}

The International Organization for Standardization (ISO) defines a process as a "set of interrelated or interacting activities that use inputs to deliver an intended result" (ISO, 2015). A process can be broken down into phases conveying the inputs, outputs and operations executed during a certain period (Kabir, 2016). Often, modeling techniques are used to visualize complex structures and to identify opportunities for optimization (Vergidis et al., 2008).

Business process modeling often references information already available in companies, for example, enterprise resource planning (ERP), workflows or customer relationship management (CRM). The aim is to gain a better and more detailed understanding of the actual executing of a process, find bottlenecks and identify areas requiring improvement (Celino et al., 2007). Except from these aims, which are more focusing on gaining information about the own organization, models offer an easier possibility to benchmark solutions with third parties, for example, competition (Duval, 2017).

In business process modeling, the manual and automated process steps and potentially the needed resources for this specific step are documented (Caporale, 2015). A process model can be the basis to discuss responsibilities, explore the actual status and generate forecasts (Aalst, 2016).

Tangkawarow and Waworuntu (2016) describes the most commonly used techniques in the comparative phase of exploration and lists them as follows:

1. Data Flow Diagram

2. Business Process Modelling Notation (BPMN)

3. Activity Diagram

4. Integration Definition for Function Modelling 
BPMN is a flowchart-based notation of business processes and has have been executed several times for the research in this thesis. It is a rather young technique, which was only created at the beginning of this millennium. It consists of standardized elements such as flow objects and connectors (Hinkelmann, 2020; Koskela and Haajanen, 2007).

\subsubsection{QUESTIONNAIRES}

Deakin (2020) states that questionnaires are one of the best-known techniques to gain information and can be executed in a personal or online meeting, via telephone or electronic form. Besides their supposed operational simplicity, this technique holds risks too: Wording, question orders and other aspects can intentionally or unintentionally influence the results (Harkness et al., 2016). In addition to disadvantages due to poor design or a missing validation, questionnaires offer some convincing advantages: They are inexpensive in production and distribution, can reach a wide audience and are a technique that delivers a good external validity (Sansoni, 2011).

Questionnaires are most often standardized and consist of several questions that are provided in a set format. In general, two general forms of question types are possible: The first option is an open-ended question, letting the respondent answer individually to gain different answer possibilities and opinions. The second option is a closed-ended question, for which Kabir (2016) names four different types of possible responses:

- Type "Dichotomous" (the responding person has two possible responses to choose from)

- Type "Nominal-polytomous" (the responding person has more than two unordered options from which they can choose)

- Type "Ordinal-polytomous" (the responding person has more than two ordered options from which they can choose)

- Type "Continuous/bounded" (the responding person has a continuous scale in order to reply)

To develop an effective questionnaire, Colosi (2006) advises clearly defining the sought information, reviewing previous questionnaires on similar research questions to create a logical and reasonable format and giving clear instructions to the recipient.

\subsubsection{INTERVIEWS}

Interviews are a data collection method in which an interviewer and participants communicate in a systematic form. The participant gets involved and is able to express his/her opinion, to give their point of view to a certain statement and to interpret from his/her perspective (Kajornboon, 2005).

Partington (2001) sees "art" as needed to proceed in successful interviews and to gain a good quality of data, stating, "Many of the factors that contribute to the quality of an 
interview, however, can be developed through careful attention to a range of skills such as careful listening and responding as well as skills in the development of rapport and empathy." Englander (2012) describes the most essential steps: the selection of participants, the correct definition of sample size (number of participants) and the instrumentation and procedure of interviewing (face-to-face interview versus written).

In an interview, the questions are directly asked, and answers are directly received. Kabir (2016) lists three types of interviews:

- Structured interview (same series of questions for all respondents; questions are prepared and known for all parties before the interview)

- Semi-structured interview (the interviewer follows a general guideline for all respondents. Nevertheless, the conversation may lead to additional questions.)

- Unstructured interview (formal interview, most often with a scheduled time, clear understanding of the goal of the interview and mostly open-ended questions)

\subsection{RESEARCH DESIGN}

In Table 3, the motivation to choose the usage of these research methods used in this thesis is described.

Table 3: Motivation of usage for the research methods used

\begin{tabular}{|l|l|}
\hline Method & Motivation to use method in this thesis \\
\hline Literature review & $\begin{array}{l}\text { The literature review in this thesis has been executed to gain } \\
\text { information about the actual situation within the industry: It is } \\
\text { today's market actors, products and their production processes. } \\
\text { The motivation to use this method was to get the latest status } \\
\text { of information, to have a broad basis of data, to gain an } \\
\text { overview of the existing publications and to define the } \\
\text { research gap of this thesis. The reason this method was chosen } \\
\text { was the great importance of literature reviews for all kinds of } \\
\text { research, as Snyder (2019) highlights: "They can serve as a } \\
\text { basis for knowledge development, create guidelines for policy } \\
\text { and practice, provide evidence of an effect, and, if well } \\
\text { conducted, have the capacity to engender new ideas and } \\
\text { directions for a particular field." }\end{array}$ \\
\hline Interactive research & $\begin{array}{l}\text { The interactive research in this thesis has been used in cases in } \\
\text { which the feedback or evaluation of a finding was required or } \\
\text { helpful. This feedback gave the possibility to verify } \\
\text { information, led to new information and partly led to new sub- } \\
\text { questions to be investigated. This method was chosen for this } \\
\text { thesis as it provides a "fruitful way of handling the classic }\end{array}$ \\
\hline
\end{tabular}




\begin{tabular}{|c|c|}
\hline & $\begin{array}{l}\text { conflict between the action and research component in } \\
\text { collaborative research," as Svensson et al. (2007a) described it. }\end{array}$ \\
\hline Case studies & $\begin{array}{l}\text { Case studies were executed to gain a better and more detailed } \\
\text { understanding of matters where the actual literature had gaps } \\
\text { or where more detailed or more actual information was } \\
\text { needed. Moreover, it gave the chance to summarize and verify } \\
\text { existing information as a basis for the first publications. This } \\
\text { research method was chosen for this thesis as it provides many } \\
\text { benefits highlighted by Baxter (2008): Complex situations can } \\
\text { be explored, and the method can describe as well as explain a } \\
\text { phenomenon and is very suitable for young researchers. }\end{array}$ \\
\hline Process visualization & $\begin{array}{l}\text { The motivation to use this technique was to summarize and } \\
\text { visualize complex processes. The reasons for choosing BPMN } \\
\text { as a technique to use in this exploration were the advantages of } \\
\text { BPMN highlighted by Tangkawarow and Waworuntu (2016): } \\
\text { It is flexible, easy to understand and suitable for technical as } \\
\text { well as business processes. }\end{array}$ \\
\hline Questionnaires & $\begin{array}{l}\text { Questionnaires have been used to receive data in a very short } \\
\text { period of time and being able to evaluate it in an efficient way. } \\
\text { Moreover, this technique was able to deliver information in a } \\
\text { field where literature is not so much available yet, as the topic } \\
\text { is very young and continues to demonstrate dynamic changes: } \\
\text { the transition towards the electrification of vehicles. } \\
\text { Questionnaires have been used in this thesis as they provide } \\
\text { many advantages, as demonstrated by Sansoni (2011): They } \\
\text { are inexpensive to carry out and to evaluate, they can reach a } \\
\text { large number of participants in a rather short time frame, and } \\
\text { they can ideally deliver high external validity. }\end{array}$ \\
\hline Interviews & $\begin{array}{l}\text { Interviews are used in this thesis as they provide several } \\
\text { advantages as a data collection method, as highlighted by } \\
\text { Alshenqeeti (2014): their relative flexibility, a high return rate } \\
\text { and fewer incomplete answers. At the same time, this method } \\
\text { is time-consuming, can hardly be fully anonymous, is only } \\
\text { suitable for small-scale studies and offers potential for } \\
\text { subconscious bias. Nevertheless, besides using questionnaires, } \\
\text { this method has been chosen specially to gain new approaches } \\
\text { and information in an early phase of the research, as interviews } \\
\text { using open questions are an ideal source to gain such data. }\end{array}$ \\
\hline
\end{tabular}




\subsection{RESEARCH PROCESSING}

In the following subchapter, the processing of the research methods used in this thesis is described.

\subsubsection{Processing of the Literature Review}

In the initial step, the basic literature available on remanufacturing was studied for this thesis. In particular, books focusing on automotive remanufacturing (Steinhilper, 1998) and recent academic publications (Golinska and Kawa, 2011; Oestlin, 2008; Wei et al., 2015; Kurilova-Palisaitiene, 2018; Sundin and Dunbäck, 2013) were reviewed. In the second step, the literature focusing on future trends in connection with the electrification of vehicles was reviewed. As these trends were still young, the sources mainly resulted from recent academic publications (Björnsson et al., 2018, Bloomberg, 2016, Briguglio et al., 2011, Mohammadia, 2018, Sanderson, 2017). In the last step, the research questions were created to conduct a more detailed literature review, especially by using primary data sources.

The main keywords for the literature research were remanufacturing, remanufacturing challenges, closed-loop supply chain, electric vehicles, battery electric vehicles and hybrid vehicles. For the literature research, different databases accessible on the internet have been used, especially the databases of Emerald, the Journal of Remanufacturing and the electronic database of Linköping University.

\subsubsection{Processing OF InTERACTIVE ResearCh}

Interactive research has been applied in this thesis on several occasions and in several different ways. For example, intermediate results have been shared and discussed with industry experts, theoretical packaging concepts have been investigated together with responsible people in the field of logistics, and findings have been summarized in statements and have been evaluated by researchers and managers within the industry branch. This has been done in this thesis in particular by using the method of questionnaires (see 2.4.5) and interviews (see 2.4.6).

\subsubsection{Processing of CASe Studies}

Case studies were heavily used to generate data in the field phase. Results from these cases studies have been used expressly in Paper I. This research method has especially been used in areas of this thesis in which a large amount of information needed to be reviewed, evaluated and compressed beforehand. Examples of the usage of case studies for this thesis and the four papers are as follows:

- A case study analyzing the automotive remanufacturing market in Germany

- A case study surveying the technical and economic criteria and methods for an evaluation of core parts

- A case study explaining predictive maintenance in passenger cars 


\subsubsection{Processing of Process Visualization}

Process visualization using BPMN as a flowchart-based notation has been used in this thesis in the theory chapter to envisage remanufacturing processes. The information about the processes was gained from literature reviews and interactive research (here, questionnaires and interviews). Moreover, several visits to remanufacturing sites and personal process recording and documentation were conducted. Results have been shared as part of the interactive research to verify and complete them.

Process visualization of remanufacturing processes was executed for the following automotive parts:

- Combustion engines

- Turbochargers

- Gearboxes

- Injection system

- Battery packs

- Electric motors

\subsubsection{PROCESSING OF QUESTIONNAIRES}

Questionnaires were used, especially for the research presented in Paper III, as a major technique to gain information and data in the following form: A standardized questionnaire has been created. It consisted of seven statements to be evaluated and four open questions to be answered. It was sent to 40 experts of the remanufacturing industry that have been chosen from the author's and the university's network. In total, twenty $(=50 \%)$ validly completed questionnaires were received in return. The list of experts (Appendix B2) the questionnaire (Appendix B3) and all answers received from the experts (Appendix B4) can be found in an anonymous form at the end of this thesis.

Table 4: Summary of sent and received questionnaires (see Appendix B2, B3 and B4) for Paper III

\begin{tabular}{|l|l|}
\hline Criteria & Information \\
\hline Questionnaire type & $\begin{array}{r}\text { Standardized interview questionnaire containing: } \\
\text { seven statements to be evaluated using a continuous } \\
\text { scale } \\
\text { four open-ended questions }\end{array}$ \\
\hline Peer group & $\begin{array}{l}\text { Experts in the European automotive industry } \\
\text { (List of the background of experts: see Appendix B2) }\end{array}$ \\
\hline Quantity sent & 40 questionnaires \\
\hline Quantity received & 20 questionnaires (return rate $=50 \%)$ \\
\hline
\end{tabular}




\subsubsection{Processing OF INTERVIEWS}

The method of unstructured interviews was used in this thesis to gain a deeper understanding of today's challenges in automotive remanufacturing. Interviews were conducted with several defined experts and managers from the remanufacturing industry, as shown in Table 5.

Table 5: Interview partner with experts from the industry

\begin{tabular}{|l|l|l|}
\hline Company type & Function & Content \\
\hline $\begin{array}{l}\text { Automotive } \\
\text { remanufacturing } \\
\text { company }\end{array}$ & CEO / president & $\begin{array}{l}\text { Challenges in today's remanufacturing } \\
\text { from the industry perspective }\end{array}$ \\
\hline $\begin{array}{l}\text { Consulting company } \\
\text { focusing on } \\
\text { automotive } \\
\text { remanufacturing }\end{array}$ & Consultant & $\begin{array}{l}\text { Market and marketing-related perspectives } \\
\text { of remanufacturing (sales, logistics, } \\
\text { customers, products) }\end{array}$ \\
\hline $\begin{array}{l}\text { Automotive } \\
\text { remanufacturing } \\
\text { company }\end{array}$ & $\begin{array}{l}\text { Production } \\
\text { Manager }\end{array}$ & Technical challenges in remanufacturing \\
\hline $\begin{array}{l}\text { Automotive } \\
\text { remanufacturing } \\
\text { company }\end{array}$ & General Manager & $\begin{array}{l}\text { Technical and production-related issues in } \\
\text { remanufacturing }\end{array}$ \\
\hline $\begin{array}{l}\text { Automotive } \\
\text { remanufacturing } \\
\text { company }\end{array}$ & $\begin{array}{l}\text { Production } \\
\text { Manager }\end{array}$ & Technical challenges in remanufacturing \\
\hline
\end{tabular}

\subsection{VALIDITY, RELIABILITY AND GENERALIZABILITY}

Validity is whether a measurement actually measures what it was supposed to (Golafshani, 2003). Several steps are needed to gain a high level of validity: Initially, an exhaustive literature review is executed to extract major findings. In the second step, the essential findings are shared, discussed and validated with experts within the same field of research (Taherdoost, 2016).

In this thesis, the above-mentioned steps to gain validity have been carried out. As mentioned in the chapters before, a structured literature review has been executed and summarized in the theory chapter. The methodology, as well as the results of this review, have been shared and verified in multiple ways with experts, and their feedback has been respected in this thesis.

In contrast to validity, reliability refers to the consistency of a result. It gives information regarding which measurements are repeatable, especially when the measurements are 
carried out by different researchers, with alternative instruments and on other occasions (Drost, 2011).

In research today, different techniques, which are mentioned and explained in Table 6, are used to ensure reliability. Here, the usage of each technique in this paper is also highlighted.

Table 6: Reliability techniques and their usage in the thesis

\begin{tabular}{|c|c|}
\hline Techniques & Usage in this thesis (examples) \\
\hline $\begin{array}{l}\text { Test-retest reliability: } \\
\text { Using the same measurement under the } \\
\text { same conditions two or more times } \\
\text { (Aldridge et al., 2017), e.g., executing a } \\
\text { test in Company A and executing } \\
\text { additionally the same test in Company B }\end{array}$ & $\begin{array}{l}\text { - Interviews with different kinds of } \\
\text { experts } \\
\text { - Questionnaires to different } \\
\text { relevant companies } \\
\text { - Market studies in different markets }\end{array}$ \\
\hline $\begin{array}{l}\text { Parallel forms of reliability: } \\
\text { In parallel, the tests (e.g., set of } \\
\text { questions) are separated into subsets and } \\
\text { conducted with two or more groups. Both } \\
\text { subsets must contain a similar construct, } \\
\text { focus and informational basis (Hilger and } \\
\text { Beauducel, 2017); e.g., questions from a } \\
\text { questionnaire are randomly divided into } \\
\text { two subsets. Each subset is handed out to } \\
\text { one of two groups. }\end{array}$ & N/A \\
\hline $\begin{array}{l}\text { Inter-rater reliability: } \\
\text { This gives information about the } \\
\text { homogeneity of the rating made by } \\
\text { various judges about one result (McHugh, } \\
\text { 2012); e.g., a sports competition is } \\
\text { observed and evaluated by several judges }\end{array}$ & $\begin{array}{l}\text { Papers have been reviewed and } \\
\text { evaluated independently by } \\
\text { experts } \\
\text { - Case studies, questionnaires, } \\
\text { interviews and other results have } \\
\text { been evaluated by different } \\
\text { academic staff }\end{array}$ \\
\hline $\begin{array}{l}\text { Internal consistency reliability: } \\
\text { Choosing different aspects of the same } \\
\text { characteristic to check the consistency of } \\
\text { a result (Revicki, 2014); e.g., in an } \\
\text { interview, different aspects of a question } \\
\text { are questioned. }\end{array}$ & $\begin{array}{l}\text { Questionnaires and structured } \\
\text { interviews were designed to proof } \\
\text { the consistency of the answer }\end{array}$ \\
\hline
\end{tabular}


Generalization is an essential technique used in research. By analyzing a single event, case or observation, researchers draw interferences to new, more general statements (Mayring, 2007). With respect to generalization, three different frameworks are to be mentioned (Polit and Beck, 2010, based on Firestone, 1993), which are shown in Table 7.

Table 7: Forms of generalization and their usage in this thesis

\begin{tabular}{|l|c|}
\hline Forms of generalization & Usage in this thesis (examples) \\
\hline $\begin{array}{l}\text { Analytic generalization: } \\
\text { One model has relevance for research. } \\
\begin{array}{l}\text { For example, further case studies show } \\
\text { resembling results and can be used to } \\
\text { support research questions (Wikfeldt, } \\
\text { 2017) }\end{array}\end{array} \quad \begin{array}{l}\text { Results from several case studies } \\
\text { were used to make statements } \\
\text { about research questions. }\end{array}$ \\
\hline $\begin{array}{l}\text { Case-to-case translation: } \\
\text { Most case studies in research have an } \\
\text { appeal for more general relevance, and } \\
\text { their results are applied in other case } \\
\text { studies (Gomm et al., 2011) }\end{array}$ & $\begin{array}{l}\text { Several cases studies were } \\
\text { executed. Later, case studies used } \\
\text { findings from prior case studies } \\
\text { and verified their results. }\end{array}$ \\
\hline
\end{tabular}

\section{"All generalizations are false, including this one." Quote attributed to Mark Twain (STANDS4, 2021)}

Whether Mark Twain truly said this cannot be proven today. Even so, it is widely known and accepted that generalizations, on the one hand, are needed in a complex world, and on the other hand that they constitute a serious risk. With knowledge of these two perspectives, this thesis was executed using generalization as described in Table 7. The validity and the reliability of all findings were assured by the techniques described in Table 6 . 


\section{THEORETICAL FRAMEWORK}

This chapter introduces the theoretical basis for this research. First, the relevant market characteristics are introduced: the products and the market actors. In the second step, the main products are explored more deeply from a technical perspective: their typical defects and their remanufacturing process. The information provided in this chapter is the basis for a deeper exploration in Chapter 4.

\subsection{REMANUFACTURING}

Remanufacturing is a process that brings used parts back to a "like-new" state. It is often seen as a sustainable way of manufacturing and as environmentally friendly. Moreover, parts can have a lower price, as materials and value added from the initial part can be recovered (Matsumoto and Ijomah, 2013). A more detailed reflection on the term "remanufacturing" can be found in the first chapter.

The main industrial sectors in respect to turnover in Europe are the aerospace industry, the automotive industry, the heavy-duty off-road industry and the industry for electrical and electronic equipment (see Paper IV). In total, a turnover of nearly 30 billion euros is generated in about 7,000 companies that employ nearly 200,000 people, as shown in Table 8 (ERC, 2020; Gray and Charter, 2008; Parker et al., 2015).

Table 8: Industrial sectors performing remanufacturing in Europe (based on Parker et al., 2015)

\begin{tabular}{|l|r|r|r|}
\hline & $\begin{array}{c}\text { Turnover } \\
\text { (in billion } \\
\text { euros) }\end{array}$ & $\begin{array}{c}\text { Company } \\
\text { (quantity) }\end{array}$ & $\begin{array}{l}\text { Employees } \\
\text { (in 1,000 } \\
\text { people) }\end{array}$ \\
\hline Aerospace Industry & 12.4 & 1,000 & 71 \\
\hline Automotive Industry & 7.4 & 2,363 & 43 \\
\hline Heavy-Duty Off-Road Industry & 4.1 & 581 & 31 \\
\hline Electrical \& Electronic Equipment & 3.1 & 2,502 & 28 \\
\hline Machinery & 1.0 & 513 & 6 \\
\hline Medical Equipment & 1.0 & 60 & 7 \\
\hline Furniture & 0.3 & 147 & 4 \\
\hline Railroad & 0.3 & 30 & 3 \\
\hline Marine & 0.1 & 7 & 1 \\
\hline Total & $\mathbf{2 9 . 7}$ & $\mathbf{7 , 2 0 3}$ & $\mathbf{1 9 4}$ \\
\hline
\end{tabular}


As the main drivers for remanufacturing, Oestlin (2008) was able to define three groups:

1. The first driver has been defined as "profit": Remanufacturing offers a business concept that is profitable and provides a part that meets the customer's requirements and offers the possibility the save costs compared to buying a new part. Reman can meet the demands of new business concepts, for example, concepts in which parts are returned by the customer: A forklift returned by the initial user to the company after a contracted period time of usage can be remanufactured and handed over "as new" to the next customer. Moreover, remanufactured parts can cover the demand for spare parts. Especially for lowvolume demands and end-of-life demands, this procedure can save costs.

2. As a second driver, "policy" has been identified: Remanufacturing, in this case, is not just economically driven but driven by company policy issues. Examples are:

- Protection of a company's own aftermarket share: By collecting and remanufacturing parts, they are not available for independent manufacturers, who would run into a potential competition.

- Protection of quality level and brand reputation: A similar motivation could be the protection of the brand. Companies collecting their core parts prevent independent remanufacturers from remanufacturing these parts in a way that does not meet the quality expectations of the company.

- Gaining information and data: Gaining information about customer needs, the performance of parts and providing aftermarket solutions matching the customer's needs can be a motivation for remanufacturing.

- Latest technical trends in the field of digitalization strengthen the possibilities of the OEM to control the parts and influence the market. Subramoniam et al. (2021) highlight in their investigation that the OEMs "are in the process of taking control of the part-specific data, such as monitoring the trends in defects from returned devices compared to those of the competition."

3. A third driver is "environment": As remanufacturing, in general, uses less material and energy, it is environmentally friendly. Despite potential negative impacts from prolonging the product life of obsolete parts that probably do not meet the latest pollution standards, the overall sustainability of remanufacturing has been shown to be superior to the production of new parts (see Section 3.2.1).

Typical remanufacturing process steps have been described by Gray and Charter (2008) and consist of the following elements, which can be found in nearly all kinds of remanufacturing processes:

- Return of used part ("core")

- Identification and inspection

- Disassembly 
- Cleaning

- Reconditioning/replacement of worn-out parts by using new parts

- Re-assembly

- Testing

The basis for resource-efficient remanufacturing is the core part, a used part intended for reuse, for example, remanufacturing (Wei et al., 2015). "A core is a previously sold, worn or non-functional product or part, intended for the remanufacturing process. During reverse logistics, a core is protected, handled and identified for remanufacturing to avoid damage and to preserve its value. A core is not waste or scrap and is not intended to be reused before remanufacturing" (APRA, 2016; Wei et al., 2015). Tsang sees returned core parts as the "raw" material for remanufacturing companies, for which the design and the material are defined previously (Kin et al., 2014). A lack of an appropriate core part hinders a remanufacturing process. It can be compensated for by injecting a new part into the remanufacturing process. This injection of new parts, however, could have a negative impact on the economic and ecological evaluation (e.g., higher costs, less environmentally friendly).

Uncertainties with respect to return time, return volume and core part quality are potential risks. Core acquisition management actively deals with this issue and aims to prevent or at least lower the uncertainties (Gavidel and Rickli, 2018; Wei, 2014). A reverse logistics process shall assure a safe, protected return process to prevent damages and to maintain the value of the core part (ANSI, 2017).

Kurilova-Pališaitienè (2018) explored the challenges of remanufacturing, which influence the process lead time. She grouped them into industry level, system level and process level. The main challenges are summarized in Table 9.

Table 9: Challenges of remanufacturing effecting process lead times (based on Kurilova-Pališaitienè, 2018)

\begin{tabular}{|l|l|}
\hline Challenge & Detail \\
\hline Core & $\begin{array}{l}\text { - Unpredictable core availability } \\
\end{array}$ \\
\hline Operations & - Insufficient core availability \\
& $\begin{array}{l}\text { - Unclarity in the process } \\
\end{array}$ \\
\hline Parts & - High inventory levels \\
\hline Costs & Production quality assurance \\
\hline Upgrades & - Cost fluctuation due to uncertainty \\
& - Availability to knowledge about upgrades \\
\hline
\end{tabular}


In the last years, the first approaches were made for a more efficient remanufacturing process already in the design phase. Methods gathered around the term "Design for Environment" (DfE) deal with optimizations to improve the end-of-life usage of parts. For example, the capability to disassembly parts after their usage phase is a matter of this design approach, as a non-destructive, efficient disassembly process is essential for remanufacturing (Tchertchian et al., 2012). Design approaches specifically focusing on improving the feasibility and efficiency in the product design phase are gathered around the term "Design for Remanufacturing" (DfRem) and are described by Hatcher et al. (2011). Asif et al. (2021) explored designing products for multiple lifecycles and investigated ways for the manufacturer to "systematically evaluate different design options with respect to efforts needed to make modules of a product reusable, upgradable, remanufacture-able and recyclable."

\subsection{Automotive ReMANUFACTURING}

As demonstrated in the previous chapter, of all remanufacturing industries in Europe, the remanufacturing industry for automotive parts is the second largest sector (Parker et al., 2015). In addition to the previously mentioned general remanufacturing processes in other industries, the remanufacturing of automotive parts is one of the most common industrial branches to conduct remanufacturing. In the following subchapters, the motivation to decide to perform automotive remanufacturing ( $\rightarrow$ ecological and economic benefits), the technical reasons for a need to remanufacture ( $\rightarrow$ wear and tear, defects, faulty operating), the "raw material" basis to remanufacture ( $\rightarrow$ core parts) and finally how to remanufacture automotive parts ( $\rightarrow$ production processes) is described.

\subsubsection{Motivation - BenEFITS FROM AUtOMOtIVE REMANUFACtURING}

Shortly after selling new products, a certain portion of all new products reach their end of life. A part of these products reaching this stage is replaced by spare parts; another part of these products is, for economic and ecological reasons, replaced by remanufactured products, as shown in Figure 4 (Matsumoto and Ikeda, 2015). 


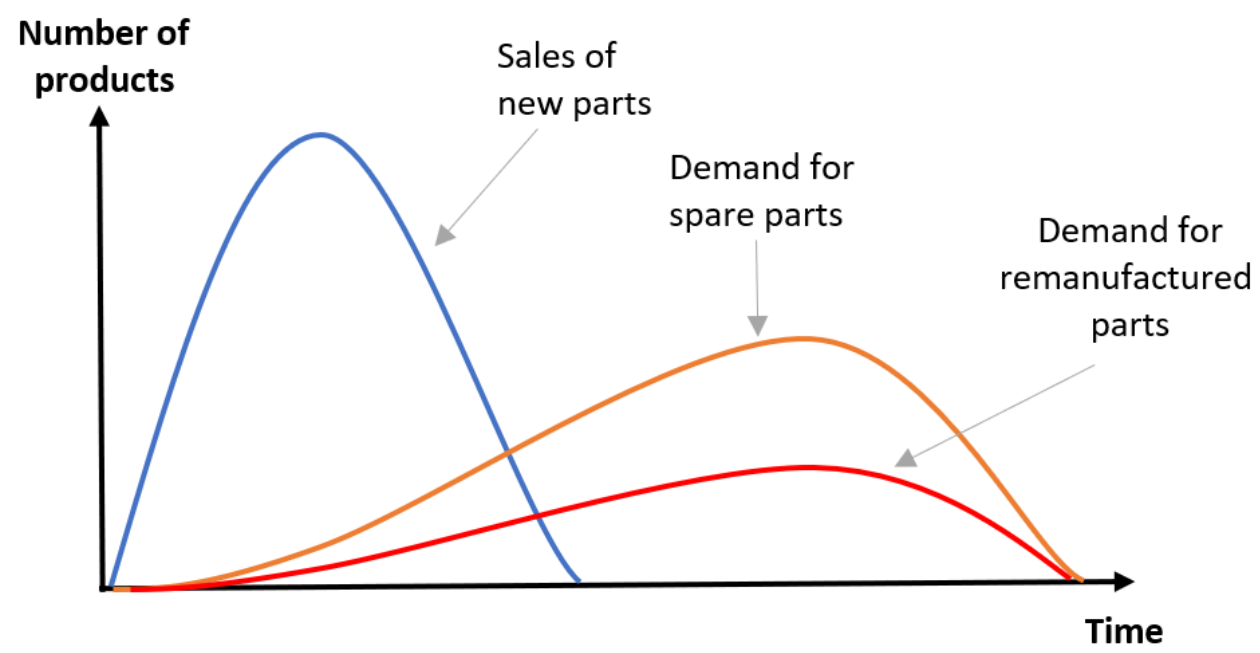

Figure 4: Visualization of the distribution of new parts and demand for spare and remanufactured parts (based on Matsumoto and Ikeda, 2015)

Nearly all OEMs today have a program with parts that have been remanufactured. The relevance of these programs has grown in the last years. One reason is that manufacturers are trying to gain an earlier end of production (EOP) for spare parts. This is especially of interest for decreasing and low demand. These production lines for low quantities can be used for other spare parts with increasing or higher volumes. The production costs per produced unit decreases, and resources (e.g., machinery, staff, and space) can be used more efficiently.

Both remanufactured and spare parts can both come from different distribution channels, as shown in Table 10. Depending on the relationship between the remanufacturer and the OEM, the following three main groups can be defined (Oestlin, 2008):

1. Original Equipment Manufacturer (OER)

2. Contracted Remanufacturer (CR)

3. Independent Remanufacturer (IR) 
Table 10: Distribution channels and business concepts of remanufactured parts (based on Capgemini, 2010; ILO, 2005; KBC, 2017; McKinsey, 2017; Oestlin, 2008; Subramoniam, 2012)

\begin{tabular}{|c|c|c|c|}
\hline \multicolumn{2}{|c|}{ Distribution Channel } & \multirow[t]{2}{*}{ Reman Business Concept } & \multirow{2}{*}{$\begin{array}{l}\text { Reman market } \\
\text { share } \\
\text { (\% of market value in } \\
\text { Europe according to } \\
\text { Optimat, 2013) }\end{array}$} \\
\hline $\begin{array}{c}\text { Spare } \\
\text { Part }\end{array}$ & $\begin{array}{c}\text { Reman } \\
\text { Part }\end{array}$ & & \\
\hline OES & OER & $\begin{array}{l}\text { Remanufacturing by OEM and } \\
\text { using own network for service and } \\
\text { parts in the aftersales phase (OES) } \\
\text { for distribution }\end{array}$ & $14 \%$ \\
\hline Tier-ns & $\mathrm{CR}$ & $\begin{array}{l}\text { Remanufacturing by a contracted } \\
\text { third party and supplying the } \\
\text { OEM/OES directly (Tier-1) or } \\
\text { within a direct supply chain (Tier- } \\
\text { 2, Tier-3, Tier-n) }\end{array}$ & $38 \%$ \\
\hline IAM & IR & $\begin{array}{l}\text { Remanufacturing and distribution } \\
\text { not being controlled by } \\
\text { OEMs/OESs }\end{array}$ & $48 \%$ \\
\hline
\end{tabular}

In the early phase of the lifetime of a product, high customer loyalty and potential warranty matters lead to a higher share for the distribution channels of the OES/OER (including their Tiers). In later phases, this loyalty decreased and raised the share of the IAM (Capgemini, 2010; ILO, 2005; KBC, 2017; McKinsey, 2017; Subramoniam, 2012).

The positive ecological effects of automotive remanufacturing have been explored in several research works and are often used in marketing campaigns by car manufacturers to underline the "green perspective" of remanufacturing. These research works and publications use different research objects (here: different remanufactured parts) and different ways to evaluate, quantify and demonstrate these benefits from an ecological point of view, as shown below:

- Zhang et al. (2014a) compared the global warming potential index (GWP), which quantitatively compares the integrated greenhouse effect of different kinds of gases of the production for new parts with the production of remanufactured parts of a diesel engine. He came to the result that the GWP of the remanufacturing process is $67 \%$ lower compared to new part production (Rosa and Schaeffer, 1995).

- Kumar et al. (2013) concluded that the process of remanufacturing a diesel engine uses about $40 \%$ less energy and reduces the consumption of natural resources by around $18 \%$ compared to the production of the same new part. 
- Gabhane and Kaddoura (2017), who explored the remanufacturing process of a transmission from a Volvo vehicle, came to the result that the remanufacturing process reduced the global warming potential $\left(\mathrm{CO}_{2}-\mathrm{eq}\right)$ by $36 \%$ when comparing this process to new part production. According to Gabhane and Kaddoura, this is primarily resulting from lower emissions in the phase of raw material extraction.

- Kara (2008), who investigated the remanufacturing of a 6-speed automatic transmission of $\mathrm{ZF}$, came to very similar results: She could prove that remanufactured transmissions had $34 \%$ less carbon impact compared to new parts. She traced back this circumstance mainly to the manufacturing operation of the main housing in the new part production.

- Warsen et al. (2011), who compared the new part production of a 5-speed manual transmission with the remanufacturing process of the same part, came to the result that $33 \%$ of energy can be saved by remanufacturing.

- Gao et al. (2017) compared the remanufacturing process of turbochargers to the production of new parts with respect to environmental aspects. For all his six investigated categories, the remanufacturing process significantly reduced the environmental impact.

- Volkswagen (2013) chooses a very concrete, vivid language to underline the goals achieved by its remanufacturing program: "983 million $\mathrm{kWh}$ of energy and about 350,000 tons of steel were saved only by remanufacturing engines. Enough to rebuild the Eiffel tower 50 times."

- The German car manufacturer BMW (2006) advertises that it has a reuse rate of up to $60 \%$, depending on the product group, without specifying the reuse in more detail.

- Daimler (2021a) states that "the reconditioning of a single remanufactured G281 truck transmission saves $445 \mathrm{~kg}$ of carbon dioxide and 7,300 megajoules of energy compared with production of a new unit. In other words: eleven trees would take ten years to convert the $\mathrm{CO}_{2}$ saved by remanufacturing." Daimler states that remanufacturing "requires less energy and fewer raw materials compared with producing new parts. It makes a contribution to a positive eco-balance."

- Remanufacturer FPT (2010) states that remanufacturing is "saving about 28 million tons of carbon dioxide. That's as much as is released by ten 500-megawatt, coal-fired electricity plants in a year."

- A Scottish transmission remanufacturer estimates that remanufacturing a transmission can reduce material consummation by approximately $85 \%$ (Zero, 2014a).

- Even higher results are shared by transmission remanufacturer ZF (2016). Jens Uhl, manager of the division for remanufacturing and repair at ZF Services, states, "Energy consumption and emissions can be reduced by up to $90 \%$ by refabrication 
of parts. Moreover, the material consumption can be reduced by $50 \%$ to $90 \%$ compared to the production of new parts."

- For the remanufacturing of batteries of EVs, Kampker et al. (2016) learned that "in a functioning circular economy remanufacturing the batteries can improve the environmental impact in all relevant sustainability indicators, especially for the consumption of resources and the reduction of the greenhouse warming potential."

GWP, $\mathrm{CO}_{2}$-equivalent, energy consumption, steel usage, emissions, carbon dioxide impact-the chosen ways to measure the positive impact of automotive remanufacturing - are very much the drivers. Nevertheless, the results of studies come to the same conclusion: Remanufacturing from the ecological perspective is superior to the production of a comparable new part.

In addition to the above-mentioned ecological benefits, the remanufacturing of automotive parts has economic ones as well. Often, these economic advantages are linked to or result from the ecological advantages:

- The handbook of remanufacturing states, "because remanufacturing recovers a substantial fraction of the materials and value added to a product in its first manufacture, and because it can do this at low additional cost, the resulting products can be obtained at reduced price" (Matsumoto and Ijomah, 2013).

- Colledani et al. (2014) states that remanufacturing "preserves more or less $85 \%$ of the initial value, (...). Remanufacturing processes use $20-25 \%$ of the energy needed to manufacture the same part. The cost of remanufacturing can be between $45 \%$ and $65 \%$ less than the manufacturing cost."

- The magazine Manufacturing states in an article that "savings in raw material and energy consumption produce an end product which is 40-50 percent less expensive than a new one-an impressive margin in a highly price-sensitive market" (Manufacturing, 2021).

- The manufacturer Daimler (2021b) creates a direct link between ecological and economic benefits. It states that it saves "valuable raw materials and energy in the reconditioning process - cost savings that we can transfer directly to our customers as price benefits."

- Several OEMs define the price level of a remanufactured part from $40 \%$ to $60 \%$ below the price for a new part (BMW, 2006; Daimler, 2020a; VW, 2004; VW, 2013). "All used parts which are technically and economically for remanufacturing are reworked to quality specifications identical to those found in the production of new parts" (VW, 2004).

- An evaluation for batteries of EVs came to the conclusion that "a vehicle application remanufactured battery could be produced for about $60 \%$ of the cost of a new battery" (Foster et al., 2014). Mahmood and Gutteridge note a "30 to 70 
percent cost advantage that second-life batteries are likely to demonstrate in 2025" but adds that the cost advantage of remanufactured batteries may decrease as the price for new batteries will be lower with the rise of production capacities (Mahmood and Gutteridge, 2019).

As already seen when analyzing the ecological benefits, remanufactured parts are also superior to newly produced parts from the economic perspective. This is not surprising, as the ecological and economic benefits are in direct causal dependence. As less energy, material and labor need to be invested, the costs of the remanufactured parts can be lower.

\subsubsection{ISSUES-TECHNICAL REASONS FOR AUTOMOTIVE REMANUFACTURING}

Automotive parts can be subject to a need for replacement. Reasons for this need could be:

- Design and production reasons: A car today consists of, on average, 20,000 interacting different parts. Each part or each interaction of different parts can lead to issues. Therefore, defects resulting from an inferior design, insufficient production process or poor material quality can occur (Chi et al., 2020; Lucky and Takim, 2015).

- Wear and tear: This consists of defects occurring from the ordinary use of the product (Cambridge, 2021b). Parts that typically need regular replacement within the lifetime of a vehicle are brake parts, tires, clutch parts, windscreen wipers, bulbs, filters, chains and belts, the (starter) battery, suspension parts, operating liquids and parts of the exhaust system (ADAC, 2014; Springer, 2021; VW, 2021a).

- Faulty operation and misuse: This includes defects resulting from the vehicle user (driver) operating "in an unsuitable way or in a way that was not intended" (Cambridge, 2021b). Examples are exceeding required service intervals, using the wrong or incorrect volume of operation liquids (e.g., petrol instead of diesel), nonprofessional repairs and maintenance, over-speeding of combustion engines and usage of wrong gears in a manual transmission (ADAC, 2019; ADAC, 2020; JHG, 2021; Wiesinger, 2021; ZDK, 2021).

- Technical obsolescence and changes: To achieve product improvements and implement the latest knowledge and experiences, automotive parts require technical changes during their production lifetime. These changes can lead to the need for replacement. The management and evaluation of these changes are gathered in their own discipline: "change management" (Knackstedt, 2017; Köhler, 2019; Milling and Jürging, 2008). It is estimated that about $40 \%$ of the car manufacturer's challenge "is due to the frequent engineering changes which cause disruption in their original plan as well as the product lifecycle" (Prolim, 2021). The remanufacturing process offers the opportunity to update or upgrade to the latest technical change level (Ijomah and Danis, 2012; ZF, 2012). 
"Remanufacturing upgrade could enhance the products' performance and realize the product's multi-life cycle for the efficient use of products" (Jukun et al., 2014).

In the focus of automotive remanufacturing are parts of the so-called "powertrain." The powertrain summarizes all the main parts generating the power and transmitting it to the wheels of the car. For ICE, these main parts are the engine, the transmission and the exhaust system. For EVs, they are the electric motor and the battery system (Collins, 2021; McKinsey, 2021a).

In the following overviews, the most common defects and the reasons for these defects are highlighted for the most important remanufactured parts.

Common defects of internal combustion engines (MSI, 2015; Mahle, 2020a):

- Piston shows rubbing (chafing) marks and longitudinal scratches (Reason: Dirt in combustion air or the engine oil)

- Wear of piston rings (Reason: Oil deficiency, petrol in the oil, defects in the injection system)

- Hole in piston (Reason: Wrong plugs)

- Marks of valves on piston (Reason: Faulty valve timing)

- Bearing shells show rubbing (chafing) marks and longitudinal scratches (Reason: Dirt in oil)

- Piston jamming (Reason: Overheating, oil deficiency)

Common defects of transmissions (Gregorius, 2006):

- Contamination

- Material crack/fracture

- Seizing/jamming

- Wear

- Corrosion

- Micro pitting

- Internal reasons for defects:

- Normal wear of bearings, tooth and seals

- Fatigue of material due to normal aging

- Insufficient lubrication and/or cooling

- External reasons for defects:

- Misconstruction

- Poor quality of housing, bearing and tooth system

- Modification

- Leak of maintenance

- Insufficient lubrication 
- Overstress

- Sabotage

Common defects and issues of injection systems (Bosch, 2018a; Cardone, 2018; OFI, 2020):

- General:

○ Low performance

- High fuel consumption

- Noises and smoke

○ Problems while starting engine

- Alert of on-board-diagnosis system (OBD)

- Common defects of injectors: (Muenster, 2015)

- Damaged electrical connector (Reason: Improper handling)

- Damaged hydraulic connector (Reason: Improper disassembly tool)

- Deformations and carbonization (Reason: Mechanical damage from engine breakdown; Leakage; Overheating)

- Common defects of injection pumps: (Baran, 2020)

○ Corrosion at valve for fuel pressure regulation (Reason: Contamination)

- Worn-out piston (Reason: Wear)

○ Material erosion (Reason: Contamination)

Common defects of turbochargers (BTS, 2017; Koehler, 2017; Mahle, 2020b; Mahle, 2020c; Polichronis et al., 2013):

- Inadequate lubrication (Reason: Low level of engine oil, poor quality or wrong type of oil, turning off engine when still hot, high speeding with cold engine, blocked oil system)

- Contaminated oil (Reason: Exceeded maintenance intervals, blocked oil filter, water in the oil system, contamination by improper repair, engine wear (metal), combustion faults)

- Oil leakage (Reason: Clogged lines, too high supply of oil in the engine, high pressure in the crankcase)

- Foreign object damage (Reason: Foreign objects entering on intake or exhaust side (e.g., dust, sand, screws, parts of piston rings))

- Damage due to excessive exhaust temperatures (Reason: Tuning, combustion faults, turning off hot engine)

- Over-speeding (Reason: Tuning, blocked VTG air guide plates, defect (pneumatic or electric) control) 


\section{Common defects of battery packs of EVs:}

- Performance issues due to end of life. When reaching $80 \%$ of the initial capacity, they are no longer suitable for EV standards (Kampker et al., 2016; Ramoni and Zhang, 2012; Zhang et al., 2011). The durability is strongly dependent on the battery technologies used and varies strongly between the different technologies (Sanguesa et al, 2021).

- Zhang et al. (2014b) define three characteristics showing the end of life of a battery:

- Major defects of electrodes

- Electrolyte decay

- Serious corrosion

- Benger (2020) summarizes reasons for internal short circuits in lithium-ion batteries, which can lead to defects, including fires and explosions:

○ Mechanical abuse (e.g., deformation)

- Electrical abuse

○ Thermal abuse (e.g., overheating, insufficient cooling)

$\circ$ Insufficient design and assembly quality

Common defects of electric motors of EVs (Prasad and Krishnanunni, 2020; Sahni, 2010):

- Overloading

- Power supplies not within specification

- Friction

- Strong contamination

- Winding failures and defects

- Bearing failures

- Worn-out/abrasive wear

- Insufficient lubrication instability

F Fatigue

- Corrosion

○ Cracks

\subsubsection{CORE - The BASIS FOR AUTOMOtIVE REMANUFACTURING}

The starting point and essential basis for an automotive remanufacturing process is the availability of a suitable core, as defined before. Remanufacturing companies can source core parts from different distribution channels, as shown in Table 11 (KBC, 2017). Forecasting and monitoring the core sourcing and core return, the so-called core management, is seen as an important key factor for successful remanufacturing. It prevents issues in production, keeps inventories low and increases profitability (Pillai, 2017; Wei et al., 2015). 
Table 11: Distribution channels for core parts for OEM/OES and IAM (based on KBC, 2017)

\begin{tabular}{|l|c|c|}
\hline & OEM/OES & IAM \\
\hline Returned parts from warranties & $28 \%$ & $5 \%$ \\
\hline Returned parts from own sales & $41 \%$ & $29 \%$ \\
\hline Parts from third parties/core brokers & $31 \%$ & $67 \%$ \\
\hline
\end{tabular}

Additionally, the used part from the customer can be used for remanufacturing (so-called "1-to-1-reman" or "core-in-advance reman," which is mainly done if there is no alternative core part available. Disadvantages of this method are long lead times due to logistics processes (as the core part needs to be picked up first) and a risk that the customer part is no longer suitable for remanufacturing.

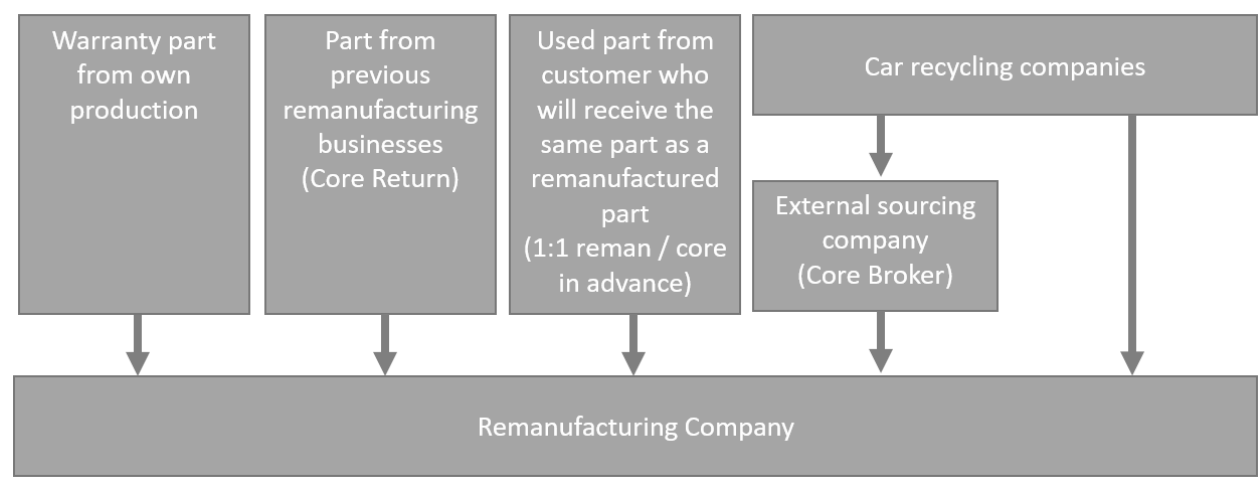

Figure 5: Internal and external sources for core parts (based on KBC, 2017; Pillai, 2017; Wei et al., 2015)

Remanufacturing companies attach a particular value to receive core parts in good condition. A study conducted by Kemény Boehme \& Company came to the result that $69 \%$ of all OEMs/OESs evaluate their cores as "good," whereas only 54\% of IAM companies and only $38 \%$ of Tiers come to the same result (KBC, 2017). To improve their core quality, VW has defined many strict and very clear criteria for the reception of core parts (VW, 2016). Nevertheless, not all OEMs have such strict criteria to accept core parts. As the acceptance of a core is combined with a financial uncertainty on the customer side, Ford, for example, has defined a "no-risk" core return policy: "100\% core credit regardless of damage or quality of returned core. This policy provides our customers confidence when quoting repairs with Ford parts. When returning core, these guidelines must be followed: Returned core is the same part as the assembly returned. Core is $100 \%$ complete with all parts attached and all fluids drained and is returned in the original package" (Ford, 2019). Should a suitable core part not be available, the remanufacturing company could try to use the old part of the customer. An alternative is trying to source a core from a car recycling company. This sourcing can be carried out 
with an external partner, a so-called core broker, a company specialized in the supply and the sourcing of core parts.

Besides defining the technical requirements for the return of a core part, remanufacturing companies often use deposits as an incentive to get back old parts. An alternative to deposit is adjustment surcharges to motive customers to return their cores (KBC, 2017).

The criteria for the reception of engine core parts as defined by several automotive OEMs are (Daimler, 2013; VW, 2016):

- Part is properly packed

- Not contaminated

- No corrosion

- Not damaged

- Complete

- Not disassembled

- Not modified

- No foreign material

- All fluids removed

- Use caps/dummy plugs

- Surfaces undamaged

- No damaged block

- No fire damages

- Part number legible

These are the criteria for the reception of transmission core parts as defined by OEMs (Daimler, 2013, VW, 2016):

- Relevant criteria from engine core part reception (see above)

- Usage of protection caps and closing plugs

- Closing of all borings

- Attaching torque converter (only for automatic transmissions)

These are the criteria for the reception of core turbochargers (BW, 2018; BW, 2020; Daimler, 2013; VW, 2016):

- Relevant criteria from engine core part reception (see above)

- Only OEM/OES turbocharger

- No dismantled turbochargers

- No broken connecting flanges

- No missing parts (e.g., bracket, actuator) 
These are the criteria for the reception of core parts of the injection system as defined by an OEM (VW, 2016):

- Relevant criteria from engine core part reception (see above)

- Injector nozzles must be protected by a protection cap

- No damaged electrical plug connections

In the following subchapters, the general automotive remanufacturing process and the individual processes of the most important automotive remanufactured parts are described.

\subsection{Automotive Remanufacturing Processes}

"People do not always understand that remanufacturing can be more complex than manufacturing new," Colin Pettigrew, Product engineering manager of the remanufacturing subsidiary of Cummins, states (Zero, 2014b). This chapter describes the most relevant remanufactured parts and their remanufacturing processes.

The general process of remanufacturing parts of ICE powertrains has been explored in the literature, for example, by Steinhilper (1998), Subramoniam et al. (2009) or Sundin and Dunbäck (2013). As EVs are just now gaining a higher market relevance, the number of academic publications is much lower. Therefore, this field has been investigated in its own publication. Subramoniam (2012) investigated remanufacturing in the automotive industry and focused on organization (strategic planning, decision making), whereas this thesis focuses on providing an actual state-of-the-art exploration of future challenges and opportunities resulting from technology and market changes.

The starting point for an automotive remanufacturing business process is the demand for a part, which is not covered by a newly produced, reused or recycled part. This demand is covered by a remanufactured part. Motivation for this can be an awaited economic or an ecological benefit from the remanufacturing process or both.

Assuming a core part is available, the remanufacturing process can be carried out. This process is described for the most important products in the following subchapters. After shipment of the remanufactured part, the company will assure the return of the old part of the customer if it has not already been used (in the business case, "core in advance"). The general remanufacturing business flow as well as all other remanufacturing process visualized with BPMN can be seen in the in the process flow in the Appendix B1. 


\subsubsection{InTERnAl COMbUSTION ENGINE REMANUfaCtuRING}

A central part of the powertrain of an ICE car is the combustion engine. As it is subject to wear and has a high value, it is the focus of remanufacturing. In this chapter, the main remanufacturing process steps are described and visualized.

The German quality standards association, GMI, has issued a quality label, "RAL RG797," defining standards for a remanufactured engine. An engine remanufactured in accordance with this label must fulfill all of the following criteria: The engine has been dismantled completely, and all parts have been inspected and checked, whether they have to be machined or can be reused. Wear parts must be replaced, in any case, by new parts in original part quality. Supplied engine-auxiliary items have to be checked, if technically possible, in the same way, and defects have to be eliminated to the same standards. The aim is to re-establish the functioning of the engine (GMI, 2009). The list of compulsory new parts is extensive: All kinds of sealings, all filters, nozzle inserts, spark/glow plugs, all operational liquids, bearings, pistons including rings and pins, hoses/pipes, hydraulic tappets, rails, screws and thermostats (GMI, 2020b).

A standardized remanufacturing process has been explored in specialized remanufacturing companies and is described in the literature. This process consists of the following main process steps (GMI, 2015; FPT, 2010; Sauer, 2016; VW, 2004):

\section{Disassembly and cleaning}

The ANSI defines disassembly as the "complete sequential removal of parts of an assembled product into its constituent materials or parts" (ANSI, 2017). In the remanufacturing process for engines, the complete part is disassembled, wear parts are scrapped, and all parts are cleaned. Especially in this step, it becomes clear if the design of the part is remanufacturing-friendly. In many design concepts, remanufacturing has not been respected, and parts are not easy to disassemble or get damaged/destroyed in this attempt (also see "DfE" and "DfRem" in Chapter 3; Sundin, 2004; Huber, 2001).

\section{Checking and machining of the cylinder block}

Check and machine the surfaces of the cylinder block. Replace cylinders (if technically possible); otherwise, hone cylinders. Cylinder blocks made from aluminum, which was first used in gasoil engines and since the 1990s also for diesel engines, are a special challenge. Some engine manufacturers reject the repair of aluminum engine blocks if the bearing covers of the crankshaft main bearing have been disassembled (MSI, 2006). 


\section{Checking and machining of the cylinder head(s)}

Perform initial checks for fine cracks. If there are no cracks, renew valve seat rings and valve guides. Check rocker arms, rocker arm shafts, bearing bushes, valve springs or tappets. Perform leak detection of the ventils with a vacuum tester. If there are cracks, check if repair by welding is possible. Otherwise, replace it with a new part.

\section{Checking and machining of the crankshaft}

Execute an electromagnetic crack test. Detect fine cracks with UV light. Check for wobble and hardness. If necessary, harden the crankshaft. Check, measure, precision grind and polish the bearing journals. Finally, fine balance it.

\section{Checking and machining of the conrods}

Hone blind holes, renew conrod bushes, weight check and align. Renew bearings and screws.

\section{Checking and machining of the camshaft(s)}

Check and machine cams and bearing points.

\section{Check of the supplied engine-auxiliary items}

Check engine-auxiliary items, if they have been supplied, for example, the turbocharger, injection pump, water pump, oil pump, hydraulic pump and cooling system of water and oil. If necessary, machine or renew.

\section{Assembly}

Assemble all parts according to the manufacturer's instructions.

\section{Quality check/test bench run}

If the dress level of the engine allows this, run the engine on a test bench. Check engine performance, torque and emission. Perform leak detection. Today, this process step is often no longer executed, as the dress levels of the engines are more compact. In the past, the scope of delivery "long block" (engine block with cylinder head) was more common. Today, it is rather the scope of delivery "short block" (no cylinder head). In this scope, the engine cannot be tested on a test bench without great investments. For these small dress levels, reliable upstream quality gates are of high importance.

\subsubsection{Remanufacturing Process of Transmissions}

All vehicles, whether ICEs, PHEV, HEV or BEVs or others, need a transmission (or gearbox) to convert the power, control it and transmit it to the wheels (Ngo, 2012; Voelkner and Robkhob, 2010). 
In general, transmissions can be divided into two main groups: manual transmissions where gears are shifted manually, and automatic transmissions where the gears are changed by a mechanism without the help of the driver (Meti, 2020). The usage of a manual or automatic transmission has an influence on the (subjective) driving comfort, fuel efficiency and costs, for example, for maintenance (Mogre, 2012).

There are different arrangements possible for the transmission in the vehicle depending on the type of drive (here: front-wheel drive, rear-wheel drive, all-wheel drive) and the location of the engine (here: front or rear), which influence the design of the transmission on the one hand and the driving performance on the other (Naunheimer et al., 2011). Moreover, transmissions can be differentiated by the number of gears and different shafts (Mingchuan, 2014). In the definition of the ideal customer benefit, a "magic triangle" of comfort, performance and emissions must be respected. Moreover, overall product requirements of size, cost and weight must be respected (ZF, 2013a).

Compared to ICEs, the requirements for a transmission for a BEV are different due to the different characteristics of a combustion engine and an electric motor. Transmissions for $\mathrm{BEV}$ s require fewer gears but more torque tolerance capacity at the input shaft (Chuan et al., 2013).

As transmissions have many rotating parts, wear is a huge consideration. As a transmission, moreover, is a part of high value, it is of great interest for remanufacturing. The remanufacturer MACKIE states that the price for remanufactured transmissions is around $60 \%$ less than for a new part (Zero, 2014a).

The processes of transmission remanufacturing have been explored. A general, simplified remanufacturing process is shown below. In practice, this process can differ significantly due to very different design types, as described before (Daimler, 2020a; Vege, 2020; Warsen et al., 2011; ZF, 2013b).

\section{Disassembly and cleaning}

If not done in advance by the customer, the oil is drained by opening the drain plugs. The transmission is disassembled completely (Voelkner and Robkhob, 2010). "Missing a worn spline or leaving a small fragment inside a transmission will cause premature failure" (TRC, 2014). All parts of one transmission remain together and are not mixed with parts from other transmissions. All bearings, bands, seals, gaskets and all damaged parts are replaced. Daimler highlights that they replace all quality-relevant parts using the latest, potentially improved replacement part. They add that this makes the remanufactured transmission 
superior to the initial part and leads to an improved functionality and extended lifetime (Daimler, 2020b).

\section{Washing}

The parts are cleaned and degreased in a process respecting their size, design and material. A general aim is to keep the quantity of wastewater low to protect the environment and reduce high disposal costs.

\section{Inspection}

After the washing cycle, all parts planned for reuse are thoroughly inspected and the dimensions are measured to evaluate whether they can be reused or not. All parts not within the tolerance are discarded and replaced by new, genuine parts. Especially parts of the transmission synchronization, the shifter forks and the shifter shafts are accurately checked to guarantee a smooth shifting of gears.

\section{Machining and finishing}

If needed, surfaces are machined. Body parts are painted.

\section{Assembly}

If required, the parts are updated to the last technical revision level to make them technically equal to new parts. All parts are assembled according to the requirements of the manufacturer, and the torque values, in particular, are respected and monitored.

\section{Testing}

The finished transmission is tested on a testbench under dynamic loads using specific shift programs per model to ensure operation, reliability and durability like a new part. The results are verified in a report.

If the transmission consists of a torque converter, it is remanufactured in a separate process that consists of the following steps: The torque converter is mechanically cut open, and its parts are washed and blasted. Afterward, the torque converter goes to a balancing process and is closed by welding and bonding. In the final step, all parts are checked by performing a leak test (SIR, 2017).

\subsubsection{INJECTION SySTEM REMANUFACTURING}

The purpose of the fuel injection system is to transport the correct amount of fuel from the fuel tank to the combustion engine and to provide it to the combustion chamber. It has replaced carburetors, which were previously used for this purpose. Different technical solutions have been used in the past or are still being used today. The in-line injection pump has been the conventional solution for diesel engines for about 100 years. A widely 
used technology today is the common rail technology, which consists of a reserve of fuel under very high pressure, which is sent by the pressure of up to 2,700 bar via the injectors into the combustion chambers. In addition to the supply lines, the main parts of an injection system are the injection pump generating the pressure needed in the system and the injectors spraying the fuel into each combustion chamber (Bosch, 2018b; Krafthand, 2013; Krafthand, 2016; Pham and Cao, 2019; Reddy and Yamini, 2015; Reif, 2012; Renault, 2008).

The important supplier of parts of the injection system, German Tier-1 BOSCH, has set its own core return service to assure the basis of its remanufacturing activities. "A fast and reliable procedure is guaranteed by providing clear return conditions and implementing the "back-in-box" process of returning the core in the original packaging provided with the exchange part. (...). The Göttingen site receives and processes cores from over 50 countries." (Bosch, 2012c).

The processes of injector and injection pump remanufacturing have been explored. A general, simplified remanufacturing process is shown in Table 12.

Table 12: Remanufacturing processes of injectors and injection pumps

\begin{tabular}{|c|c|c|}
\hline & $\begin{array}{l}\text { Injector } \\
\text { Bosch, 2012a; Bosch, 2012b; } \\
\text { BWD, 2020; Carwood, 2020; } \\
\text { Daraba et al., 2017; Delphi, } \\
\text { 2018a; Delphi, 2018b; ERN, } \\
\text { 2020b; Steinhilper, } 2017\end{array}$ & $\begin{array}{l}\text { Injection Pump } \\
\text { Bosch, 2012b; Bosch, 2015; } \\
\text { Cardone, 2018; NAPA, 2020; } \\
\text { TDS, } 2020\end{array}$ \\
\hline & $\begin{array}{l}\text { After initial check and flushing, } \\
\text { the injector is disassembled } \\
\text { completely. Scrapping of } \\
\text { critical and defective parts. } \\
\text { Critical parts: } \\
\text { O-rings, nozzles, valves, seals, } \\
\text { bearings }\end{array}$ & $\begin{array}{l}\text { Critical parts: } \\
\text { O-rings, gaskets, bushings of the } \\
\text { drive shaft }\end{array}$ \\
\hline & \multicolumn{2}{|c|}{ All parts are washed and degreased using ultrasonic baths } \\
\hline 3. Inspection & \multicolumn{2}{|c|}{$\begin{array}{l}\text { All parts are sorted and inspected. Parts showing wear and which do } \\
\text { not meet the specifications are scrapped and replaced by new parts }\end{array}$} \\
\hline 4. Assembly & \multicolumn{2}{|c|}{ Reassembly in a room that meets clean room standards. Pre-testing } \\
\hline $\begin{array}{l}\text { 5. Testing and } \\
\text { timing }\end{array}$ & \multicolumn{2}{|c|}{$\begin{array}{l}\text { Testing and adjustment on special test benches according to OEM } \\
\text { specifications }\end{array}$} \\
\hline
\end{tabular}


All work on parts of the fuel injection system requires a high level of technical cleanliness, as even tiny contamination would influence the functionality of the system. Process steps as described below must be spatially separated. The layout and the technical equipment used should be designed to prevent carrying over contamination from one process step to another (Bosch, 2012a).

Steinhilper and Nagel (2017) carried out complex, successful research to explore alternative technologies to repair common rail injectors. He was able to find a process in which the contaminated injectors are operated with a special cleaning liquid instead of fuel. The first results are promising.

Already in the 1950s, the injection system was mentioned in technical publications as the main cause of failures of diesel engines (Agrartechnik, 1952). Zhang and Chen (2018) state that the injector is seen as one of the most critical parts of a diesel engine, which makes it an interesting part for remanufacturing. An industry survey came to the result that about a third of all injectors can be remanufactured at low cost. The reasons for the failure of the fuel pump are mainly a poor quality of fuel or a lack of lubrification of the moving parts of the pump (Cardone, 2018). Jung et al. (2011) conclude that most failures of injectors result from contamination of the nozzle tip.

\subsubsection{TURBOCHARGER REMANUFACTURING}

Turbochargers use the exhaust gases of internal combustion engines. The gas stream drives a turbine, which is connected via a shaft to a compressor wheel (Moulin, 2010). The purpose of the turbocharger is to raise the efficiency of the engine to decrease fuel consumption and emissions (Oertel, 2015). "We are getting into a stage where consumers can choose from multiple turbocharged four-cylinder vehicles that have as much power as the high-performance eight-cylinder vehicles from 15 years ago. These smaller engines operate at a 40 percent lower rate of fuel consumption when compared to a larger, naturally aspirated eight-cylinder engine, so the prospects for the turbocharger segment are indeed bright," states Bob German, Business Development Manager at the Flight Systems Automotive Group (German, 2015).

Other related and comparable technical systems to increase the quantity of inlet air into the combustion engine are, for example, (Rothgang, 2015; Woongkul et al., 2017):

- The supercharger, which is mechanically driven by transferring energy from the crankshaft via a belt or chain

- Electric forced induction systems, which are driven or assisted by electrical energy. Examples are electric compressors or electrically assisted turbochargers

These less common systems are not a matter of research in this thesis. 
The turbocharger technology was invented at the beginning of the $20^{\text {th }}$ century but was in the first decades exclusively used in large diesel engines. In the 1950s, this technology was applied in trucks. The first serial car was equipped with a turbocharger in the 1960s. After getting more attention due to their application in racing cars, turbochargers were used in sports cars such as the famous Audi 200/Quatro, BMW 2002, Saab 900 and Porsche 911. Today, they are state of the art in all kinds of combustion engines in all vehicles. A market share of $70 \%$ for turbocharged light vehicles is predicted for the year 2020 (Honeywell, 2020; Koehler, 2017; Vogel, 2014; Walsham and Winterbone, 1990).

Today's design of turbochargers is laid out for a time of usage covering the complete lifetime of the car. (Koehler, 2017). Nevertheless, technical problems can occur. Most failures of turbochargers result from a lack of lubrication. Other reasons are misuse, not respecting the maintenance intervals and external effects and foreign objects entering the turbocharger from the intake or exhaust side (Polichronis et al., 2013). In particular, the rotating parts of the turbocharger show wear: that is, the shaft and wheel assembly, including their journal bearings, piston rings and the bearing housing. Moreover, foreign parts can lead to severe damage to the compressor wheel or wheel assembly (Vogel, 2014). A rising number of engines equipped with turbochargers made this part an interesting object for new business for replacements as a new part as well as a remanufactured part (MSD, 2018).

The processes of turbocharger remanufacturing have been explored. A general, simplified remanufacturing process is shown below (AET, 2020; BTS, 2017; BW, 2018; BW, 2020; Caterpillar, 2008; Delphi, 2020; Gao et al., 2017; Koehler, 2017; Melett, 2020; TH, 2020; TT, 2020; Vege, 2012):

\section{Disassembly and cleaning}

Perform pre-sorting and initial inspection of core parts to identify parts suitable for remanufacturing. Complete disassembly of all parts. Scrape all bearings, sealings and worn-out parts.

\section{Washing}

Perform thermal, ultrasonic or chemical cleaning and degreasing dependent on the part and the material specification.

\section{Inspection}

Inspect and measure all critical surfaces, tolerances and dimensions.

\section{Machining and finishing}

If needed, machine surfaces, mill, drill, grind and perform turn operations. Shot blast the turbine housing. 


\section{Pre-assembly}

Assemble, balance and test the CRHA (Center Rotating Housing Assembly). CRHA and other parts are assembled according to OEM specifications. If a wastegate actuator is part of the dress level, it is set and calibrated. Scrapped parts are replaced by new parts in OEM quality.

\section{Balancing and testing}

The fully assembled turbocharger is balanced on a specific high-precision test bench. Check of functionality and final inspection.

\subsubsection{EleCtRIC VEHICLE BATTERY REMANUFACTURING}

From their first usage onward, the capacity of lithium-ion batteries degrades. The design of battery packs is designed to cover a mileage of approximately $150,000 \mathrm{~km}$ before they need to be replaced (EUCAR, 2019). Of all lithium-ion batteries in use globally, today, about $90 \%$ are in EVs. This led to a strong increase in the demand for raw materials needed to produce lithium-ion batteries, for example, cobalt; a scarcity and increasing prices for these raw materials was the result (Sanderson, 2017). This increase in raw material prices nevertheless did not lead to an increase in costs per kilowatt-hour $(\mathrm{kWh})$ as the production processes and the technologies used improved and the production volume rose. In 2010, the costs were around $1,000 \$ / \mathrm{kWh}$ and had decreased to 200 $\$ / \mathrm{kWh}$ in by 2017 (Bourbon, 2020). Remanufacturing can promote this development. The cost per kWh of new lithium-ion batteries can be reduced by an extension of the lifetime of a battery, for example, by remanufacturing (Foster et al., 2014).

Bobba et al. (2000) highlights this scarcity of raw materials as an important motivation to remanufacture or recycle batteries of EVs. Apart from the previously described ecological and economic benefits of remanufacturing automotive parts, the importance of gaining an additional source for these "critical raw materials" is crucial.

The battery pack consists of a housing designed to protect it against negative environmental influences, including crashes. It includes the actual battery, which stores the energy for the propulsion. Moreover, there is high-voltage routing and often a cooling system, which assures that the ideal operating temperature is not exceeded (Benteler, 2021).

Different strategies and procedures to recover battery packs from EVs are used today. The three most important alternative strategies at the moment are as follows: (Standridge and Lindsay, 2014; Standridge and Mehedi, 2015): 


\section{Alternative 1: Remanufacturing of battery packs}

In the first step, the battery pack is picked up at its last place of use (e.g., a car dealer) and brought in a reverse logistics process to a company specialized in the remanufacturing of battery packs. Most often, battery packs consist of different modules that consist of different battery cells. For example, a battery pack consisting of 96 battery cells can be organized into 12 modules with 8 battery cells each. The remanufacturing company will inspect every single battery cell in a defined process. Damaged cells or cells not no longer meeting the specifications are replaced. The process steps are as follows (Dynamic, 2021; Foster et al., 2014; Kampker et al., 2016; Kampker et al., 2020; Schneider et al., 2009; Standridge and Lindsay, 2014; Zhang et al., 2014b):

- Step 1: Battery disassembly

- Step 2: Visual inspection of cells, if parts are within specification

- Step 3: Verification of voltage for cells passed initial inspection and are within specification

- Step 4: Re-grouping and new configuration of cells into battery modules

- Step 5: Re-assembly

- Step 6: Proceeding a test of charge retention

Studies were made to evaluate the economic benefits of remanufacturing battery packs. When compared to the production of new battery packs, remanufacturing showed economic benefits (Schneider et al., 2009).

\section{Alternative 2: Repurposing of battery packs}

As described in the previous process (see "Alternative 1"), the battery pack is picked up and transported to a company specialized in non-automotive applications. A potential use could be as power storage in a stationary solution. Again, all cells are checked. If damage is found or the cells are not within the specification, they are replaced by new cells. In the second step, the cells are re-grouped into new modules and a different battery control system is installed. The complete process consists of the following main process steps (Casals et al., 2009; Dynamic, 2021; Foster et al., 2014; Standridge and Lindsay, 2014):

- Step 1: Dismantle the battery into modules

- Step 2: Re-group modules with cells of similar characteristics

- Step 3: Assemble in a new configuration

An evaluation of the economic benefits of this form of recovery is difficult, as the outcome of the evaluation is strongly dependent on the future usage of the off-highway 
application. The variation here is very broad and needs to be investigated for each specific application.

\begin{abstract}
Alternative 3: Recycling of battery packs
A third alternative for recovering battery packs is recycling. This procedure is still widely used today and most the most efficient way of dealing with battery packs. This recycling process consists of the following process steps (Dynamic, 2021; Foster et al., 2014; Groenewald and Barai, 2016; Mahmood and Gutteridge, 2019; Mancha, 2016; Standridge and Lindsay, 2014):
\end{abstract}

- Step 1: Collecting the battery packs

- Step 2: Transporting battery packs to recycling company which is specialized in battery packs

- Step 3: Disassembling battery packs and separating them into sub-components

- Step 4: Separating different metals, chemicals and other components, especially using Hydrometallurgy (chemical separation and recovery process)

- Step 5: Reusing, selling or disposing of separated materials. Regulations for environmental protection, safety and health need to be followed carefully

Recycling battery packs is today a process resulting in high costs. Some companies successfully set up a profitable business with the recycling of battery packs. But the financial benefits from this recycling process do not in all cases cover the costs. Regulations for environmental protection, health and safety are strong and are cost intensive. Moreover, costs for disposing of materials that are not reusable are high. Nevertheless, the motivation to recycle battery packs is strong and important to protect the environment, gain resource efficiency, and meet CLSC policies or other legal regulations. Such regulations are already in power today in the EU and in China (Berggren and Kageson, 2017; EU, 2013; Reuters, 2018). Mahmood and Gutteridge conducted a market research in 2019 and found out that, at that time, EV battery remanufacturing had been carried out by the OEMs General Motors, Nissan, Tesla and Volvo (Mahmood and Gutteridge, 2019). As this market is changing rapidly, this situation may already be obsolete today.

\title{
3.3.6 EV MOTOR REMANUFACTURING
}

An electric powertrain consists of fewer parts compared to the powertrain of an ICE, and each of these parts has lower complexity from the mechanical engineering perspective. This circumstance leads to less and leaner disassembly, machining and assembly processes (Kampker et al., 2017). Hollah et al. (2016) point out that the wear and tear of an electric motor are significantly lower compared to that of combustion engines. The car manufacturer KIA highlights that the "simplicity of the electric motor that drives EVs, perhaps half a dozen moving parts which the motor contains, which leads to less wear 
and tear of components" has economic benefits resulting from this circumstance (KIA, 2021).

Here, the most important steps in the process of remanufacturing an EV motor are shown (DuraSource, 2021; Groenewald and Barai, 2016; Niir, 2021; Sahni et al., 2010):

- Step 1: Identification and first inspection (visual)

- Step 2: First testing (functional)

- Step 3: Disassembling and unwinding (if required)

- Step 4: Cleaning

- Step 5: Second visual inspection of parts

- Step 6: Second functional testing of parts

- Step 7: Insert new replacement parts, e.g., bearings

- Step 8: Rewinding (if required)

- Step 9: Reinsulating and reassembly

- Step 10: Final testing

Weiland states, "Electric motors, induction or permanent magnet synchronous motors, are much simpler; they consist only of a stator, rotor and bearings. Remanufacturing is, in principle, much easier compared to remanufacturing an internal combustion engine. Changing the bearings is not a problem, but the main challenge will be to replace failed windings of the stator or rotor for which processes do not exist yet" (Weiland, 2020). 


\section{TODAY's Challenges in Automotive}

\section{REMANUFACTURING}

This chapter concerns the first research question, "What are today's challenges in the automotive remanufacturing industry?" To provide the answer, the relevant information has been generated in Papers I and II using literature research, semi-structured interviews with experts within the remanufacturing industry and questionnaires. Based on this research, the following chapter provides and summarizes the main challenges within the automotive remanufacturing industry today.

To explore today's challenges in the automotive remanufacturing industry, several different techniques have been used to gain new data and evaluate it. Besides a literature review, interviews with experts in the remanufacturing industry were conducted and questionnaires have been sent out. Details about the methodology can be found in Chapter 2. The results of this research work have been used in Papers I and II.

All results are grouped and presented in this thesis as they appear along the supply chain: from challenges of suppliers (see 4.1), to challenges of core management (see 4.2), to challenges of core evaluation, inspection, disassembling and cleaning (see 4.3), to challenges in the remanufacturing process itself (see 4.4) and finally to challenges in the transportation of remanufactured parts (see 4.5).

Groups have been named to link them more easily to comments presented in the conclusion. Here, the term ICE stands for "internal combustion engine," and a consecutive number per group has been used.

\subsection{Challenges in CONNECTION With Suppliers}

As part of Paper I, this matter has been explored, and the following findings have been made in connection with the sourcing of spare parts to remanufacture parts:

Challenge ICE-01: Availability of spare parts: In interviews with sales and marketing experts in the automotive industry (see Section 2.3.2), it has been highlighted that the distribution of spare parts, which are needed as replacement parts in the remanufacturing process, is not yet set up by the OEM/OES: The process of producing the new part is launched, but the after-sales department of the OEM has not yet launched these articles in their ERP system. If the OEM at this time announces the demand for remanufactured parts, the spare parts used for replacement are not available. Deloitte (2013) stresses the 
overall importance of spare parts supply chain management, which "is more complicated than that of finished products, with the challenges stemming from the huge number in parts stock-keeping units, unstable and unpredictable demand, as well as the complexity of the overall supply and distribution network." And highlights further the "critical role of a sufficient spare part management "in the stability and agility of the supply chain." New opportunities are resulting from the latest trend of digitalization within the industry: Subramoniam et al. (2021) are describing the possibilities of covering part demands by 3D printing, which is an especially interesting alternative for low volume items for which the production has already been stopped.

Challenge ICE-02: Allocation of spare parts: Another result from these expert interviews (see Section 2.3.2) was that the suppliers, at an early stage, only supply to the production lines. Contracts between the supplier and the after-sales organization of the OEM/OES for after-sales are most often not yet existent. Frequency of delivery, packaging concepts, content and scope of delivery are not adapted to spare part demand of remanufacturers. Auweraera et al. (2019) describes the circumstance in her research: The demand for spare parts is with a delay in time following the demand of the main product. As the main product sales slowly ramp up, the spare part demands also ramp up with a slight postponement. As the spare part network is still in the building-up phase, it can lead to issues in availability (see also Challenge ICE-01).

Challenge ICE-03: Packaging and quantities: One lesson learned from the interviews was also that, in many cases, the method of packaging, packaging size and quantity per packaging is not compatible with the needs of the remanufacturing processes. As described by Riza and Purba (2018), inventory management in companies is searching for an economic order quantity (EOQ). This is the quantity in which the cost of containment and the cost of ordering and transportation are minimized. However, at the same time, suppliers often define minimum order quantities (MOQ), which specify a minimum value or minimum quantity per order (Slimstock, 2019). When the EOQ and MOQ differ, the potential consequences can be as follows:

- MOQ too high: This is especially an issue when the quantity of remanufactured parts is low, or just a single part must be remanufactured (1-to-1 remanufacturing; batch size 1). A high MOQ leads to a high investment in working capital. Storage costs are high, and there is a risk of obsolescence of parts. On the other hand, parts need to be ordered less often, which reduces the costs of ordering and minimizes the risk of stockouts.

- MOQ too low: Parts for a serial production run of remanufactured goods are sometimes provided in a form that is not compatible with serial processes. MOQs are too small, and the logistics or handling processes of the spare part supplier are not capable of meeting higher volumes. This leads to high ordering and 
administration costs. At the same time, the working capital, storage costs and risk of obsolescence can be lower.

\subsection{Challenges in the Core Management Process}

The main issues in connection with core management today are as follows:

Challenge ICE-04: Core Management: Most often, the demand for core parts needs to exceed the planned quantity of remanufactured parts. The reason for this is that, eventually, not all received core parts are suitable (e.g., severe damages or core part not within specification or arrival of core part not within the forecasted timeframe) or core parts are missing (e.g., as it has not been returned or got lost in the reverse logistics process). Therefore, the minimum inventory level must respect this circumstance and needs to be higher, even if it leads to higher costs. Modern technical monitoring systems and the trend of digitalization in the industry can reduce issues here (UniSussex, 2017; Wei et al., 2015). Pillai (2017), who explored forecasts for core returns, highlights this matter in his work: "The remanufacturing process is way more erratic and unpredictable in terms of the timing, quantity and quality of incoming cores than the traditional manufacturing process itself." New opportunities are given by the latest trends in digitalization within the industry. Subramoniam et al. (2021) highlight the great importance of data to evaluate in which state the parts is and where the parts are located.

Challenge ICE-05: Uncertainty of core quality: As the quality of the expected core parts is unclear until they arrive at the remanufacturing company, similar issues as described in the first point arise (UniSussex, 2017). Wei et al. (2015) state that the low quality of received core parts can force the remanufacturing company to "convert other types of cores, tooling, or even use new parts to meet the demand, and such operations can be very costly. On the other hand, if an overstock of cores occurs, it increases the holding cost and the risk of obsolescence."

Challenge ICE-06: Core complexity: Part numbers for automotive parts are often on the market in a wide range of revision levels resulting from technical and design changes during the lifetime of the part. This leads to high complexity and the need to manage this complexity. The identification process gets more difficult, and the need for a higher inventory level increases (Westermann, 2012). Oestlin (2008) states that "the variety of the parts' condition also complicates the machine setup times. Some operations are known with certainty, but others are dependent on the age and condition of the cores. This makes remanufacturing more complex than traditional production in the perspective of capacity and resource planning, scheduling, shop floor and inventory control." 


\subsection{Challenges in the Identification, Visual Checking, DISASSEMBLY AND CLEANING}

In this first process step, carried out within the remanufacturing company with the core part, an important part of the value-adding of remanufacturing can be generated. If this process step is not organized and conducted efficiently, a loss can be generated, for example, by incorrect identification of the part, destructive disassembly processes, faulty results of quality evaluations or insufficient cleaning processes. More detailed examples and the most important challenges are described below:

Challenge ICE-07: Identification and variety: Equivalent to the sourcing of the correct core part (see: "core complexity" in 4.2), the correct identification of the part is a challenge. Westermann (2012) highlights the main effects resulting from complexity in remanufacturing: High efforts for internal coordination and broad experience are needed. As the main drivers of this complexity for remanufacturing, he defines the core quality, the number of different product groups and the experience of staff. His overall recommendation is that "Remanufacturing companies should focus on reducing or handling complexity." He is suggesting to carefully identify the drivers and effects from complexity and to apply a method of optimization.

Challenge ICE-08: Remanufacturing-unfriendly designs: In many cases, the design of parts does not regard the later disassembly processes, with the potential result that nondestructive disassembly is not possible (EPA, 2021; Huber, 2001; Nikolaidis, 2013; Sundin et al., 2012, Tchertchian et al., 2012). Sundin (2004), who explored the product and process design for remanufacturing, suggests that "design for remanufacturing (DfRem) aspects could be better integrated into a company's environmental management systems" (see also DfRem/DfE in Section 3.1).

Challenge ICE-09: Hazardous, heavy contamination: After a phase of usage, core parts are often contaminated with hazardous materials. These can be operational liquids (e.g., oil, grease) or other substances resulting from the usage or from wear (e.g., particles, oxide). Parts in some cases contain hazardous materials (e.g., those found in batteries). Cleaning these parts and reaching a required level of technical cleanliness is a major challenge of remanufacturing companies. At the same time, it is seen as a very unique and specific challenge of this industry (Sundin et al., 2012). In a study that Liu et al. (2013) conducted on the remanufacturing cleaning technology for mechanical equipment, he summarizes the main issues identified: "In spite of the simplification and effectiveness of present remanufacturing cleaning process, unified standards for cleanliness judgment and the knowledge base of remanufacturing cleaning are insufficient. Furthermore, problems such as secondary pollution, energy waste, and low cleaning efficiency due to low levels of automation also arise." Challenges in connection with hazardous, heavy contamination can be categorized into two groups: 
- The challenge to gain the requested cleanliness of the part

- The challenge to guarantee an environmentally friendly, efficient recycling process of the hazardous waste

\subsection{Challenges in the Remanufacturing Production Process}

In the remanufacturing production process step, remanufacturing companies can gain the highest value-added. The process step can consist of many different sub-processes that are dependent on the remanufactured part and the depth of production. In these important process's steps, several challenges have been identified:

\section{Challenge ICE-10: Remanufacturing of electronic and mechatronic automotive} parts: Often, procedures and applications for testing are not available and need to be designed and created. The sourcing of spare parts needed for replacement must be organized and carried out. As most traditional remanufacturing companies main work with mechanical parts, the challenges of reorganizing and rethinking the business processes are high (Weiland, 2012). Kleylein-Feuerstein et al. (2015) sees remanufacturing processes for electronic control units as a great difficulty and highlights that the actual existing technology of remanufacturing is insufficient. Electronic parts are furthermore more fragile than mechanical parts. Extra care, specific packaging and transportation could be necessary (Sundin and Dunbäck, 2013). This challenge can be evaluated from two perspectives:

- The remanufacturing of electronic and mechatronic automotive parts offers new business opportunities for remanufacturing companies. More and more such parts are used in cars. Their lifetime is limited, and there is the need for replacement, which can be partly covered by remanufactured parts.

- On the other hand, many remanufacturing companies that have operated prior in the field of remanufacturing of mechanical parts are not prepared for such new business concepts. In particular, mastering the different spare part sourcing processes, the new requirements of testing and repair and managing the operating software can lead to issues.

Besides the challenges in connection with electronic components, Steinhilper et al. (2006) highlight the opportunities in this field: a high potential for business due to the increasing amount of mechatronic systems and the opportunity to reprogram and upgrade parts during the remanufacturing process.

Challenge ICE-11: Remanufacturing-unfriendly materials. During the interviews with experts from remanufacturing production companies, several examples have been highlighted regarding the usage of remanufacturing-unfriendly materials (see Section 2.3.2):

- In some cases, remanufacturing-unfriendly materials were used in engine blocks. Examples were the usage of the materials Nikasil and Alusil, which led to issues 
in the process of drilling and honing the cylinders. "Today often modern technology of cylinder machining and surface coating are being used, which cannot be used in remanufacturing, as the production facilities and processing machines are not available" (MSI, 2006).

- A different circumstance leading to issues mentioned by the experts was the trend of lightweight construction of engine blocks. Again, this circumstance leads to issues in the process of drilling and honing the cylinders as specifications and tolerances afterward can no longer be met. "One engine manufacturer even recommends changing the complete aluminum engine block after opening the bearing covers of the crankshaft main bearings. This manufacturer assumes that due to internal tension in the block the specifications after the opening cannot anymore be met" (MSI, 2006).

- In some cases, experts described materials and part designs that made machining harder or even impossible. They described, for example, crankshafts that were hardened in a special process that made it more difficult to machine them or fractional conrods that were also not feasible for machining. Another example was coated cylinders, which needed special equipment and tools to machine (see also "unfriendly-remanufacturing material" above). "Although the engines are more durable, when they are remanufactured, there are high-tech parts that may need replacement, such as cam phasers, valve lift control systems, and cylinder deactivation modules. Although remanufacturers are primarily dealing with engines 7 to 15 years old, some engines from high-end cars still pose remanufacturing issues from comparatively early use of high-technology, and their precision manufacturing for lightweight and size optimization" (Weissler, 2014).

Challenge ICE-12: Quality and functional testing: The dress levels, which define the delivery scope of automotive remanufactured parts, were lately a matter of significant changes. For combustion engines, the common dress level was for many years defined as a "long block engine." These engines consisted of the engine block, including crankshaft, pistons and connecting rods, cylinder head with camshaft, lifters and valves (Ridley and Ijomah, 2021; Walton, 2021). As this dress level is very complete and close to the state as mounted in the vehicle, it allowed one to conduct a hot test using an engine test bench after the remanufacturing process. The motivation of this hot test was to verify the engine performance and to conduct a quality test procedure. Today, less complete dress levels are increasingly common. One example is the "short block engine," which just consists of the engine block, including crankshaft, pistons and connecting rods. Such an engine is not suitable for a host test or the effort to conduct such a test would be very high. A "cold test," where the engine is connected to an electronic motor that rotates the crankshaft, can be an alternative. Data is recorded and compared to an ideal engine standard. Fogaça et al. (2018) compared the hot and cold test procedures and came to the following result: "Despite the cold test showing several benefits in its process, important requirements of 
hot test approval, such as leaks and test in the turbo compressor, are not identified in the cold test. That is why the hot test has better reliability and, consequently, better advantage. The cold test prevents the company from not having process defects (bolts without torque, lack or exchange of components) in the validated engine, fully assembled. Such conclusions bring the idea of complementarity of processes."

\subsection{Challenges with Logistics}

Logistics processes play an important role in a CLSC. Managing the challenges with respect to packaging, transportation and reverse logistics is key for successful remanufacturing. As they are often needed to deal with the transportation of parts that are heavily contaminated or that contain hazardous substances (also see challenge "ICE-09: Hazardous, heavy contamination"), strict environmental restrictions and regulations must be respected. This can lead to both increased efforts and costs. More efficiency within logistics has no direct positive effect on the part. Nevertheless, it can improve the reliability and profitability of a business. Motivated by this circumstance, lately, several research works have explored logistics within the remanufacturing industry. They dealt with improvements within the logistics networks (Springer, 2013), the challenges of exchanging data (UniBayreuth, 2012), the legal framework and sustainability aspects (Westermann, 2012). As logistics networks and logistics processes within the automotive industry are very complex, they have been explored in a great number of studies. This has often made logistics processes within this industry an innovation driver for logistics in general (Stroehmer, 2009). As part of Paper II, this matter has been explored, and the main challenges have been identified:

Challenge ICE-13: Challenges in the transportation of core parts: As core parts are parts that have been previously used, they are, in many cases, strongly contaminated (see also challenge "ICE-09: Hazardous, heavy contamination"). This requires special attention and actions to meet strict environmental regulations. Handling, storing and transporting core parts may not lead to any form of environmental harm. These special requirements have been explored in Paper II. The key findings in this paper were as follows:

- The packaging used for the forward logistics process (here: sending the remanufactured part out) should also be suitable and used for the reverse logistics process (here: returning the core part). Several OEMs and remanufacturing companies suggest this. For example, regarding its core requirements, Volkswagen states, "Just use the packaging in which the original remanufactured part has been delivered. Here you will find cardboard or pallets including inlays, covers, fixations and plugs and caps for electric connections. This not only saves time and money but also protects the environment" (VW, 2016). 
- The design and concept of packaging used in the forward logistics process transporting the remanufactured part should respect requirements to prevent contamination when returning the contaminated core parts.

- Used packaging should be easy to clean so it can be used again. In general, the packaging design should be reusable.

- When packaging can no longer be used and needs to be disposed of, it should ideally not be necessary to handle this packaging as hazardous waste (as it is probably still contaminated, e.g., with oil) as this would lead to additional costs and amount of hazardous waste.

Challenge ICE-14: Challenges in the usage of return packaging: The automotive industry often uses packaging for transportation specifically designed for remanufactured goods. The most common solutions have been explored (see Paper II) according to the above-mentioned requirements to compare and evaluate these different forms of packaging. The main findings were as follows:

- One finding of the study was that very different forms of packaging are used within the remanufacturing industry. The requirements for ideal packaging as described in challenge ICE-13 were, in many cases, not fulfilled.

- The study found that, in many cases, cardboard boxes are used as packaging. Often, this form of packaging can only be used for forward logistics as it already has wear from this initial transportation. If it is used for reverse logistics, it cannot safely protect against contamination. Contaminated cardboard must also be treated as hazardous waste. Using plastic bags inside the cardboard boxes can reduce the risk of contamination. Nevertheless, these bags increase the costs, the amount of waste and sightly the weight.

- Another finding was that metal frames are ideal forms of packaging for the transportation of large mechanic automotive parts, such as engines and engines. The part can be easily secured for transportation using bolts. Additionally, applied plastic bags can protect the parts in the forward logistics process. In the reverse logistics process, the same plastic bag can prevent contamination (e.g., from dropping oil). Extra mounted oil pans under the metal frame can offer extra safety from contamination. Moreover, this form of packaging is stackable and can be reused many times. Of disadvantage are the rather high costs for the initial investment in such packaging. Also, the weight of the metal frames is greater compared to other materials, which can have a negative impact on transportation costs and environmental evaluations.

- Kroon and Vrijens (1995), who investigated the use of returnable containers in reverse logistics, concluded that besides the environmental benefits, the economic benefits must be respected, as the companies otherwise choose the cheapest solution. "From this point of view, it is disadvantageous for the sender that the 
service fee of a returnable container usually needs to be somewhat higher than the cost of a cardboard box."

Challenge ICE-15: Challenges in connection with packaging guidelines and instructions: Continued research (see Paper II) has shown that only one in thirteen guidelines gives the advice to return used goods with the aim to remanufacture them. Several instructions describe the process of returning reusable packaging (e.g., plastic boxes or metal frames) but limit this return to the packaging itself. The return of the used part is not regarded. In all explored cases, the guidelines referred to regulations for the transportation of hazardous goods. Nevertheless, only one forwarder made strict, clear, practical instructions to prevent contamination (e.g., by oil). Nevertheless, even if packaging guidelines exist, and even if they define return processes, the OEMs and suppliers sometimes leave the final decision about packaging to their (sub-)supplier/sender. Continental (2019) states in its packaging guidelines that "Our environmental target is to use returnable packaging wherever possible." However, it allows non-returnable packaging in the same guideline if it is more economical: "If expendable packaging is preferred to returnable packaging for economic reasons, only packaging, ancillary packaging and loading packaging approved by Continental may be used." 
TODAY'S CHALLENGES IN AUTOMOTIVE REMANUFACTURING
Automotive Remanufacturing in a Changing Market 


\section{Future ChaLLENGES AND OPPORTUNITIES}

IN THE TECHNOLOGY TRANSITION

\section{TOWARDS ELECTRIC VEHICLE PART}

REMANUFACTURING

While the previous chapter highlighted today's challenges in the automotive remanufacturing industry, this chapter describes the challenges resulting from the latest technical developments in the transition phase from vehicles with combustion engines to electric" vehicles. It describes the actual changes in respect of technology and market, compares the two different propulsion concepts (ICE/EV) and highlights the differences and their effects on remanufacturing. From these effects, the challenges are defined and described.

To explore the future challenges and opportunities resulting from the actual changes in the automotive industry towards the electrification of cars, the latest developments have been explored and summarized, from the history of EVs and their missing success in the beginning to the latest technical and market developments leading them to an increased market share. In the second step, the most common technologies for EV cars are presented, and a comparison of the powertrain concept of an ICE and a BEV is provided. Using this as a basis, the remanufacturing processes of the different ICE and BEV parts were compared with each other. The differences in these processes and the effects from these differences were highlighted and provided to experts for verification. Taking this feedback into account, the challenges and opportunities have been carved out.

\subsection{Characteristics of The Transition Phase}

The transition phase, from the production of vehicles with combustion engines to vehicles with alternative forms of propulsion, is strongly influencing the actual automotive supply chains. In addition, the design processes and the production are a matter of significant changes. OEMs face the need for large investments in research and development (R\&D) and changes in their machinery and tooling in factories. These investments are partly supported by large national development programs (Gruening and Witte, 2011). Not only will the parts and their production processes change; completely new market actors will appear on all levels of the supply chain, from OEMs (e.g., Tesla) to all levels of suppliers. The new parts of EVs are not, in all cases, produced and mounted by the previous suppliers for ICE parts (Berggren and Kageson, 2017; Deloitte, 2019). All the changes 
need to be explored and monitored carefully by the actors in the supply chain. In addition to the changes for the production of new EV cars, there will be a change occurring with a postponement: The design, production and sourcing of spare parts for EVs will change as soon as the cars are sold. This demand for EV spare parts will increase with the increasing number and vehicle age of EV cars.

As previously described, a certain share of the spare part demand will be covered by remanufacturing (see Section 3.2.1), as it provides economic and ecological benefits compared to newly produced spare parts.

General remanufacturing processes of ICE parts have been described in the literature. Steinhilper (1998), Subramoniam et al. (2009) and Sundin and Dunbäck (2013) have described these processes, which provided an important basis for the research work of this thesis. Their research work was the basis for this thesis (see Chapter 3) and has been completed and updated (see Chapter 4). Finally, these findings are compared with the latest changes in the phase of transition in this chapter.

The remanufacturing process of battery packs has been described by Schneider et al. (2009). Gronewald (2016) described the remanufacturing process steps of EV parts. Erich and Witteveen (2017) explored the differences of parts used in BEVs and in ICE and compared the number of moving parts in both concepts.

First, OEMs and suppliers have reacted to the actual and future needs and have set up or are planning to set up processes of battery recycling and/or remanufacturing. Actual examples are as listed below (Nikkei, 2021; VW, 2021b; Woollacott, 2021):

- Nissan is using used batteries from its 'Leaf' model in automated guided vehicles for in-house transportation of material within its sites.

- Renault is recycling all batteries using a consortium.

- Toyota, together with partners, announced it was moving to transform used batteries into power storage systems for renewable energy.

- Volkswagen is in the process of setting up a pilot plant for battery recycling in Salzgitter / Germany.

\subsection{Historical DeVElopment of EleCtriC VeHiCleS}

Since the production of the car began in the late $19^{\text {th }}$ century, EVs have existed beside cars with combustion engines. Being quiet, reliable and easier to operate offered EVs advantages to cars with combustion engines of that time (Idaho, 2016; Intg. Engineering, 2019). Nevertheless, EVs did not take advantage of these benefits, and cars with combustion engines became standard for many centuries. EVs were rare and rather exotic exceptions. The reasons for the success of ICEs were as follows (U.S. Energy, 2020b): 
- Gasoline power was easier to access after the discovery and opening of new oil fields.

- Decreased costs for ICE cars due to the invention of mass production by Henry Ford.

- Improved quality of roads, which made long-distance traveling possible. EVs had a very limited radius of use due to their battery capacity.

- Improved technology of ICEs, which made their use more comfortable and easier (e.g., the invention of the electric starter).

Lately, this situation has changed, and the dominance of ICE cars has decreased significantly. Climate change, the fear of peak oil and improved EV technology are some of the reasons for the increasing share of EVs (Eberle and Helmolt, 2010). After nearly 100 years in which EVs were an almost the exotic exception without real market relevance, today, all major OEMs have extended their product ranges and are adding EVs, as shown in Table 13.

Table 13: EV strategy of prominent OEMs (Deloitte, 2020)

\begin{tabular}{|c|c|}
\hline OEM & EV Company Strategy \\
\hline BMW & $\begin{array}{l}\text {-2021: Aim to electrify 25\% of European market and } \\
\text { have one million EVs on the road } \\
\text { - 2023: Aim to have } 25 \mathrm{EV} \text { models in the product range } \\
\text { - 2030: Aim to electrify 50\% of European market }\end{array}$ \\
\hline FORD & $\begin{array}{l}\text { - 2022: Aim to have } 40 \mathrm{EVs} \text { in the product program } \\
\text { - 2030: Brand "Cadillac" to mainly produce EVs }\end{array}$ \\
\hline GM & - 2023: Aim to have $20 \mathrm{EVs}$ in the product program \\
\hline $\begin{array}{l}\text { RENAULT NISSAN } \\
\text { MITSUBISHI Group }\end{array}$ & $\begin{array}{l}\text { 2022: Aim to have } 12 \text { electrified and } 8 \text { pure EVs in the } \\
\text { product program. } 42 \% \text { of European NISSAN sales } \\
\text { with EVs }\end{array}$ \\
\hline TOYOTA & $\begin{array}{l}\text { - 2021: Target to set sell 30,000 EVs } \\
\text { - 2025: Target of } 5.5 \text { million EV sales }\end{array}$ \\
\hline VW Group & $\begin{array}{l}\text { - 2025: Generate } 25 \% \text { of global sales with EVs and have } \\
\text { three million EVs on the road } \\
\text { - 2028: } 70 \text { new EV models and } 40 \% \text { of global sales with } \\
\text { EVs }\end{array}$ \\
\hline
\end{tabular}

The technical transition proceeds fast. In 2019, in total, 143 new EVs were launched, to be followed by an additional 450 models by 2022. (McKinsey, 2020) Important manufacturers are Tesla (US), BYD (China), BJEV (China), BMW (Germany) and Nissan (Japan). The regional production focus for EVs lies in China (forecast 2027: 44\%), followed by Europe (forecast 2027: 29\%), North America (forecast 2027: 12\%) and 
Japan/Korea (forecast 2027: 12\%) (Statista, 2021b). The forecast for increasing global market shares of sales of EVs is illustrated in Fig. 6.

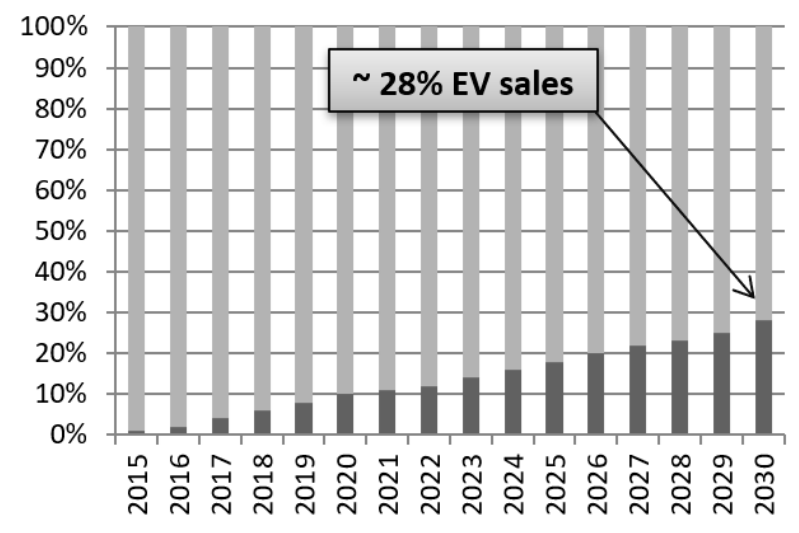

\section{EV Sales (\%)}

ICE Sales (\%)

Figure 6: Forecast of annual share of sales of EVs and ICEs (based on Deloitte, 2020; a previous version has been published in Paper III)

These increasing volumes of produced EVs lead to an increased need for battery production capacity. As of today, $80 \%$ of the global production of batteries for EVs is located in China. This will change in the next years, as there will be around 30 so-called "gigafactories" for battery production in Europe and another 10 sites in the U.S. The majority of them will not be directly operated by the car manufacturers but by Tiers (Jacobs, 2021; Reuters, 2021).

\subsection{MAIN TyPes OF EleCtRIC VEHIClES}

The powertrain of an EV car consists of one or more electric engines. Lately, all major OEMs have invested vast amounts in the development of EVs to extend their product program and keep up with the transition of the market demand for alternative powertrain concepts.

This market today for EVs is still very heterogeneous, with several different competing technical concepts. The four main types are battery electric vehicles (BEVs), hybrid electric vehicles (HEVs), plug-in hybrid electric vehicles (PHEVs) and fuel cell electric vehicles (FCEVs). A summary of these concepts and a description of their technology is provided in Table 14 (Ding et al., 2017; Mahmoudi et al., 2014; Mohammadia, 2018; UnNoor et al., 2017). 
Table 14: Main types of today's electric vehicles (based on BMW, 2021; Mahmoudi et al., 2014; a previous version has been published in Paper III)

\begin{tabular}{|c|c|}
\hline Type & Description of technical concept \\
\hline $\begin{array}{l}\text { Battery electric } \\
\text { vehicle (BEV) }\end{array}$ & $\begin{array}{l}\text { The power for the propulsion of BEVs is stored } \\
\text { in battery packs. These battery packs need to be } \\
\text { connected to an electric power source for } \\
\text { recharging. }\end{array}$ \\
\hline $\begin{array}{l}\text { Hybrid electric } \\
\text { vehicle (HEV) }\end{array}$ & $\begin{array}{l}\text { HEVs consist of an electric motor and } \\
\text { combustion engine. In urban areas and at low } \\
\text { speed, the car uses the electric motor. On } \\
\text { motorways and at high speeds, it uses the } \\
\text { combustion engine. The power of the electric } \\
\text { motor is also stored in battery packs and is } \\
\text { recharged by the combustion engine. }\end{array}$ \\
\hline $\begin{array}{l}\text { Plug-in hybrid } \\
\text { electric vehicle } \\
(\mathrm{PHEV})\end{array}$ & $\begin{array}{l}\text { A PHEV uses a concept that is very close to the } \\
\text { HEV concept described above. The major } \\
\text { difference is that a PHEV can additionally be } \\
\text { recharged by connecting it to an electric power } \\
\text { source. } \\
\text { A bridge between a BEV and a PHEV is an } \\
\text { EREV (Extended Range Electric Vehicle): A } \\
\text { fully electric car equipped with a small } \\
\text { combustion engine to recharge the battery and } \\
\text { extend the range (Yatheesha et al., 2014). }\end{array}$ \\
\hline $\begin{array}{l}\text { Fuel cell electric } \\
\text { vehicle (FCEV) }\end{array}$ & $\begin{array}{l}\text { FCEVs use an electric motor for propulsion and } \\
\text { are therefore classified as EVs. An FCEV has no } \\
\text { battery to store the electricity as the other EVs. It } \\
\text { is transforming the electricity in its internal } \\
\text { "power plant": the fuel cell. Here hydrogen } \\
\text { (from a tank) reacts with oxygen (from the } \\
\text { ambient air). Electricity, heat and water are } \\
\text { gained. }\end{array}$ \\
\hline
\end{tabular}

Besides the described concepts, different technologies exist that today do not have market relevance. One example is the solar electric vehicle (SEV), which is recharged by solar panels using sunlight. As such solutions have no significant market share and a very unclear outlook, they are not explored further in this thesis. 


\subsection{POWERTRAIN DIFFERENCES OF BEVS AND ICES}

The concept and the parts of BEV powertrains differ strongly from the concept and the parts used in ICEs; the major differences between the two concepts are shown in Figure 14. ICEs consist of one central combustion engine, which is most often located in the engine compartment in the front of the car. The power from the engine is transferred using a transmission and a clutch to two or more wheels of the car. The engine consists of complex parts in the periphery, for example, to start the engine, cool it, and control it and for passenger safety and comfort. Gasoline or Diesel is stored in a tank, most often located in the back. Using a fuel pump and via fuel lines, it is led to the engine compartment. Parts of the exhaust system manage the exhaust and lead to the back of the car. In contrast to this, a BEV consists of one or more electric motors. Most often, one central motor is located in the front, or there are separate motors for each axle. It moreover consists of one central battery pack, often located under the passenger compartment. Additional parts for the cooling of the battery, for control and safety and for comfort are also used. The peripherical parts are fewer and less complex. 


\section{Vehicles with Internal Combustion Engines (ICE)}

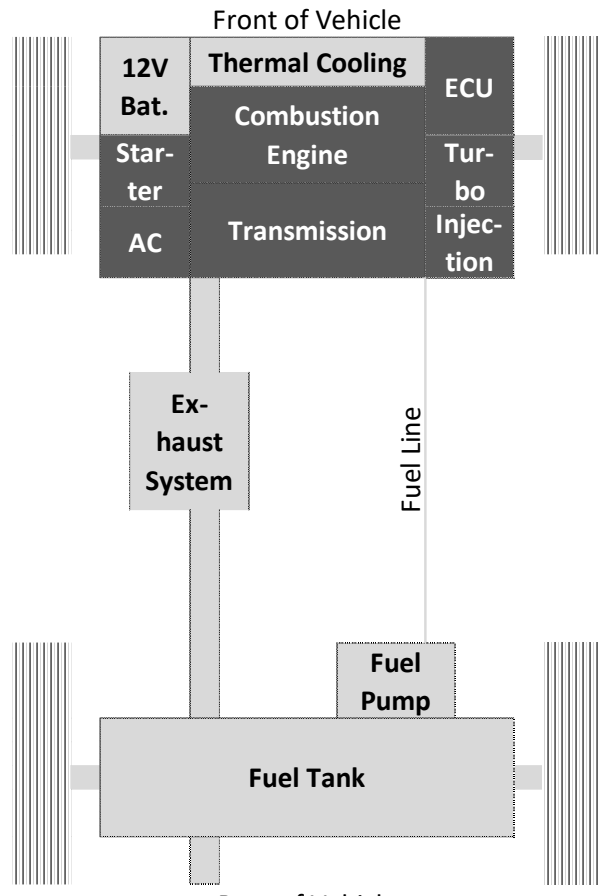

Rear of Vehicle

\section{Battery Electric Vehicles (BEV)}

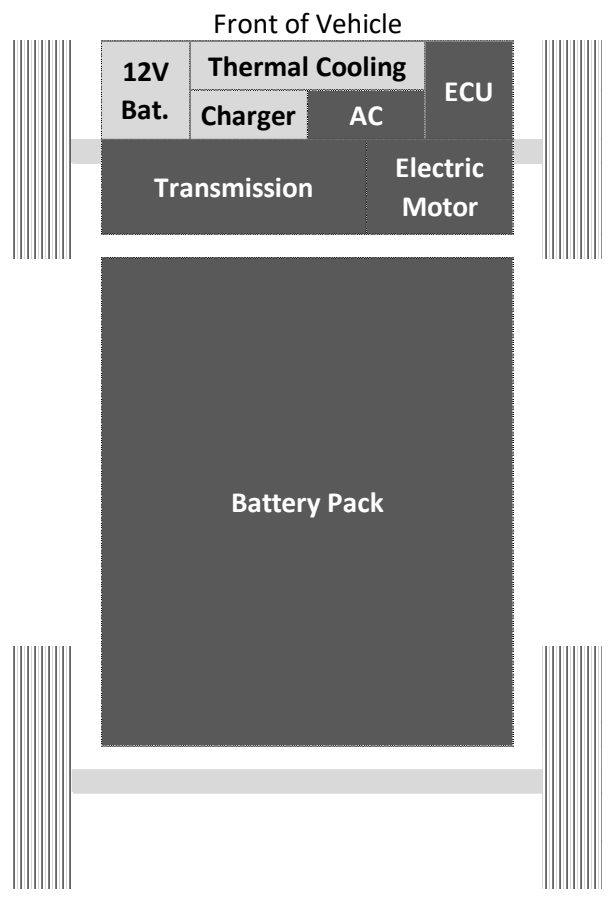

Rear of Vehicle

(Potential) component for remanufacturing

(Most likely) not a component for remanufacturing

Figure 7: Simplified illustration of the main parts of cars with internal combustion engines (ICE) (left) and battery electric vehicles (BEV) (right). Parts that have the potential for remanufacturing are highlighted (based on U.S. Energy, 2020a; a previous version of this figure has been published in Paper III)

As shown in Figure 7, the two powertrain concepts consist of common parts as well as differing parts. Parts that are the same or at least similar are, for example, the transmission, systems for cooling, air conditioning (AC) systems and electronic control units (ECU). The remanufacturing for these parts has been explored in the literature, for example, by Steinhilper (1998), Subramoniam et al. (2009) and Sundin and Dunbäck (2013). Moreover, this thesis has updated the existing research work (see Chapter 3) and explored the actual challenges (see Chapter 4). These parts, therefore, will not be explored in this chapter again but will deal with the parts differing between the two concepts: the battery pack and the electric motor. 
Besides the fact that the two systems consist of different parts, there is also a difference in the quantity of the parts. Previous research, for example, by Erich and Witteveen (2017) and Kampker et al. (2017), came to the result that the number of moving parts in a BEV is much lower compared with an ICE: On average, an ICE consists of 1,400 moving parts, whereas a BEV only has about 200 moving parts (Erich and Witteveen, 2017).

\subsection{EFFECTS OF POWERTRAIN DIFFERENCES OF BEVS AND ICES}

In addition to the comparison of the parts used in the two powertrain concepts in the previous section, the remanufacturing processes of ICE parts and BEV parts have been explored to find the differences and the effects of these differences.

The most important steps in the process of remanufacturing ICE parts have been described by Sundin and Dunbäck (2013). In parallel, the major steps of EV part remanufacturing have been described by Groenewald and Barai (2016). These processes have been simplified and illustrated together in Table 15 to find similarities and differences.

Table 15: Simplified process flows of the remanufacturing procedure of mechanical parts from internal combustion engines (left column, based on Sundin and Dunbäck (2013)) and parts from an electric motor (right column, based on Groenewald and Barai (2016)). A previous version of this table was published in Paper III.

\begin{tabular}{|l|l|}
\hline $\begin{array}{c}\text { Remanufacturing process of internal } \\
\text { combustion engines (ICE) }\end{array}$ & \multicolumn{1}{|c|}{$\begin{array}{c}\text { Remanufacturing process of electric } \\
\text { motors from BEVs }\end{array}$} \\
\hline First visual inspection & First visual inspection \\
\hline Disassembly & First functional testing \\
\hline Cleaning & Disassembly \\
\hline Second visual inspection & Cleaning \\
\hline Measuring & Second visual inspection \\
\hline Machining & Second functional testing \\
\hline Insert new (replacement parts) & Insert new (replacement parts) \\
\hline Reassembly & Reassembly \\
\hline Final testing & Final testing \\
\hline
\end{tabular}

This comparison clearly shows several similar process steps: parts in both concepts are inspected several times, in both cases are disassembled and cleaned, worn-out or defective parts are replaced in all cases, and after reassembly, they are both tested.

However, differences in the processes also became obvious: The remanufacturing of BEV parts used more steps of functional testing, whereas the ICE remanufacturing consisted more of measuring and machining parts. 
All explored differences and their effects are highlighted in Table 16.

Table 16: Effects based on the main differences between the remanufacturing procedure of powertrain parts from ICEs and BEVs (a previous version of this table was published in Paper III)

\begin{tabular}{|c|c|c|}
\hline \multicolumn{2}{|c|}{ Differences (D1-D7) } & Effects (E1-E11) \\
\hline \multirow[t]{4}{*}{ 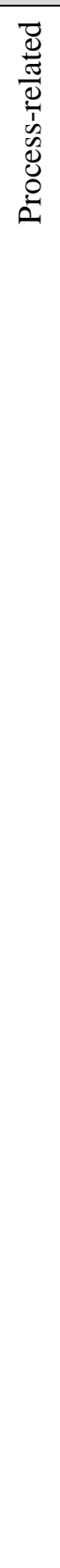 } & $\begin{array}{l}\text { D1: Functional tests are of great } \\
\text { importance for electrical parts. In } \\
\text { this process step, the decision is } \\
\text { made if a part can be reused or } \\
\text { must be replaced. }\end{array}$ & $\begin{array}{l}\text { E1: Availability of special test } \\
\text { equipment, including the relevant } \\
\text { software. The staff must be trained } \\
\text { and highly skilled. }\end{array}$ \\
\hline & $\begin{array}{l}\text { D2: Measuring procedures are of } \\
\text { integral importance in the } \\
\text { remanufacturing of mechanical } \\
\text { parts (e.g., diameter of cylinders, } \\
\text { diameter of connecting rod bores, } \\
\text { roughness of surfaces). They } \\
\text { provide the decision of if a part is } \\
\text { still within specification or has to } \\
\text { be replaced. }\end{array}$ & $\begin{array}{l}\text { E2: Measuring } \\
\text { equipment/technical } \\
\text { specifications must be available, } \\
\text { and permissible limits must be } \\
\text { known. }\end{array}$ \\
\hline & $\begin{array}{l}\text { D3: When electrical parts are } \\
\text { identified as defective (part not } \\
\text { within specification), they are most } \\
\text { often replaced with new parts. In } \\
\text { contrast, mechanical parts are often } \\
\text { machined to make them usable } \\
\text { again. }\end{array}$ & $\begin{array}{l}\text { E3: Less spacious machinery } \\
\text { parks are needed because parts are } \\
\text { often not machined, and parts not } \\
\text { within the specification are } \\
\text { replaced. More compact factory } \\
\text { layouts are possible. } \\
\text { E4: Recovery rate of parts } \\
\text { becomes lower since fewer parts are } \\
\text { machined when using part weight } \\
\text { as a unit of measure. When using } \\
\text { the financial value as a unit of } \\
\text { measure, this effect could be } \\
\text { different due to very expensive } \\
\text { electrical parts. For this study, the } \\
\text { recovery rate is defined as the sum } \\
\text { of remanufactured or recycled parts } \\
\text { in ration to the sum of all parts } \\
\text { (Yoda et al.; 2020). }\end{array}$ \\
\hline & $\begin{array}{l}\text { D4: Even if both procedures consist } \\
\text { of cleaning process steps, the } \\
\text { quality is different: Mechanical } \\
\text { parts are most often contaminated }\end{array}$ & $\begin{array}{l}\text { E5: Less demanding cleaning } \\
\text { processes are needed, leading to an } \\
\text { improved work environment and } \\
\text { less use of cleaning agents. }\end{array}$ \\
\hline
\end{tabular}




\begin{tabular}{|c|c|c|}
\hline & $\begin{array}{l}\text { with oil, grease, coal and other } \\
\text { operating residues. }\end{array}$ & $\begin{array}{l}\text { E6: Different hazardous waste is } \\
\text { generated. For the new hazardous } \\
\text { waste, recycling concepts must be } \\
\text { set up (especially for the battery } \\
\text { pack). }\end{array}$ \\
\hline \multirow[t]{3}{*}{ 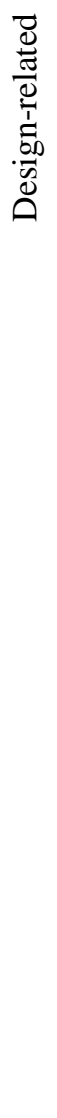 } & $\begin{array}{l}\text { D5: The big and heavy battery } \\
\text { packs of BEVs contain hazardous } \\
\text { materials. } \\
\text { EVs use voltages between } 200 \text { and } \\
800 \text { Volts. Voltages exceeding } 25 \\
\text { volts for AC and } 60 \text { volts for DC } \\
\text { lead to injuries and even fatal } \\
\text { accidents. Unclear charging status, } \\
\text { defect insulations and cables, } \\
\text { damages from transportation and } \\
\text { incorrect operations by } \\
\text { maintenance staff are increasing } \\
\text { factors of this risk (Hao, 2019). }\end{array}$ & $\begin{array}{l}\text { E7: Work environment must be } \\
\text { carefully designed and monitored. } \\
\text { High-voltage operation training } \\
\text { could be needed. } \\
\text { E8: Additional hazardous waste; } \\
\text { not all materials can be recycled } \\
\text { (see also Effect E6). }\end{array}$ \\
\hline & $\begin{array}{l}\text { D6: Electric motors are smaller } \\
\text { and less complex than ICEs. } \\
\text { Highly automated production sites } \\
\text { for electric motors and for battery } \\
\text { packs are technically possible. }\end{array}$ & $\begin{array}{l}\text { E9: Less staff but potentially more } \\
\text { expensive staff, as higher qualified } \\
\text { (see also E1 above). }\end{array}$ \\
\hline & $\begin{array}{l}\text { D7: Fewer parts - the number of } \\
\text { moving parts has decreased from } \\
\text { about } 1,400 \text { in an ICE to just } 200 \text { in } \\
\text { a BEV (Erich and Witteveen, } \\
\text { 2017). }\end{array}$ & $\begin{array}{l}\text { E10: Fewer and possibly different } \\
\text { suppliers. } \\
\text { E11: Decreased complexity and a } \\
\text { smaller range of potential parts for } \\
\text { remanufacturing. }\end{array}$ \\
\hline
\end{tabular}

A survey has been carried out as part of Paper III to validate these effects: A questionnaire stating the seven effects shown in the table below (Table 17) has been created and was sent out to industry experts. The experts could evaluate each statement in order using a continuous scale. Moreover, they had a chance to make remarks and give feedback to open questions. Additional information about the method can be found in Section 2.3.1. The questionnaire, a list with all experts taking part and all replies are available in the Appendix B2. The twenty received, valid answers have been summarized in Table 17. 
Table 17: Evaluation of statements made by industry experts $(\mathrm{N}=20)$. The entire questionnaire sheet is shown in the Appendix B3 (a previous version of this table was published in Paper III).

\begin{tabular}{|c|c|c|c|c|c|}
\hline Statement & 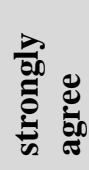 & 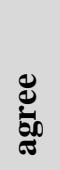 & & 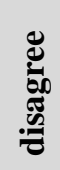 & 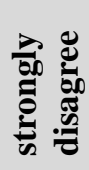 \\
\hline $\begin{array}{l}\text { S1. The market for remanufactured parts for EVs } \\
\text { (electric vehicles) will grow fast in the next twenty } \\
\text { years. }\end{array}$ & 11 & 3 & 5 & 0 & 1 \\
\hline $\begin{array}{l}\text { S2. Market actors for remanufactured parts for EV are } \\
\text { not set yet. }\end{array}$ & 5 & 9 & 5 & 1 & 0 \\
\hline $\begin{array}{l}\text { S3. Large, cost-intensive machinery parks are no longer } \\
\text { needed for remanufactured parts for EVs. }\end{array}$ & 2 & 5 & 7 & 6 & 0 \\
\hline $\begin{array}{l}\text { S4. Handling hazardous waste is not so important when } \\
\text { remanufacturing EV parts. }\end{array}$ & 0 & 1 & 4 & 9 & 6 \\
\hline $\begin{array}{l}\text { S5. Labor costs will be lower when remanufacturing } \\
\text { EV parts. }\end{array}$ & 1 & 4 & 4 & 9 & 2 \\
\hline $\begin{array}{l}\text { S6. Knowledge and testing equipment will be a } \\
\text { challenge for EV part remanufacturing. }\end{array}$ & 11 & 9 & 0 & 0 & 0 \\
\hline $\begin{array}{l}\text { S7. The recovery rate (= material saved due to the } \\
\text { mechanical remanufacturing process) is lower for EV } \\
\text { parts. }\end{array}$ & 2 & 5 & 6 & 6 & 1 \\
\hline
\end{tabular}

The feedback received from experts has been used in this thesis. The content of the feedback can be divided into the following three groups:

1. Supported: Feedback from experts confirming the statements. This can be said about statements S1, S2, and S6.

2. Partly supported: Feedback from experts giving new input leading to changes in the evaluation already respected in this thesis. Examples of such changes are the statements S3 and S5: The experts did not fully agree with the statements that the space needed for machinery will decrease and that labor costs will decrease.

3. Additional research needed: Feedback from experts made it clear that additional research work is needed. The statements S4 and S7 can be mentioned in this connection. There was controversial feedback about future forms and quantities of waste for remanufacturing companies and the future recovery rates for EV parts. For these topics, there will be a need for future research work. 


\subsection{OPPORTUNITIES AND CHALLENGES IN THE REMANUFACTURING of Automotive PARTS FOR ELECTRIC VEHICLES}

The actual changes within the market and the transition phase of powertrain concepts are, at the same time, offering opportunities and challenges for companies remanufacturing mechanical parts today. Moreover, they also offer opportunities and challenges for companies not yet operating in this field.

Based on the comparison of parts and concepts, the differences in the parts and their remanufacturing processes and the feedback from the experts, these opportunities and challenges have been summarized. In the group of "opportunities," topics are gathered that can lead to new, additional or improved business for companies. In the group of "challenges," topics are gathered that can lead to potential risks for the companies.

The opportunities and challenges mentioned in this list are specifically linked to the latest EV market trends and technology. Additionally, many of the challenges pointed out in the previous chapter (see Chapter 3) about today's automotive challenges in remanufacturing are also valid but not repeated. Moreover, the previous chapter highlighted the challenges, whereas here, the opportunities are also highlighted. This is because the EV market is new and growing, which leads to many opportunities for market entry or extension of a product program. Certainly, classical remanufacturing also offers opportunities, but which are not a matter of this research.

Opportunity EV-01: Steadily growing EV market: The market for EVs is constantly growing (see Section 5.5, Table 17, Statement S1). This offers potential new or additional fields of business activities (Deloitte, 2020). With the growing numbers of EVs on the road, the demand for spare parts and remanufactured parts will grow (see Figure 5 in Chapter 3). This is offering opportunities, such as:

- Extending an existing remanufacturing product program and adding EV parts additionally to ICE parts (here: battery packs and/or electric motors).

- Extending the customer range to new customer groups within the EV market.

Opportunity EV-02: Uncertainty within the main market actors: The main market actors (for example, suppliers, remanufacturers and customers) are not finally set yet (see Section 5.3, Table 16, Effect E10). This effect is of relevance for remanufactured EV parts such as batteries or electric motors. It is of less relevance for other "classical" remanufactured parts, such as steering parts, AC parts or parts of the braking system. For them, the main market actors for remanufactured parts are already set. The Boston Consultant Group (BCG, 2020) states the following in its research about the actual changes in the automotive industry: "There is a huge wave of change ahead in many industrialized nations as automation, digital manufacturing, new factory processes, and new types of parts and materials increasingly play a bigger role. For automakers, smartly 
leveraging and balancing those elements will be key to mastering the transition." These changes offer, besides risks (see Challenge EV-01 within this list), opportunities such as:

- Entering the market of remanufacturing of EV parts for companies not dealing with remanufacturing as of today.

- Extension of the product program of remanufacturing companies producing only ICE parts or other remanufacturing parts as of today.

Opportunity EV-03: Responsibility to recycle battery packs: Some countries have already made the manufacturer responsible for the recycling of their battery packs. Such regulations are in power or in preparation in China, Europe and the US state of California (Groenewald and Barai, 2016; Morse, 2021). One potential regulation considered could be an extended producer responsibility (EPR). This would make OEMs "responsible for covering the cost of collecting and recycling batteries, providing them with incentives to establish (or support the establishment) of efficient recycling value chains, as well as to incorporate "design for recycling" considerations into their product development activities and those of their suppliers" (Beaudet et al., 2020). Effects resulting from this could be:

- The capacity would increase for battery recycling.

- The availability of remanufactured battery packs would improve.

- Lower prices for batteries due to higher volumes, increased volumes and more competition.

Opportunity EV-04: Space-saving remanufacturing processes and equipment: Machines needed for the remanufacturing of EV parts are often more space saving compared to the machinery needed for ICE remanufacturing (see Section 5.3, Table 16, Effect E3):

- Huge machines for mechanical work (e.g., drilling machines, milling machines) are not, in all cases, needed anymore in the remanufacturing of EV parts. Here, mainly testing equipment is needed, which is comparably space saving. For this matter, there was no clear feedback from the experts. Future research work will be needed to explore this matter in more detail.

- High investments are needed in new equipment for remanufacturers and especially to test $\mathrm{EV}$ parts.

Challenge EV-01: Changing market conditions and technical developments: The uncertainty and ongoing changes in the market situation, as well as the ongoing technical development, are a challenge for the industry (see Section 5.3, Table 16, Effects E1, E2 and E11).

- Besides the opportunities resulting from a new, growing market (see Opportunities EV-01 and EV-02 in this list), there are risks of not being successful in the new market due to economic or technological reasons. 
- Test equipment is partly not available yet or is leading to high investments (see Section 5.3, Table 16, Effect E1).

- Missing standards make quality definitions, technical evaluations and validations difficult (see Section 5.3, Table 16, Effect E2).

- Standardization of the chemical formulation and the battery pack design is not yet given. Such a standardization could make processes safer and more efficient (Sanderson, 2017). Brereton (2020) states in this connection: "The dangerous business of processing this waste is complicated by the fact that different manufacturers use different battery chemistries and their packs come in a range of different shapes and sizes. Standardization is clearly part of the solution here. If there was less variation in the size and shape, then the removal of the packs would be cheaper and less dangerous. It could also pave the way for more automation in the disposal process. At the very least, better standards around the labeling of batteries would be of benefit. This would allow the batteries to be more easily recycled or repurposed."

- As BEV parts, their design and their production are rather new, and the remanufacturing processes for these parts are also new. Industry standards need to be defined. Best practice needs to be found, proven and set.

- Kampker et al. (2017), who explored the challenges in production planning of EVs, stated, "To enable remanufacturing of complex products like electric vehicles, an integrated production planning and control system is required that is able to manage uncertainties and the resulting system dynamics."

Challenge EV-02: Changing recovery rates: As shown in Section 5.3, Table 16, Effect $\mathrm{E} 4$, the recovery rates change.

- On average, the weight and quantity of ICE parts are higher compared to EV parts. Therefore, using weight or quantity of parts as an indicator for the recovery rate could lead to a decrease in EV parts compared to ICE parts.

- In particular, the battery pack of EVs is a very expensive part. Thus, here, an opposite effect could occur when using the value for the recovery rate: the recovery rate for EVs could increase compared to ICEs.

- For the development of recovery rates, there was no clear agreement among the experts. Future research is needed.

Challenge EV-03: Changing cleaning demands and different types of waste: When remanufacturing EV parts, different kinds of contamination and waste types must be dealt with compared to ICE remanufacturing. The cleaning process and the requirements for handling waste change. "Potentially toxic materials in LIBs are copper, nickel, lead and organic chemicals, such as toxic and flammable electrolytes" (Murphy, 2017) (see Section 5.3, Table 16, Effects E5, E6 and E8). 
- In the ICE part remanufacturing process, remanufacturers especially face contamination resulting mainly from the combustion process (e.g., oil, coal). The main need for disposal results from operating fluids, such as oil or fuel and substances resulting from the combustion process.

- The cleaning process for EVs faces different challenges. Remanufacturers do not need to dispose of many operating fluids as described in the previous bullet point. Now they must deal with hazardous materials and chemicals from the battery pack.

Challenge EV-04: Changing requirements for the operational staff: The work process and the requirements for the operational staff members are changing (see Section 5.3 Table 16 Effects E7 and E9).

- Personnel needed for cleaning and machining tasks will be less needed.

- Personnel performing testing and assembly work will be needed more.

- With the changing requirements on staff's skills, the labor costs will change. This circumstance could lead to different decisions regarding where to allocate remanufacturing businesses.

- Moreover, there are new health risks operating with new operating liquids and chemicals and preventing the risk of electrical shocks, which can lead to severe or even deadly incidents (Hao, 2019). Murphy (2017) states that "damaged LithiumIon Batteries in particular carry risks such as thermal runaway, electric shock, and hazardous substance emissions to the workers who handle them. During the actual recycling process, Lithium-Ion Batteries can explode through radical oxidation. This occurs when lithium metal produced from the battery overcharges and sustains a mechanical shock on exposure to the air."

A summary of these opportunities and challenges is given in the next chapter. Moreover, the next chapter evaluates how these findings supported answering the research questions. 
FUTURE CHALLENGES

AND OPPORTUNITIES
Automotive Remanufacturing in a Changing Market 


\section{DISCUSSION}

The purpose of this chapter is to answer the initially defined research questions and to reflect the research methods used. This is done by analyzing the results gained from this thesis and comparing them to the research questions presented in Sections 6.1 and 6.2. In this chapter, the research methods used in this thesis are explored and evaluated with respect to their effectiveness.

The objective of this doctoral thesis was to provide an exploration of the automotive remanufacturing industry and to identify current and future challenges and opportunities with special consideration of a growing share of EVs. Two research questions were developed to reach these aims (see Section 1.5). The question about the actual challenges has been gathered in the first research question. The question dealing with future opportunities and challenges resulting from the transition phase towards EVs has been summarized in the second research question. This chapter summarizes the results to answer these two questions and provides recommendations from the author to decisionmakers in the industry on how to react to the questions based on the answers found in this thesis.

\subsection{TODAY'S CHALLENGES IN THE AUTOMOTIVE REMANUFACTURING INDUSTRY}

The first research question focused on the current industrial situation and the actual challenges: "What are today's challenges in the automotive remanufacturing industry?" To answer the first research question, Papers I and II provided relevant research results. In Chapter 4 of this thesis, the identified today's challenges in the automotive remanufacturing industry are described in a detailed way. The challenges found have been separated into five groups:

Challenges related to suppliers (see Challenges ICE-01, ICE-02 and ICE-03 in Section 4.1): Within the remanufacturing process, defective or worn-out parts are scrapped and need to be replaced by new ones. If these parts are not efficiently available, remanufacturing will not be efficiently possible. Recommendations of the author of this thesis in connection with this group of challenges:

- Develop a broader supplier base to be able to use alternative sourcing options when needed

- Communicate expectations (quantities, prices, packaging, timing, etc.) to suppliers to give the supplier the chance to prepare and fulfill the forecasted quantities 
- Define and monitor efficient stock level to have security when parts cannot be sourced in the short term

- Use "over-stripping" (instead of replacing a defect part with a new part, inject a used but good part from another part. "Two become one") to reduce the need for spare parts and improve rentability and ecological evaluation

- Exchange with other remanufacturing companies on their stock levels to be able to support with needed parts

- Evaluate possibilities of 3D printing as an alternative source for low-volume items to have an alternative to classical spare part supply

Challenges related to core management (see Challenges ICE-04, ICE-05 and ICE-06 in Section 4.2). The basis for a remanufacturing process is the existence of a suitable core part. Recommendations of the author of this thesis in connection with this group of challenges:

- Monitor the return process efficiently and create incentives to return the core part

- Raise (reasonable) deposits to increase the return rate of core parts

- Define an easy logistics return process to make it as easy and convenient as possible to return core parts to achieve higher return rates

- Provide return packaging and shipping documents together with the forward shipment to simplify the process (see above) and guarantee a safe transportation

- Communicate the reasons for the need for the part return to create higher awareness and understanding of the need for a high core return rate

- Generate core parts by injecting new parts. The returning parts from the customer side can be used as core parts for future remanufacturing

- Increase the recovery rate of core parts by extending the value added (e.g., more cleaning activities, additional mechanical processes)

- Develop and extend sourcing options and alternatives for core parts (e.g., via a core broker or core industry networks)

- Use data generated from increasing digitalization within the industry to evaluate the technical condition of a part and to trace its location.

Challenges related to identification, visual checks, disassembly and cleaning (see Challenges ICE-07, ICE-08 and ICE-09in Section 4.3). These process steps are the first major value added of a remanufacturing company. Faulty or inefficient processes risk the complete remanufacturing process. Recommendations of the author of this thesis in connection with this group of challenges:

- Recognize the value added in these process steps and provide to the staff dealing with these tasks the following: 
- Best possible technical equipment to have higher efficiency and fewer failures/defects

○ Best possible information and schooling to prevent mistakes and faulty designation of parts

- Refrain from employing unskilled staff and presume low potential staff in these departments

- Create an attractive and safe work environment for staff

- Follow the latest technical trends and consider investments

Challenges related to the remanufacturing production process (see Challenges ICE10, ICE-11 and ICE-12 in Section 4.4). The actual value-added process step. Here, the main value shall be generated. Recommendations of the author of this thesis in connection with this group of challenges:

- Follow the latest machine trends and consider investments to always use state of the art of the industry

- Guarantee the availability of data sources and schooling of staff to make sure staff is fully skilled according to the latest available know-how

- Use own power and support via lobby groups to push society, politics and companies to guarantee a remanufacturing-friendly design and remanufacturingfriendly usage of materials. Ways to create a design that meets these requirements are gathered in the approaches "Design for Environment" and "Design for Remanufacturing” (EPA, 2021; Huber, 2001; Sundin, 2004; Sundin et al., 2012, Tchertchian et al., 2012)

Challenges related to the transportation phase (see Challenges ICE-13, ICE-14 and ICE-15 in Section 4.5). A process step that is often not in the focus of companies. Nevertheless, it can be crucial for a successful remanufacturing process, as defects and contaminations can be prevented. Recommendations of the author of this thesis in connection with this group of challenges:

- Define a logistics process adapted to remanufacturing needs and guarantee a return process to guarantee an efficient damage-free forward and return logistics process

- Use return packaging that protects the part and the environment to prevent damages and contamination

- Make return processes easy and attractive for customers (see also "Challenges related to core management" in this list) to achieve high core return rates

By providing the information mentioned in the bulleted list above, today's major challenges in the automotive remanufacturing industry were provided. Therefore, it can be stated that the first research question has been answered successfully, comprehensively and sufficiently. 


\subsection{CHALLENGES AND OPPORTUNITIES FOR THE AUTOMOTIVE REMANUFACTURING INDUSTRY IN A PHASE OF TECHNOLOGY TRANSITION TOWARDS ELECTRIC VEHICLE PART REMANUFACTURING}

The second research question focused on challenges and opportunities resulting from the actual transition phase from vehicles using combustion engines to EVs: "What are the challenges and opportunities for the automotive remanufacturing industry in a phase of technology transition towards electric vehicle part remanufacturing?" To answer the second research question, Paper III was provided relevant research results. In Chapter 5 of this thesis, the identified challenges and opportunities are described in a detailed way.

Opportunities related to a steadily growing EV market (see Opportunity EV-01 in Section 5.6): Most forecasts assume a strong growth within the EV market in the next years (see Section 5.1). At the beginning of the transition phase, the market growth is expected to be slow. One industry respondent gave the following feedback in their questionnaire: "Market size will, for a start, not be attractive." Recommendations of the author of this thesis in connection with this opportunity:

- Be prepared and flexible to react to the market trends to use opportunities (chances) and react to challenges (threads)

- Evaluate changes carefully and critically to react quickly to them

- Use opportunities to extend the business

- Evaluate investment options and business cases carefully and prepare an "exit strategy" to prevent loss

Nevertheless, there are also major uncertainties and threats. These are discussed in the bullet point "Challenges related to changing market conditions and technical developments" within this list.

Opportunities related to uncertainty in main market actors (see Opportunity EV-02 in Section 5.6): The market for EV parts is changing rapidly. Main market actors throughout the complete supply chain are not set or still unclear: suppliers, remanufacturers and customers. This leads to opportunities for companies to start remanufacturing or to extend the remanufacturing program. Recommendations of the author of this thesis in connection with this opportunity:

- As in the prior bullet point, "Opportunities related to a steadily growing EV market"

- For threads linked to this matter, see bullet point "Challenges related to changing market conditions and technical developments" within this list 
Opportunities related to the responsibility to recycle battery packs (see Opportunity EV-03 in Section 5.6): This matter will increase the capacity of battery recycling and the availability of remanufactured batteries. Recommendations of the author of this thesis in connection with this opportunity:

- Follow changing regulations steadily to comply with all actual demands

- Use market opportunities resulting from national and international regulations to gain and extend business

- Check and use governmental incentives in this respect to optimize business results

- Be aware of growing competition and decreasing price levels to prevent loss

Opportunities related to space-saving remanufacturing processes and equipment (see Opportunity EV-04 in Section 5.6): In connection with a lower demand with respect to the space of machinery needed for EV remanufacturing, an expert stated, "Most likely, current tooling cannot be used; completely new tooling has to be developed and bought." Recommendations of the author of this thesis in connection with this opportunity:

- Evaluate opportunities for a simpler and less cost-intensive entry into the market of remanufacturing EV parts resulting from different layout options (Effect E3 in Table 16) to guarantee a cost-efficient business

- Evaluate actual and future plant layouts and allocation decisions for remanufacturing sites to use the best location possible

Challenges related to changing market conditions and technical developments (see Challenge EV-01 in Section 5.6): Related to this challenge, a remanufacturing expert gave the following feedback "I consider the main parts of EVs, batteries, are not very suitable for remanufacturing. They are more suitable for material recycling or cascading usage for other purposes." Recommendations of the author of this thesis in connection with this challenge:

- Investments into specifications, know-how and testing will be needed (Effects E1 and E2 in Table 16) in order to remanufacture these new parts sufficiently

- Pressure on governments to define national and international standards should be made to solve issues resulting from missing standards and missing chemical formulations. Additionally, definitions of standards within the industry lobby groups should be established.

- Test equipment should be developed together with the industry to assure that requirements are met and to reduce costs

- As remanufacturing of EV parts is a rather new technology, further research are needed. Furthermore, an exchange between remanufacturing companies and defining common processes (see previous bullet point above) could help to increase efficiency

- The latest technical and market trends need to be monitored and evaluated carefully 
Challenges related to a change in the recovery rate of material (see Challenge EV-02 in Section 5.6): On the one hand, the weight of remanufactured parts decreases; on the other hand, the value increases. These two effects will influence the environmental performance (Effect E5 in Table 16) of EV part remanufacturing. Industry experts are unsure about this matter, and further investigations and monitoring seem to be needed. Recommendations of the author of this thesis in connection with this challenge:

- Additional remanufacturing processes for EV parts should be investigated to increase the recovery rate

- Possibilities for an environmental-friendly recycle and reuse process for chemicals should be explored further to increase the positive impact of remanufacturing

- Even if the recovery rate for EVs is lower than for ICE parts, the general economic and ecological benefits of remanufacturing remain

Challenges related to changing waste (see Challenge EV-03 in Section 5.6): The new parts and their new remanufacturing processes lead to the circumstance that remanufacturing companies must deal with new types of cleaning demands and new types of waste. An expert for remanufacturing replied, "Environmental issues for disposed of EV parts could be more serious because more hazardous materials are contained in EV parts. Proper treatments for used EV parts, including reman, are especially needed." Recommendations of the author of this thesis in connection with this challenge:

- Invest in know-how and machinery to deal with cleaning demands and new types of waste to master these future tasks

- Follow and respect the latest and changing regulations and trends to make decisions based on the latest information and to comply with regulations

- Guarantee a safe work environment for staff to protect their health and security

- Assure an environment-friendly waste management process for safety and to protect natural resources

- Search for options to increase the recovery rate to decrease the amount of waste (see previous bullet point above)

Challenges related to changed requirements for operational staff (see Challenge EV04 in Section 5.6): Work and work conditions are changing, as are the requirements of job profiles. Less disassembly and cleaning operations will be required, but more assembly and testing operations for highly skilled workers will be needed. Recommendations of the author of this thesis in connection with this challenge:

- Different kinds of work will require different kinds of qualifications of staff. This will also influence labor costs

- Create attractive work conditions in all process steps to stay an attractive employer for potential staff

- Invest in staff and schooling to have skilled workers doing a good job 
- Reevaluate the role of so-called "best-cost countries" where wages are lower, such as Eastern Europe or Mexico. Some locations chosen for ICE remanufacturing could seem less attractive for EV remanufacturing.

- The new parts are linked to new risks resulting from the chemicals used and from electrical shocks. High-voltage operation training and schooling in how to deal with chemicals should be considered to meet safety and health requirements.

By providing the information mentioned in the bulleted list above, the challenges and opportunities resulting from the actual transition phase from vehicles using combustion engines to EVs were provided. Therefore, it can be stated that the second research question has also been answered successfully, comprehensively and sufficiently.

\subsection{Reflections on the Research Methods Used}

In the following sections, the research methods used in this thesis are evaluated with respect to their effectiveness. Furthermore, the validity, reliability and generalizability (see Section 2.4) are again reviewed and discussed.

\subsubsection{Data Collection, Analyzation And Visualization}

As the first research question dealt with the challenges within the industry today, it was possible to answer mainly using existing data, expert interviews and literature review. Finding previous research work as a basis for further investigation was easier for the remanufacturing of ICE parts. This kind of remanufacturing is proceeded in the automotive industry since several years and a lot of research has already been done.

The situation for the second research question dealing with the remanufacturing of EV parts is slightly different. As this research question deals with technical and market trends that began just some years ago, data was scarce. A literature review was difficult, as the existing literature for these new issues is rather limited.

Different methods of data collection were needed. In particular, two main methods were used in this thesis:

Questionnaires: A standardized questionnaire was developed to gain information from experts. It was sent out to experts in the automotive remanufacturing industry and the related research sector. The following SWOT analysis made by the author summarizes the main results to evaluate this research method: 
Table 18: SWOT analysis reflecting the usage of questionnaires in this thesis

\begin{tabular}{|c|c|}
\hline Strengths & Weaknesses \\
\hline $\begin{array}{l}\text { Time-efficient method, as it can be } \\
\text { sent out easily and fast results are } \\
\text { possible } \\
\text { - Cost-efficient method, especially } \\
\text { when online techniques are being } \\
\text { used }\end{array}$ & $\begin{array}{l}\text { - Often, regular follow-ups needed to } \\
\text { gain a sufficient rate of return } \\
\text { - Limited space for open answers as } \\
\text { the document is mainly standardized } \\
\text { - Language barriers, especially for } \\
\text { open answers } \\
\text { - Distance, as not a personal way of } \\
\text { communication }\end{array}$ \\
\hline Opportunities & Threats \\
\hline $\begin{array}{l}\text { - Opportunity to repeat the method to } \\
\text { achieve a higher rate of return or to } \\
\text { use a modified questionnaire } \\
\text { - Moreover, it is a scalable method } \\
\text { - If requested, the method can be } \\
\text { executed anonymously }\end{array}$ & $\begin{array}{l}\text { - Risk of missing information not } \\
\text { explicitly requested in the } \\
\text { questionnaire } \\
\text { - Risk of dishonest or skipped answers } \\
\text { - Threat of influential questions } \\
\text { - Not knowing who answered in } \\
\text { anonymous replies } \\
\text { - Not knowing who really fills in } \\
\text { questionnaire or who influenced the } \\
\text { answer }\end{array}$ \\
\hline
\end{tabular}

The questionnaire offered a time and cost-efficient method to request input on defined, standardized questions. Even though several follow-ups were needed to have a sufficient return rate, it led to a valuable source of information. As it has been sent out to international experts in several different countries, there could have been issues resulting from language barriers. These barriers were limited by support from people using the same native language. Even though it is rather an impersonal method, especially compared to an interview, personal contact to the expert occurred before and after sending the questionnaire to explain the motivation and background of the questionnaire. The method is both repeatable and scalable. The option to perform this method anonymously has been offered to the experts as an option and has been used in some cases. As a questionnaire mainly consists of a standardized section, there is the potential risk of missing information not explicitly requested. To lower this risk, the questionnaire offered the possibility for open answers and comments (see Appendix B3). The awareness about the general threat of influential questions was respected, and the questions and complete questionnaire were reviewed by experienced users of this method. The threat of dishonest answers, however, exists. As the group of consulted experts was rather large, a single faulty answer does matter less. All in all, it can be stated that the questionnaire was a very helpful and efficient method to gain new data. 
Interviews: In addition to the standardized and rather formal questionnaires, interviews were executed for this thesis to gain data. Again, experts from the industry and from the research sector were defined. This time, the questions that were defined before were raised in a personal meeting. This method, therefore, offered more space for open answers. Thus, it was especially possible to gain information that had not been assumed or not been awaited before by the researchers. The main summary of the reflection of this research method can be found in the following SWOT analysis:

Table 19: SWOT analysis reflecting the usage of interviews in this thesis

\begin{tabular}{|c|c|}
\hline Strengths & Weaknesses \\
\hline $\begin{array}{l}\text { - Option to conduct an online meeting, } \\
\text { then very time and cost efficient } \\
\text { - Open answers possible, providing } \\
\text { unexpected information new } \\
\text { impulses } \\
\text { - Take into account non-verbal } \\
\text { information observed in the meeting } \\
\text { (e.g., emotions, gestures, behavior, } \\
\text { etc.) }\end{array}$ & $\begin{array}{l}\text { - Limitations with respect to the } \\
\text { quantity of interviewed persons } \\
\text { - Language barriers } \\
\text { - Hardly scalable } \\
\text { - High workload of noting and } \\
\text { evaluating }\end{array}$ \\
\hline Opportunities & Threats \\
\hline $\begin{array}{l}\text { Repeatable by asking the same } \\
\text { questions again to the same or other } \\
\text { interview partners }\end{array}$ & $\begin{array}{l}\text { - Less personal, if executed online } \\
\text { - Refusal, as not everyone is open for } \\
\text { a personal meeting } \\
\text { - Risk of misinterpretation or faulty } \\
\text { notetaking }\end{array}$ \\
\hline
\end{tabular}

As indicated above, this method offers an inexpensive and fast opportunity to gain data, especially if conducted online. Nevertheless, if conducted online, it is less personal, and non-verbal information (e.g., emotions, gestures and behavior) cannot be taken into account so easily. When executed, it is a rather time and sometimes cost-intensive method (e.g., due to travel expenses). There are limitations with respect to the quantity of conducted interviews, as they need to be carried out directly by a researcher. It is hardy scalable, and the workload to note findings and to evaluate them is rather high. Language barriers occur and are even more severe compared to the language issues mentioned for questionnaires since, in verbal communication, good language skills are essential. For this thesis, all interviews have been executed in English, Swedish or German, depending on the interview partner. Language barriers did not occur. As interviews have a very flexible character, they are hard to repeat. Moreover, there is the risk that potential 
interview partners will reject the invitation, as they do not feel comfortable using this kind of method. Additionally, there is the risk of misinterpreting or noting information incorrectly. To conclude, it can be stated that interviews were a very helpful method to gain new information, data and ideas for further research.

In summary, it can be stated that the two used research methods were efficient in answering the two research questions. They delivered the needed data in a sufficient, reliable and cost-and-time-efficient way.

For visualization, the BPMN method has been used. The purpose of the use of this method was to envisage the different remanufacturing processes for each part. This made a comparison between different processes possible, and the difference became visible. The method is efficient and can compress complex data. Cost-free versions are available for non-commercial usage. As this method has been used in addition to the verbal description given in the related text, it helps to support the information.

\subsubsection{VALIDITY, RELIABILITY AND GENERALIZABILITY}

As highlighted in the previous section, the information and data used in this thesis have been collected from multiple sources. In addition to extensive literature research, questionnaires and interviews were executed to gain new data, and obtain new ideas on the research topic.

Validity: In order to gain validity a structured literature review has been made. The results have been summarized and shared in discussions and publications with experts in the same field of research. Feedback and additional input have been respected. The methodology chapter of this thesis is summarizing the main results.

Reliability: Several techniques have been used in this thesis in order to gain reliability. To get test-retest reliability (see table 6) interviews with different kind of experts were made, questionnaires to different market actors were send out and market studies in different markets were executed. To gain inter-rater reliability (see table 6) publications have been analyzed by different experts. Moreover, results have been evaluated by academic staff.

Generalizability: In order to use results in a generalized form, results from several case studies were used to create the research questions and to answer them. Later case studies used findings from prior case studies and verified their results. 


\section{CONCLUSION}

The purpose of this chapter is to summarize which kind of contribution and benefit this thesis provides for academia and the industry. It described how the objectives have been met. Additionally, recommendations for future work are given.

The objective of this doctoral thesis was to provide an exploration of the automotive remanufacturing industry and to identify current and future challenges and opportunities with special consideration of a growing share of EVs. The contribution of this exploration to academia and the industry is provided in the following sections.

\subsection{CONTRIBUtion TO ACADEMIA}

Within the waste management hierarchy (see Section 1.1), remanufacturing is ranked in a higher position than recycling parts after their phase of initial usage. To make a defective or worn-out part ready for a second life, remanufacturing offers a process with less energy consumption, lower $\mathrm{CO}_{2}$ emissions and reduced material usage compared to the production of new parts (see Section 3.2). Apart from the ecological benefits, remanufacturing offers economic opportunities. These facts and their background are demonstrated in this thesis.

As a contribution to academia, this thesis is an actual, state-of-the-art report of the automotive remanufacturing industry. It provides a complete overview of the background and development over the last decades. Moreover, it evaluated the benefits and the motivations to remanufacture parts from the ecological and economic points of view. The most relevant parts are highlighted to contribute to a better understanding of automotive remanufacturing in general. Furthermore, for each of these parts, a detailed description of usage, functionality, typical defects and especially their remanufacturing process are described and visualized.

This thesis gives an overview of the actual situation and a careful forecast of future development to contribute to the newest changes within this industry branch due to the transition towards alternative forms of propulsion. Parts and processes of these new technologies are described and visualized, as already done for the ICE parts. To identify and carve out the difference between ICE and EV parts remanufacturing processes, they are compared. Challenges and opportunities resulting from these differences are pointed out and evaluated, providing a first-time overview of such kind for academia. 


\subsection{CONTRIBUTION TO THE INDUSTRY}

This research has been executed in close cooperation with the industry. Much information, a large amount of data and many external ideas were provided by industry representatives or industrial consultants. Consequently, this thesis and its results are very practice-oriented and close to the actual issues of the industry. Therefore, many of the results can be seen as a direct benefit to the industry.

This thesis gives a comprehensive overview of the existing literature about automotive remanufacturing and updates it by adding effects from the latest market changes. It compares processes in the remanufacturing processes for parts of the different powertrain concepts and highlights the differences and the effects resulting from these differences.

By carving out the challenges and opportunities from these differences, it provides a comprehensive overview of the industry. This can help to define potential actions and to evaluate the potential positive as well as potential negative effects. This shall support the decision-making of executives in the industry, as it issues very concrete and detailed recommendations of action.

Concrete recommendation for today's challenges have been given for (see Section 6.1):

- Suppliers

- Core management

- Identification, checking, disassembly and cleaning

- Remanufacturing production process

- Transportation phase

Concrete recommendation for future challenges and opportunities have been given for (see Section 6.2):

- Growing EV market

- Uncertain market actors

- Responsibilities for battery recycling

- Space-saving equipment and processes

- Market conditions and technical developments

- Recovery rates

- Changing waste

- Changing requirements for operational staff

\subsection{ETHICAL REVIEW}

During this research the following aspects have been respected to prevent potential research misconduct: 
- The results given are honest and not plagiarized. The methods used are described, and all results are available in the thesis or its appendix.

- The results are fully shared and discussed with both academics and non-academics

- This thesis does not follow any commercial interests. When information is taken from commercial parties or institutions, it is highlighted by providing the correct source of information.

- The conduct of this research did not harm any person, institution or other party

- All relevant laws and regulations were respected

When it comes to the future use of results from this thesis, the author would especially see the following usages: Companies and institutions in the field of remanufacturing are more aware of actual opportunities and challenges in this industry and are able to react to these issues in an adequate way (e.g., improved parts, new production and improved production processes.). As the global society with all its acting parties is searching for possibilities to decrease $\mathrm{CO}_{2}$ emissions, this thesis provides a small but relevant solution to reducing $\mathrm{CO}_{2}$ emissions through the implementation and improvement of remanufacturing. As all results are shared free and openly with all potential market actors, The author sees it as an important benefit for the complete industry without discriminating against any potential party.

In summary, it can be said that ethical or moral problems could potentially arise from this research. This is especially true as, in many cases, data in connection with research is generated from different parties. The needed actions were performed to not create any kind of harm to any party. No person, company, institution or any other kind of group has any kind of negative impact resulting from this research work. This research work shall serve all people and the complete society by delivering new research results to improve $\mathrm{CO}_{2}$ emissions without harming anyone.

\subsection{Future RESEARCH}

Future work should follow up on the suggested implementations and potential actions recommended in this thesis (see Section 5.5). When recommendations have been followed, their effect and effectiveness should be evaluated.

Moreover, future work should reflect whether it was possible to transfer the new knowledge generated in this thesis to academia and the industry.

Of special interest, the following topics should be explored in future work:

1. An important task will be to provide future research in connection with the transition toward alternative forms of propulsion. As the market and the 
technology for EVs are especially subject to major, ongoing changes, future investigation about the latest developments are definitely needed. Together with the findings made in this thesis, these latest developments must be reviewed and the findings of this thesis verified, falsified or adapted.

2. An interesting question will be in which way the continuous digitalization of the industry can influence remanufacturing. The increasing availability of data can give new opportunities for OEMs to evaluate parts and to track their usage and location.

3. Crucial further work will be to explore how remanufacturing offers answers to the supply chain disruptions which occurred lately. This means the potential for new opportunities and the potential for a completely new importance for remanufacturing.

4. In the interviews with experts and questionnaires, it became obvious that the process of dealing with waste resulting from the remanufacturing process of EVs (e.g., chemicals) needs further investigation.

5. Among the experts, there was no clear opinion on the future recovery rates of EV parts. Here, additional exploration is needed, especially when more data is available with increasing rates of $\mathrm{EV}$ remanufacturing. 


\section{REFERENCES}

\begin{tabular}{|l|l|}
\hline Aalst, 2016 & $\begin{array}{l}\text { Aalst, van der W. "Business Process Model and Notation (BPMN)"; } \\
\text { University of Technology Eindhoven; lecture script on: Process } \\
\text { Mining; Springer; ISBN 978-3-662-49851-4; Berlin; 2016; } \\
\text { https://courses.edsa- } \\
\text { project.eu/pluginfile.php/286/mod_resource/content/0/22\%20Busines } \\
\text { s\%20Process\%20Mode1\%20and\%20Notation\%20\%28BPMN\%29.pd } \\
\text { f; downloaded 07.09.2021 }\end{array}$ \\
\hline ACEA, 2020a & $\begin{array}{l}\text { ACEA (Association des Constructeurs Européens d'Automobiles) } \\
\text { "Paving the way to carbon-neutral transport 10-point plan to help } \\
\text { implement the European Green Deal"; January 2020; } \\
\text { https://www.acea.auto/files/ACEA_10- } \\
\text { point_plan_European_Green_Deal.pdf; downloaded 07.09.2021 }\end{array}$ \\
\hline ACEA, 2020b & $\begin{array}{l}\text { ACEA (Association des Constructeurs Européens d'Automobiles) } \\
\text { "Employment trends in the EU automotive industry" } \\
\text { https://www.acea.be/statistics/article/employment; downloaded } \\
19.04 .2020\end{array}$ \\
\hline ACEA, 2020c & $\begin{array}{l}\text { ACEA (Association des Constructeurs Européens d'Automobiles) } \\
\text { "Direct manufacturing jobs in the EU, by country"; } \\
\text { https://www.acea.be/statistics/tag/category/direct-manufacturing- } \\
\text { jobs-in-the-eu-by-country; downloaded 19.04.2020 }\end{array}$ \\
\hline
\end{tabular}




\begin{tabular}{|c|c|}
\hline ACEA, 2021 & $\begin{array}{l}\text { ACEA (Association des Constructeurs Européens d'Automobiles) } \\
\text { "What We Do"; https://www.acea.be/about-acea/what-we-do; } \\
\text { downloaded: } 05.01 .2021\end{array}$ \\
\hline ADAC, 2014 & $\begin{array}{l}\text { ADAC e.V. "ADAC-Liste Mangel / Verschleiß"; published } \\
\text { 20.08.2014; https://www.adac.de/-/media/adac/pdf/jze/mangel- } \\
\text { verschleiss-liste.pdf; downloaded 14.05.2021 }\end{array}$ \\
\hline ADAC, 2019 & $\begin{array}{l}\text { ADAC e.V. "Feste und flexible Wartungsintervalle"; first published } \\
\text { 05.06.2019; https://www.adac.de/rund-ums-fahrzeug/reparatur- } \\
\text { pflege-wartung/wartung-inspektion/wartungsintervalle/; downloaded } \\
\text { 14.05.2021 }\end{array}$ \\
\hline ADAC, 2020 & $\begin{array}{l}\text { ADAC e.V. "Falsch getankt? Das müssen Sie beachten"; first } \\
\text { published 18.05.2020; https://www.adac.de/verkehr/tanken- } \\
\text { kraftstoff-antrieb/tipps-zum-tanken/falsch-getankt/; downloaded } \\
\text { 14.05.2021 }\end{array}$ \\
\hline AET, 2020 & $\begin{array}{l}\text { AET Turbos "Turbo Reconditioning the Remanufacturing Process"; } \\
\text { https://www.aet-turbos.co.uk/about/remanufacturing-process/; } \\
\text { downloaded } 05.06 .2020\end{array}$ \\
\hline Agrartechnik, 1952 & $\begin{array}{l}\text { Agrartechnik; Boeldicke, H. "Die Stoerungen an Einspritzpumpen } \\
\text { und Duesen bei Dieseltraktoren"; 2. Jahrgang; Heft 5; Berlin (Ost); } \\
\text { Mai 1952; http://440ejournals.uni- } \\
\text { hohenheim.de/index.php/de_agrartechnik/article/view/3570/3288; } \\
\text { downloaded 11.09.2021 }\end{array}$ \\
\hline Aldridge et al., 2017 & $\begin{array}{l}\text { Aldridge, V.; Dovey, T.; Wade, A. "Assessing test-retest reliability of } \\
\text { psychological measures: persistent methodological problems"; } \\
\text { European Psychologist, October 2017; DOI: 10.1027/1016- } \\
\text { 9040/a000298; } 2017\end{array}$ \\
\hline $\begin{array}{l}\text { Aleksandr and } \\
\text { Ashraf, } 2017\end{array}$ & $\begin{array}{l}\text { Aleksandr, D.; Ashraf, K. "The Calculation of the Spare Parts in the } \\
\text { Auto-service Enterprise on the Base of Real Demand"; Engineering } \\
\text { Science. Vol. 2, No. 3, 2017, pp. 78-84. doi: } \\
\text { 10.11648/j.es.20170203.14; } 2017\end{array}$ \\
\hline Alshenqeeti, 2014 & $\begin{array}{l}\text { Alshenqeeti, H. "Interviewing as a Data Collection Method: A } \\
\text { Critical Review"; Linguistics Research Vol. 3, No. 1; 2014; } \\
\text { https://doi.org/10.5430/elr.v3n1p39; downloaded 07.09.2021 }\end{array}$ \\
\hline Amin, 2012 & $\begin{array}{l}\text { Amin, S. H. "Design and Optimization of Closed-Loop Supply Chain } \\
\text { Management Management"; Electronic Theses and Dissertations; }\end{array}$ \\
\hline
\end{tabular}




\begin{tabular}{|c|c|}
\hline & $\begin{array}{l}\text { 4815; 2012; https://scholar.uwindsor.ca/etd/4815; downloaded } \\
\text { 07.09.2021 }\end{array}$ \\
\hline ANSI, 2017 & $\begin{array}{l}\text { American National Standards Institute (ANSI) "RIC001.1-2016 } \\
\text { Specifications for the Process of Remanufacturing - An American } \\
\text { National Standard for Remanufacturing"; Washington DC, February } \\
\text { 2017; https://www.pierceindustries.com/wp- } \\
\text { content/uploads/2017/07/RIC001.1-2016-Specifications-for-the- } \\
\text { Process-of-Remanufacturing.pdf; downloaded 07.09.2021 }\end{array}$ \\
\hline ANSI, 2021 & $\begin{array}{l}\text { American National Standards Institute (ANSI) "We facilitate } \\
\text { Standardization Solutions"; https://www.ansi.org/\#; downloaded } \\
\text { 05.01.2021 }\end{array}$ \\
\hline APRA, 2013a & $\begin{array}{l}\text { APRA Automotive Parts Remanufacturers Association "History of } \\
\text { Automotive Remanufacturing - Where do we come from?"; } \\
\text { https://www.apra.org/europemain.php; downloaded 27.08.2013 }\end{array}$ \\
\hline APRA, 2013b & $\begin{array}{l}\text { APRA Automotive Parts Remanufacturers Association } \\
\text { "Remanufacturing in the Automotive Industry"; presentation of Ian } \\
\text { Buxcey; } 2013\end{array}$ \\
\hline APRA, 2014 & $\begin{array}{l}\text { APRA Automotive Parts Remanufacturers Association "Automotive } \\
\text { Parts Remanufacturing - Information about common definitions / } \\
\text { wordings for the complete Remanufacturing Industry"; Paper } \\
\text { Handout; } 2014\end{array}$ \\
\hline APRA, 2016 & $\begin{array}{l}\text { APRA Automotive Parts Remanufacturers Association } \\
\text { "Remanufacturing Associations Agree on International Industry } \\
\text { Definition"; Press Release September 13, 2016; } \\
\text { https://apraeurope.org/wp- } \\
\text { content/uploads/2021/05/Remanufacturing-definition.pdf; } \\
\text { downloaded 07.09.2021 }\end{array}$ \\
\hline APRA, 2020 & $\begin{array}{l}\text { APRA Automotive Parts Remanufacturers Association "What Is } \\
\text { APRA?"; https://apra.org/page/what_is_apra; downloaded } \\
01.10 .2020\end{array}$ \\
\hline Asif et al.; 2021 & $\begin{array}{l}\text { Asif, M.A.F.; Roci, M.; Lieder, M.; Rashid, R.; Mihelič, A.; Kotnik, } \\
\text { S. "A methodological approach to design products for multiple } \\
\text { lifecyclesin the context of circular manufacturing systems"; Journal } \\
\text { of Cleaner Production; Volume 296; 2021; 126534; ISSN 0959-6526; } \\
\text { https://doi.org/10.1016/j.jclepro.2021.126534; downloaded } \\
\text { 12.09.2021 }\end{array}$ \\
\hline
\end{tabular}




\begin{tabular}{|c|c|}
\hline $\begin{array}{l}\text { Auweraera et al., } \\
2019\end{array}$ & $\begin{array}{l}\text { Auweraera, Van der S.; Boutea, R.; Syntetos, A. "Forecasting Spare } \\
\text { Part Demand with Installed Base Information: a Review"; Article in } \\
\text { International Journal of Forecasting; January 2019; DOI: } \\
\text { 10.1016/j.ijforecast.2018.09.002; } 2019\end{array}$ \\
\hline Bakker et al., 2010 & $\begin{array}{l}\text { Bakker, C.A.; Wever, R.; Teoh, Ch.; De Clercq, S. "Designing Cradle } \\
\text { to Cradle products; a reality check"; International Journal of } \\
\text { Sustainable Engineering. 3. 2-8. DOI:10.1080/19397030903395166; } \\
\text { March } 2010\end{array}$ \\
\hline Baran, 2020 & $\begin{array}{l}\text { Baran, A. "Warum geht eine Einspritzpumpe kaputt?"; } \\
\text { https://www.kfzteile-zentrum.de/infos-zu-den- } \\
\text { ersatzteilen/dieseltechnik/einspritzpumpen.html"; downloaded } \\
\text { 21.05.2020 }\end{array}$ \\
\hline Barles, 2014 & $\begin{array}{l}\text { Barles, S. "HISTORY OF WASTE MANAGEMENT AND THE } \\
\text { SOCIAL AND CULTURAL REPRESENTATIONS OF WASTE"; } \\
\text { in book: The Basic World Environmental History (pp.199-226); } \\
\text { Publisher: Springer Verlag (Heidelberg) Editors: Mauro Agnoletti; } \\
\text { Simone Neri Serneri; October 2014; DOI:10.1007/978-3-319-09180- } \\
\text { 8_7; downloaded 07.09.2021 }\end{array}$ \\
\hline Baxter, 2008 & $\begin{array}{l}\text { Baxter, P. "Qualitative Case Study Methodology: Study Design and } \\
\text { Implementation for Novice Researchers"; The Qualitative Report } \\
\text { Volume } 13 \text { Number } 4 \text { December 2008; 544-559; } \\
\text { DOI:10.46743/2160-3715/2008.1573; } 2008\end{array}$ \\
\hline BCG, 2020 & $\begin{array}{l}\text { Boston Consulting Group "Shifting Gears in Auto Manufacturing"; } \\
\text { By Daniel Küpper, Kristian Kuhlmann, Kazutoshi Tominaga, Aakash } \\
\text { Arora, and Jan Schlageter; published 28.09.2020; } \\
\text { https://www.bcg.com/publications/2020/transformative-impact-of- } \\
\text { electric-vehicles-on-auto-manufacturing; downloaded 23.09.2021 }\end{array}$ \\
\hline Beaudet et al., 2020 & $\begin{array}{l}\text { Beaudet, A.; Larouche, F.; Amouzegar, K.; Bouchard, P.; Zaghib, K. } \\
\text { "Key Challenges and Opportunities for Recycling Electric Vehicle } \\
\text { Battery Materials". Sustainability; 12(14): 5837; July 2020; } \\
\text { DOI:10.3390/su12145837; } 2020\end{array}$ \\
\hline Benger, 2020 & $\begin{array}{l}\text { Benger, R. "Lithium Ionen Batterien Chancen und } \\
\text { Herausforderungen"; TU Clausthal; LIB Chancen und } \\
\text { Herausforderungen; Unternehmergespräche Energie; 20.02.2020; } \\
\text { https://www.est.tu- } \\
\text { clausthal.de/fileadmin/EST/documents/Veranstaltungen/Unternehmer } \\
\text { gespr\%C3\%A4ch_ENERGIE/Benger_LIB- }\end{array}$ \\
\hline
\end{tabular}




\begin{tabular}{|c|c|}
\hline & $\begin{array}{l}\text { Chancen_und_Herausforderungen_UGE_20200220.pdf; downloaded } \\
\text { 11.09.2021 }\end{array}$ \\
\hline Benteler, 2021 & $\begin{array}{l}\text { BENTELER Automotive "THE BENTELER ELECTRIC DRIVE } \\
\text { SYSTEM 2.0" } \\
\text { https://www.benteler.com/fileadmin/user_upload/automotive/BEDS_ } \\
\text { 2.0/Booklet_BEDS_2019_en_final.pdf; downloaded 04.09.2021 }\end{array}$ \\
\hline $\begin{array}{l}\text { Berggren and } \\
\text { Kageson, } 2017\end{array}$ & $\begin{array}{l}\text { Berggren, C.; Kageson, P. "Speeding up European Electro-Mobility - } \\
\text { How to electrify half of new car sales by 2030"; Report (2017) for } \\
\text { Transport \& Environment; Brussels; } \\
\text { https://www.transportenvironment.org/sites/te/files/publications/Spee } \\
\text { ding\%20up\%20European\%20Electro-Mobility.pdf; downloaded } \\
\text { 18.10.2020 }\end{array}$ \\
\hline Berkshire, 2010 & $\begin{array}{l}\text { Berkshire Publishing Group LLC "The Business of Sustainability"; } \\
\text { Berkshire Encyclopedia of Sustainability; Volume 2; ISBN 978-1- } \\
\text { 933782-13-3; } 2010\end{array}$ \\
\hline $\begin{array}{l}\text { Björnsson et al., } \\
2018\end{array}$ & $\begin{array}{l}\text { Björnsson, L.-H.; Karlsson, S.; Sprei, F. "Objective functions for } \\
\text { plug-in hybrid electric vehicle battery range optimization and } \\
\text { possible effects on the vehicle fleet"; Transportation Research Part C: } \\
\text { Emerging Technologies Volume 86; Pages } 655-669,2018 ; \\
\text { DOI:10.1016/j.trc.2017.12.009; January } 2018\end{array}$ \\
\hline Bloomberg, 2016 & $\begin{array}{l}\text { Bloomberg Finance L.P. "The Rise of Electric Cars"; February 2016; } \\
\text { https://www.bloomberg.com/features/2016-ev-oil-crisis/img/ev- } \\
\text { sales.jpg; downloaded 18.10.2020 }\end{array}$ \\
\hline BMW, 2006 & $\begin{array}{l}\text { BMW AG "Original BMW Teile - Unsere Qualitaet und Technik zu } \\
\text { Ihrem Vorteil"; Printed Handout, München, June } 2006\end{array}$ \\
\hline BMW, 2021 & $\begin{array}{l}\text { BMW AG "Hydrogen fuel cell cars: everything you need to know"; } \\
\text { https://www.bmw.com/en/innovation/how-hydrogen-fuel-cell-cars- } \\
\text { work.html\#pwjt-1; downloaded 14.07.2021 }\end{array}$ \\
\hline Bobba et al., 2020 & $\begin{array}{l}\text { Bobba, S.; Tecchio, P.; Ardente, F.; Mathieux, F.; dos Santos, F.M.; } \\
\text { Pekar, F. "Analysing the contribution of automotive remanufacturing } \\
\text { to the circularity of materials"; 27th CIRP Life Cycle Engineering } \\
\text { (LCE) Conference; Procedia CIRP } 90 \text { (2020) 67-72; } \\
\text { https://doi.org/10.1016/j.procir.2020.02.052; } 2020\end{array}$ \\
\hline Bosch, 2012a & $\begin{array}{l}\text { Robert Bosch GmbH "Common Rail Injektoren prüfen, zerlegen und } \\
\text { jetzt } \mu \text {-genau reparieren"; 2012; https://aa-boschww- } \\
\text { at.resource.bosch.com/media/commonly_used_media/common_medi }\end{array}$ \\
\hline
\end{tabular}




\begin{tabular}{|c|c|}
\hline & $\begin{array}{l}\text { a/ww_common/sercives_support_workshopworld/downloads_1/brosc } \\
\text { hueren_2/teile_common_rail_injektoren.pdf; downloaded 07.09.2021 }\end{array}$ \\
\hline Bosch, 2012b & $\begin{array}{l}\text { Robert Bosch GmbH "Bosch eXchange for diesel Guaranteed, } \\
\text { without compromise"; 2012; https://aa-boschap- } \\
\text { uk.resource.bosch.com/media/parts/special_auto_parts_1/bosch_exc } \\
\text { hange_1/di_bosch_exchange_diesel_en_61300.pdf; downloaded } \\
\text { 07.09.2021 }\end{array}$ \\
\hline Bosch, 2012c & $\begin{array}{l}\text { Robert Bosch GmbH "Bosch eXchange - Quick, easy and efficient"; } \\
\text { June 2012; http://www.bosch- } \\
\text { aa.com.cn/media/parts/special_auto_parts/pdf_4/RM_eXchange_All } \\
\text { _Products_en.pdf; downloaded 07.09.2021 }\end{array}$ \\
\hline Bosch, 2015 & $\begin{array}{l}\text { Robert Bosch LLC "Diesel Common Rail Injectors and Pumps"; } \\
\text { Illinois; 2015; } \\
\text { https://www.boschautoparts.com/documents/101512/146425/150510 } \\
\text { 86_NewPrdtNEWSLTR_0515_May_Diesel.pdf/39deae4c-04da- } \\
\text { 44e8-81a9-58bc3e409fda; downloaded 07.09.2021 }\end{array}$ \\
\hline Bosch, 2018a & $\begin{array}{l}\text { Robert Bosch LLC "A Bosch Guide to Choosing the Right Common } \\
\text { Rail Injector"; Illinois; 2018; } \\
\text { https://www.boschautoparts.com/documents/101512/0/0/6b4d9d74- } \\
\text { 0398-4d94-9141-551c8699f8b5; downloaded 07.09.2021 }\end{array}$ \\
\hline Bosch, 2018b & $\begin{array}{l}\text { Robert Bosch GmbH "Diesel-Systemkomponenten von Bosch für } \\
\text { professionelle Reparaturen moderner und konventioneller } \\
\text { Dieselsysteme"; October 2018; } \\
\text { https://www.boschaftermarket.com/xrm/media/images/country_speci } \\
\text { fic/de/services_6/news_downloads/xx_pdf_11/bosch_diesel- } \\
\text { systemkomponenten_segmentbroschuere.pdf; downloaded } \\
07.09 .2021\end{array}$ \\
\hline Bourbon, 2020 & $\begin{array}{l}\text { Bourbon, J. C. "Le marché des batteries pour vehicles électriques"; } \\
\text { Bayard Presse - La Croix; published 25.06.2018; } \\
\text { https://www.google.com/url?sa=i\&url=https\%3A\%2F\%2Fwww.la- } \\
\text { croix.com\%2FEconomie\%2FEconomie-et-entreprises\%2FBatteries- } \\
\text { electriques-lEurope-course-2018-06-25- } \\
\text { 1200949876\&psig=AOvVaw0Zx9B4rUi90nUzFNP4rtGV\&ust=1603 } \\
\text { 106636892000\&source=images\&cd=vfe\&ved=0CAIQjRxqFwoTCIj } \\
\text { ZluqDvuwCFQAAAAAdAAAAABAD; downloaded 18.10.2020 }\end{array}$ \\
\hline Brereton, 2020 & $\begin{array}{l}\text { Brereton, R. "Should we standardize electric vehicle batteries?"; } \\
\text { Article in: Electric\&Hybrid - Vehicle Technology International; }\end{array}$ \\
\hline
\end{tabular}




\begin{tabular}{|c|c|}
\hline & $\begin{array}{l}\text { published 07.05.2020; } \\
\text { https://www.electrichybridvehicletechnology.com/opinion/should- } \\
\text { we-standardize-electric-vehicle-batteries.html; downloaded } \\
\text { 23.09.2021 }\end{array}$ \\
\hline Briguglio et al., 2011 & $\begin{array}{l}\text { Briguglio, N.; Andaloro, L.; Ferraro, M.; Antonucci, V. "Fuel Cell } \\
\text { Hybrid Electric Vehicles"; In book: Electric Vehicles - The Benefits } \\
\text { and Barriers, September 2011; DOI:10.5772/18634; downloaded } \\
07.09 .2021\end{array}$ \\
\hline BTS, 2017 & $\begin{array}{l}\text { BTS GmbH "Technik Ratgeber - Band 5, Turboladerschäden bei } \\
\text { Transportern"; Weilheim; 2017; } \\
\text { https://www.turboexperte.de/fileadmin/BTS_Ratgeber/BTS_Ratgeber } \\
\text { 5_Endfassung_ABZ.pdf; downloaded 08.09.2021 }\end{array}$ \\
\hline $\begin{array}{l}\text { Buclet and Gordard, } \\
2000\end{array}$ & $\begin{array}{l}\text { Buclet, N.; Godard, O. "The Evolution of Municipal Waste } \\
\text { Management in Europe: how Different are National Regimes"; } \\
\text { October 2000; Journal of Environmental Policy and Planning, Taylor } \\
\text { \& Francis; (Routledge), 2001, 3, pp.303-317; https://hal.archives- } \\
\text { ouvertes.fr/hal-00129108; } 2000\end{array}$ \\
\hline BUWAL, 2000 & $\begin{array}{l}\text { Bundesamt für Umwelt, Wald und Landschaft (BUWAL); Rolf } \\
\text { Kettler "Eine kurze Geschichte des Abfalls"; Bern; } 2000\end{array}$ \\
\hline BW, 2018 & $\begin{array}{l}\text { BorgWarner Aftermarket Europe GmbH "As good as new. REMAN } \\
\text { Turbochargers."; Kirchheimbolanden; August 2018; } \\
\text { https://cdn.borgwarner.com/docs/default-source/iam/boosting- } \\
\text { technologies/brochure-reman-turbo-en.pdf?sfvrsn=db8d93c_36; } \\
\text { downloaded 08.09.2021 }\end{array}$ \\
\hline BW, 2020 & $\begin{array}{l}\text { BorgWarner Inc. "As Good as New - Remanufactured to meet the } \\
\text { highest expectations"; } \\
\text { https://www.borgwarner.com/aftermarket/boosting- } \\
\text { technologies/reman-program; downloaded 05.06.2020 }\end{array}$ \\
\hline BW, 2021 & $\begin{array}{l}\text { BorgWarner Turbo Systems "Variable turbine geometry (VTG)"; } \\
\text { http://www.turbos.borgwarner.com/en/products/vtg.aspx; } \\
\text { downloaded 06.01.2021 }\end{array}$ \\
\hline BWD, 2020 & $\begin{array}{l}\text { BWD - Standard Motor Products, Inc. "BWD DIESEL - DIESEL } \\
\text { DONE RIGHT"; https://www.bwdbrand.com/media/2723/bw11236- } \\
\text { bwd-diesel-brochure-web.pdf; downloaded 19.05.2020 }\end{array}$ \\
\hline Calice, 2005 & $\begin{array}{l}\text { Calice, J. "Konzeption und Argumentation des } \\
\text { Abfallverwertungssystems in der DDR aus umwelthistorischer }\end{array}$ \\
\hline
\end{tabular}




\begin{tabular}{|c|c|}
\hline & $\begin{array}{l}\text { Perspektive"; Thesis; Wien, Univ., Dipl.-Arb., 2005; Verbund-ID-Nr. } \\
\text { AC04526879; https://permalink.obvsg.at/AC04526879; downloaded } \\
\text { 11.09.2021 }\end{array}$ \\
\hline Cambridge, 2021a & $\begin{array}{l}\text { Cambridge University Press; Cambridge Dictionary "auto parts"; } \\
\text { https://dictionary.cambridge.org/dictionary/english/auto-parts; } \\
\text { downloaded 03.08.2021 }\end{array}$ \\
\hline Cambridge, 2021b & $\begin{array}{l}\text { Cambridge University Press; Cambridge Dictionary "Wear and } \\
\text { Tear"; https://dictionary.cambridge.org/dictionary/english/wear-and- } \\
\text { tear; downloaded 14.05.2021 }\end{array}$ \\
\hline Capgemini, 2010 & $\begin{array}{l}\text { Capgemini Consulting "The Aftermarket in the Automotive Industry } \\
\text { - How to Optimize Aftermarket Performance in Established and } \\
\text { Emerging Markets"; Institute of Technology Management; University } \\
\text { of St. Gallen; 2010; https://www.capgemini.com/wp- } \\
\text { content/uploads/2017/07/tl_The_Aftermarket_in_the_Automotive_In } \\
\text { dustry.pdf; downloaded 11.09.2021 }\end{array}$ \\
\hline Caporale, 2015 & $\begin{array}{l}\text { Caporale, T. "A Method for Modeling and Analyzing Business } \\
\text { Processes for Knowledge Carriers"; Institute of Applied Informatics } \\
\text { and Formal Description Methods (AIFB); Proceedings of the 7th } \\
\text { Central-European Workshop on Services and their Composition } \\
\text { (ZEUS 2015); 2015; } \\
\text { https://www.researchgate.net/publication/282956004_A_method_for } \\
\text { _modeling_and_analyzing_business_processes_for_knowledge_carri } \\
\text { ers; downloaded 11.09.2021 }\end{array}$ \\
\hline Cardone, 2018 & $\begin{array}{l}\text { Cardone "Remanufactured DIESEL FUEL INJECTION PUMP"; } \\
\text { June 2018; } \\
\text { https://www.cardone.com/UserFiles/Resource/CPCX_Cardone\%20R } \\
\text { eman_Diesel\%20Fuel\%20Injection\%20Pump_Mkt.pdf; downloaded } \\
\text { 08.09.2021 }\end{array}$ \\
\hline Carwood, 2020 & $\begin{array}{l}\text { Carwood Motor Units Ltd "Diesel Systems Technical Services"; } \\
\text { https://www.carwood.co.uk/public/OECDS_Carwood_Diesel_Syste } \\
\text { ms_A4_6pg_OES.pdf; downloaded 19.05.2020 }\end{array}$ \\
\hline Casals et al., 2009 & $\begin{array}{l}\text { Casals, L.; Garcia, B.; Cremades, L. "Electric Vehicle Battery Reuse: } \\
\text { Preparing for a Second Life"; Journal of Industrial Engineering and } \\
\text { Management, JIEM, } 2017 \text { - 10(2): 266-285 - Online ISSN: 2013- } \\
0953 \text { - Print ISSN: 2013-8423, https://doi.org/10.3926/jiem.2009; } \\
2009\end{array}$ \\
\hline
\end{tabular}




\begin{tabular}{|c|c|}
\hline Caterpillar, 2008 & Caterpillar "Cat Reman Turbochargers"; 2008 \\
\hline Cave, 2017 & $\begin{array}{l}\text { Cave, S. "Recycling in Germany; Nothern Irland Assembly"; } \\
\text { Research and InformationService; Paper 11/17; NIAR 485-16; } \\
\text { http://niopa.qub.ac.uk/handle/NIOPA/4495; January } 2017\end{array}$ \\
\hline Celino et al., 2007 & $\begin{array}{l}\text { Celino, I.; Medeiros, de, A.K.A.; Zeissler, G.; Oppitz, M.; Facca, F.; } \\
\text { Zoeller, S. "Semantic Business Process Analysis"; Conference Paper; } \\
\text { Conference: Proceedings of the Workshop on Semantic Business } \\
\text { Process and Product Lifecycle Management SBPM; 2007; } \\
\text { https://www.researchgate.net/publication/220854291_Semantic_Busi } \\
\text { ness_Process_Analysis; downloaded 11.09.2021 }\end{array}$ \\
\hline Chi et al., 2020 & $\begin{array}{l}\text { Chi, C.-F.; Sigmund, D.; Astardi, M. O. "Classification Scheme for } \\
\text { Root Cause and Failure Modes and Effects Analysis (FMEA) of } \\
\text { Passenger Vehicle Recalls"; Reliability Engineering and System } \\
\text { Safety 200; 106929; https://doi.org/10.1016/j.ress.2020.106929; } 2020\end{array}$ \\
\hline Chuan et al., 2013 & $\begin{array}{l}\text { Chuan, L.; Minghui, L.; Ziliang, Z. "Characteristics of transmission } \\
\text { for electric motor"; EVS27 International Battery, Hybrid and Fuel } \\
\text { Cell Electric Vehicle Symposium; } \\
\text { https://www.evs27.org/download.php?f=papers/EVS27-3790069.pdf; } \\
2013\end{array}$ \\
\hline $\begin{array}{l}\text { Colledani et al., } \\
2014\end{array}$ & $\begin{array}{l}\text { Colledani, M.; Copani, G.; Tolio, T. "De-Manufacturing Systems"; } \\
\text { Procedia CIRP } 17 \text { ( } 2014 \text { ) } 14 \text { - 19; Variety Management in } \\
\text { Manufacturing. Proceedings of the 47th CIRP Conference on } \\
\text { Manufacturing Systems; https://doi.org/10.1016/j.procir.2014.04.075; } \\
2014\end{array}$ \\
\hline Collins, 2021 & $\begin{array}{l}\text { Collins English Dictionary; HarperCollins Publishers "Definition } \\
\text { of 'powertrain'"; } \\
\text { https://www.collinsdictionary.com/dictionary/english/powertrain; } \\
\text { downloaded 19.07.2021 }\end{array}$ \\
\hline Colosi, 2006 & $\begin{array}{l}\text { Colosi, L. "Designing an Effective Questionnaire"; Cornell } \\
\text { University; Department of Policy Analysis and Management; 2006; } \\
\text { https://ag.purdue.edu/extension/pdehs/Documents/Designing\%20an\% } \\
\text { 20Effective\%20Questionnaire.pdf; downloaded 08.09.2021 }\end{array}$ \\
\hline Continental, 2019 & $\begin{array}{l}\text { Continental AG "Packaging Requirements for CA Plants and } \\
\text { Suppliers worldwide"; Doc. Type TST; Doc. Num. N } 098 \text { 00.01; } \\
\text { Date: 2019-05-17; https://www.continental-automotive.com/en- } \\
\text { gl/Organization/Company/Supplier- }\end{array}$ \\
\hline
\end{tabular}




\begin{tabular}{|c|c|}
\hline & $\begin{array}{l}\text { Information/downloads/TST_N09800-01- } \\
\text { 000_Packaging_Process_Requirements.aspx; downloaded } \\
\text { 23.09.2021 }\end{array}$ \\
\hline Daimler, 2012 & $\begin{array}{l}\text { Daimler AG; Kohler, Prof. Dr. Herbert; Chief Environmental Officer, } \\
\text { "The Contribution of Remanufacturing to Resource Efficiency - } \\
\text { Activities at Mercedes-Benz"; Presentation slides as part of key note } \\
\text { speech within WorldReman Summit 2012; } 2012\end{array}$ \\
\hline Daimler, 2013 & $\begin{array}{l}\text { Daimler AG "Mercedes-Benz Remanufactured Parts Program - An } \\
\text { exchange that pays off"; Printed Handout; PSMKG- } \\
\text { RemanFlyDieEng; } 2013\end{array}$ \\
\hline Daimler, 2020a & $\begin{array}{l}\text { Daimler AG "Genuine Remanufactured Engines and Transmissions } \\
\text { from Mercedes-Benz"; Stuttgart; https://remanparts.mercedes- } \\
\text { benz.com/uk/wp-content/uploads/sites/34/Mercedes-Benz- } \\
\text { Remanufactured-Parts-Engines-Transmissions-Brochure-Trucks- } \\
\text { EN.pdf; downloaded 27.04.2020 }\end{array}$ \\
\hline Daimler, 2020b & $\begin{array}{l}\text { Daimler AG "Werkinstandgesetzte Getriebe - mit dem Know-how } \\
\text { der Profis"; https://remanparts.mercedes-benz.com/de-global/wp- } \\
\text { content/uploads/sites/28/REMAN-Aggregate-Factsheet- } \\
\text { Werkinstandsetzung-Getriebe.pdf; downloaded 27.04.2020 }\end{array}$ \\
\hline Daimler, 2021a & $\begin{array}{l}\text { Daimler AG "Remanufacturing. An exchange that is well } \\
\text { worthwhile"; } \\
\text { https://www.daimler.com/sustainability/closeup/remanufacturing.htm } \\
\text { 1; downloaded 11.05.2021 }\end{array}$ \\
\hline Daimler, 2021b & $\begin{array}{l}\text { Daimler AG "Genuine Remanufactured Parts. The value-for-money } \\
\text { key."; https://www.mercedes-benz.co.th/vans/en/services/customer- } \\
\text { services/genuine-parts/remanufactured-parts; downloaded 11.05.2021 }\end{array}$ \\
\hline Daraba et al., 2017 & $\begin{array}{l}\text { Daraba, D.; Alexandrescu, I.M.; Daraba, C. "Research on the } \\
\text { injectors remanufacturing"; IOP Conf. Series: Materials Science and } \\
\text { Engineering } 200 \text { (2017); 012036; doi:10.1088/1757- } \\
899 X / 200 / 1 / 012036 ; 2017\end{array}$ \\
\hline Deakin, 2020 & $\begin{array}{l}\text { Deakin University "Questionnaire Design"; } \\
\text { https://www.deakin.edu.au/__data/assets/pdf_file/0006/271536/questi } \\
\text { onairedes.pdf; downloaded 23.04.2020 }\end{array}$ \\
\hline Deloitte, 2013 & $\begin{array}{l}\text { Deloitte LLP "Driving Aftermarket Value: Upgrade Spare Parts } \\
\text { Supply Chain Deloitte China Auto Industry Spare Parts Management } \\
\text { Benchmark Survey White Paper"; 2013; }\end{array}$ \\
\hline
\end{tabular}




\begin{tabular}{|c|c|}
\hline & $\begin{array}{l}\text { https://www2.deloitte.com/content/dam/Deloitte/cn/Documents/manu } \\
\text { facturing/deloitte-cn-mfg-auto-indspareparts-whitepaper-en- } \\
\text { 171013.pdf; downloaded 21.09.2021 }\end{array}$ \\
\hline Deloitte, 2019 & $\begin{array}{l}\text { Deloitte LLP "New Market. New Entrants. New Challenges. Battery } \\
\text { Electric Vehicles"; London; 2019; } \\
\text { https://www2.deloitte.com/content/dam/Deloitte/uk/Documents/manu } \\
\text { facturing/deloitte-uk-battery-electric-vehicles.pdf; downloaded } \\
\text { 18.10.2020 }\end{array}$ \\
\hline Deloitte, 2020 & $\begin{array}{l}\text { Deloitte LLP "Electric vehicles - Setting a course for } 2030 \text { ";published } \\
28 \text { July } 2020 \text {; https://www2.deloitte.com/us/en/insights/focus/future- } \\
\text { of-mobility/electric-vehicle-trends-2030.html; downloaded } \\
\text { 14.07.2021 }\end{array}$ \\
\hline Delphi, 2018a & $\begin{array}{l}\text { Delphi Technologies, PLC. "Remanufactured All Makes Diesel Fuel } \\
\text { Injectors"; Printed Handout; Publication No. DDSU151F; } 2018\end{array}$ \\
\hline Delphi, 2018b & $\begin{array}{l}\text { Delphi Technologies, PLC. "The Delphi Advantage. } 60 \text { years of OE } \\
\text { technology and expertise"; 2018; } \\
\text { https://www.delphiautoparts.com/sites/default/files/ddsu151e_all_ma } \\
\text { kes_brochure_3_nm.pdf; downloaded 08.09.2021 }\end{array}$ \\
\hline Delphi, 2020 & $\begin{array}{l}\text { Delphi Auto Parts "Remanufacturing: What Is The Process?"; } \\
\text { https://www.delphiautoparts.com/gbr/en/toolbox/remanufacturing- } \\
\text { what-process\#; downloaded 05.06.2020 }\end{array}$ \\
\hline Ding et al., 2017 & $\begin{array}{l}\text { Ding, N.; Prasad, K.; Lie, T. T. "The electric vehicle: a review"; } \\
\text { International Journal of Electric and Hybrid Vehicles; Vol. 9; No. 1.; } \\
\text { January 2017; DOI:10.1504/IJEHV.2017.082816; } 2017\end{array}$ \\
\hline Drost, 2011 & $\begin{array}{l}\text { Drost, E. "Validity and Reliability in Social Science Research"; } \\
\text { International Perspectives on Higher Education Research; Vol. 38; } \\
\text { No. 1; 105-124; January 2011; } \\
\text { https://www.researchgate.net/publication/261473819_Validity_and_ } \\
\text { Reliability_in_Social_Science_Research; downloaded 12.09.2021 }\end{array}$ \\
\hline DuraSource, 2021 & $\begin{array}{l}\text { DuraSource "REMANUFACTURED ELECTRIC MOTORS"; } \\
\text { http://www.durasourceparts.com/PDF/DuraSourceMotors2015.pdf; } \\
\text { downloaded 13.07.2021 }\end{array}$ \\
\hline Duval, 2017 & $\begin{array}{l}\text { Duval, Y. "Introduction to Business Process Analysis"; UNESCAP; } \\
\text { Trade Facilitation Unit; WCO-UNESCAP 3rd UNNExT Masterclass: } \\
\text { Digital Customs and Single Windows in the context of WTO TFA; } \\
19-28 \text { April } 2017 \text { Customs Border Control Training Institute }\end{array}$ \\
\hline
\end{tabular}




\begin{tabular}{|c|c|}
\hline & $\begin{array}{l}\text { (CBCTI) Cheon-An, Republic of Korea; 2017; } \\
\text { https://www.unescap.org/sites/default/files/20\%20Apr\%202017\%20- } \\
\% 20 \text { BPA\%20Introduction.pdf; downloaded 08.09.2021 }\end{array}$ \\
\hline Dynamic, 2021 & $\begin{array}{l}\text { Dynamic Manufacturing Company Inc. "EV Battery lifecycle } \\
\text { Management"; } \\
\text { https://www.dynamicmanufacturinginc.com/assets/1/18/ev_battery_r } \\
\text { emanufacturing_brochure.pdf; downloaded 30.05.2021 }\end{array}$ \\
\hline $\begin{array}{l}\text { Eberle and Helmolt, } \\
2010\end{array}$ & $\begin{array}{l}\text { Eberle, U.; Helmolt, v. R. "Sustainable transportation based on } \\
\text { electric vehicle concepts: A brief overview"; Energy \& } \\
\text { Environmental Science; Vol. 3, Nr. 6; pages 689-699; June 2010; } \\
\text { DOI:10.1039/C001674H; } 2010\end{array}$ \\
\hline Ellström et al., 2020 & $\begin{array}{l}\text { Ellström, P.-E.; Elg, M.; Wallo, A.; Berglund, M. and Kock, H. } \\
\text { "Interactive research: concepts, contributions and challenges"; } \\
\text { Journal of Manufacturing Technology Management; Vol. } 31 \text { No. 8; } \\
\text { pp. 1517-1537; https://doi.org/10.1108/JMTM-09-2018-0304; } 2020\end{array}$ \\
\hline Englander, 2012 & $\begin{array}{l}\text { Englander, M. "The Interview: Data Collection in Descriptive } \\
\text { Phenomenological Human Scientific Research"; Journal of } \\
\text { Phenomenological Psychology } 43 \text { (2012) 13-35; DOI } \\
\text { 10.1163/156916212X632943; } 2012\end{array}$ \\
\hline EPA, 2021 & $\begin{array}{l}\text { EPA - United States Environmental Protection Agency "History of } \\
\text { Safer Choice and Design for the Environment"; } \\
\text { https://www.epa.gov/saferchoice/history-safer-choice-and-design- } \\
\text { environment; downloaded 05.01.2021 }\end{array}$ \\
\hline EPO, 2009 & $\begin{array}{l}\text { European Patent Office "EUROPEAN PATENT APPLICATION 'EP } \\
2065564 \text { A2' "; Application number: 08169731.0; Bulletin 2009/23; } \\
\text { Date of publication 03.06.2009; } \\
\text { https://patentimages.storage.googleapis.com/18/b6/7d/49c28eaf1dd7 } \\
\text { 98/EP2065564A2.pdf; download 08.09.2021 }\end{array}$ \\
\hline ERC, 2020 & $\begin{array}{l}\text { European Remanufacturing Council "Remanufacturing: a primer"; } \\
\text { http://www.remancouncil.eu/studies/0ba5005f0f998051c6e5.pdf; } \\
\text { downloaded 09.10.2020 }\end{array}$ \\
\hline $\begin{array}{l}\text { Erich and Witteveen, } \\
2017\end{array}$ & $\begin{array}{l}\text { Erich, M.; Witteveen; J. "Breakthrough of electric vehicle threatens } \\
\text { European car industry"; ING Economics Department; published } \\
\text { 2017; https://www.ing.nl/media/ing_ebz_breakthrough-of-electric- } \\
\text { vehicle-threatens-european-car-industry_tcm162-128687.pdf; } \\
\text { downloaded 18.10.2020 }\end{array}$ \\
\hline
\end{tabular}




\begin{tabular}{|c|c|}
\hline ERN, 2020a & $\begin{array}{l}\text { European Remanufacturing Network "What is Remanufacturing?"; } \\
\text { https://www.remanufacturing.eu/about-remanufacturing.php; } \\
\text { downloaded 21.04.2020 }\end{array}$ \\
\hline ERN, 2020b & $\begin{array}{l}\text { European Remanufacturing Network "Business Model Case Study } \\
\text { Description: Carwood - Diesel Fuel Injection Pumps and Injectors"; } \\
\text { https://www.remanufacturing.eu/studies/016d059180e3e6a3322d.pdf } \\
\text {; downloaded 18.05.2020 }\end{array}$ \\
\hline EU, 2013 & $\begin{array}{l}\text { European Commission "Directive 2006/66/EC on batteries and } \\
\text { accumulators and waste batteries and accumulators"; published } \\
\text { 30.12.2013; https://eur- } \\
\text { lex.europa.eu/LexUriServ/LexUriServ.do?uri=OJ:L:2006:266:0001:0 } \\
\text { 014:en:PDF; downloaded 18.10.2020 }\end{array}$ \\
\hline EU, 2019a & $\begin{array}{l}\text { European Commission "Reducing CO2 emissions from passenger } \\
\text { cars"; Online Publication, } \\
\text { https://ec.europa.eu/clima/policies/transport/vehicles/cars_en; } \\
\text { downloaded 01.02.2019 }\end{array}$ \\
\hline EU, 2019b & $\begin{array}{l}\text { European Commission "What is the European Green Deal?"; } \\
\text { Brussels; ISBN 978-92-76-13629-3; doi:10.2775/275924; NA-03-19- } \\
\text { 927-EN-N; December 2019 }\end{array}$ \\
\hline EUCAR, 2019 & $\begin{array}{l}\text { EUCAR - European Council for Automotive R\&D "Battery } \\
\text { requirements for future automotive applications EG BEV\&FCEV"; } \\
\text { published 2019; https://eucar.be/wp- } \\
\text { content/uploads/2019/08/20190710-EG-BEV-FCEV-Battery- } \\
\text { requirements-FINAL.pdf; downloaded 18.10.2020 }\end{array}$ \\
\hline EUROWAG, 2020 & $\begin{array}{l}\text { EUROWAG W.A.G. Payment Solutions, a.s. "ON THE ROAD } \\
\text { TOWARDS CLEAN MOBILITY"; January 2020; } \\
\text { https://www.eurowag.com/media/pages/products/automotive-and- } \\
\text { emobility/builder/clean-mobility- } \\
\text { paper/22b10c95b8/ew_position_paper_clean_mobility.pdf; } \\
\text { downloaded 08.09.2021 }\end{array}$ \\
\hline Firestone, 1993 & $\begin{array}{l}\text { Firestone, W. "Alternative Arguments for Generalizing from Data as } \\
\text { Applied to Qualitative Research"; Research Article; Volume: } 22 \\
\text { issue: 4, page(s): 16-23; First Published May 1, 1993; } \\
\text { https://doi.org/10.3102/0013189X022004016; downloaded } \\
\text { 08.09.2021 }\end{array}$ \\
\hline
\end{tabular}




\begin{tabular}{|c|c|}
\hline FMC, 2020 & $\begin{array}{l}\text { Filter Manufacturers Council "Technical Service Bulletin 94-2R1 - } \\
\text { Positive Crankcase Ventilation (PCV)"; Administered by Motor \& } \\
\text { Equipment Manufacturers Association; } \\
\text { http://www.hastingsfilter.com/Literature/TSB/94-2R1.pdf; } \\
\text { downloaded 01.10.2020 }\end{array}$ \\
\hline Fogaça et al., 2018 & $\begin{array}{l}\text { Fogaça, P.; de Souza, D. L.; Manéa, F. "Comparison between Cold } \\
\text { and Hot Test procedures in a company manufacturer of diesel } \\
\text { engines"; Gest. Prod.; São Carlos; v. 25; n. 2; p. 343-353; } \\
\text { http://dx.doi.org/10.1590/0104-530X3094-16; } 2018\end{array}$ \\
\hline Forbes, 2016 & $\begin{array}{l}\text { Forbes Media LLC. "Davos 2016: GM Boss Sees a Revolution In } \\
\text { Personal Mobility"; Article from 18.01.2016; } \\
\text { https://www.forbes.com/sites/joannmuller/2016/01/18/davos-2016- } \\
\text { gm-boss-sees-a-revolution-in-personal-mobility/?sh=45b3bc8a46bf; } \\
\text { downloaded 12.03.2021 }\end{array}$ \\
\hline Ford, 2019 & $\begin{array}{l}\text { Ford Motor Company "2019 Powertrain Components \& } \\
\text { Remanufactured Assemblies"; 2019; } \\
\text { https://parts.ford.com/content/dam/ford- } \\
\text { parts/wcdocs/PowertrainCatalog_2019.pdf; downloaded 08.09.2021 }\end{array}$ \\
\hline Foster et al., 2014 & $\begin{array}{l}\text { Foster, M.; Isely, P.; Standridge, C.R.; Hasa, M. "Feasibility } \\
\text { assessment of remanufacturing, repurposing, and recycling } \\
\text { of end of vehicle application lithium-ion batteries"; Journal of } \\
\text { Industrial Engineering and Management; JIEM, 2014 - 7(3): 698-715 } \\
\text { - Online ISSN: 2013-0953 - Print ISSN: 2013-8423; } \\
\text { http://dx.doi.org/10.3926/jiem.939; } 2014\end{array}$ \\
\hline FPT, 2010 & $\begin{array}{l}\text { FPT Industrial S.p.A. "REMAN IS A SERVICE BY } \\
\text { AFTERMARKET SOLUTIONS - TOGETHER WE ARE READY } \\
\text { FOR A NEW JOURNEY"; } \\
\text { https://www.fptindustrial.com/global/en/Documents/148x230_Broch } \\
\text { ure\%20REMAN_FPT_ES.pdf; downloaded 28.04.2020 }\end{array}$ \\
\hline FRG, 2012 & $\begin{array}{l}\text { Federal Republic of Germany, Federal Ministry of Justice "Gesetz } \\
\text { zur Förderung der Kreislaufwirtschaft und Sicherung der } \\
\text { umweltverträglichen Bewirtschaftung von Abfällen } \\
\text { (Kreislaufwirtschaftsgesetz - KrWG)"; Berlin; 2012; } \\
\text { https://www.gesetze-im-internet.de/krwg/KrWG.pdf; downloaded } \\
\text { 08.09.2021 }\end{array}$ \\
\hline FRG, 2018 & $\begin{array}{l}\text { Federal Republic of Germany, Federal Ministry for the Environment, } \\
\text { Nature Conversation and Nuclear Safety "Waste Management in }\end{array}$ \\
\hline
\end{tabular}




\begin{tabular}{|c|c|}
\hline & $\begin{array}{l}\text { Germany } 2018 \text { - Facts, data, diagrams"; March 2018; } \\
\text { https://www.bmu.de/fileadmin/Daten_BMU/Pools/Broschueren/abfal } \\
\text { lwirtschaft_2018_en_bf.pdf; downloaded 08.09.2021 }\end{array}$ \\
\hline $\begin{array}{l}\text { Gabhane and } \\
\text { Kaddoura, } 2017\end{array}$ & $\begin{array}{l}\text { Gabhane, P.; Kaddoura, M. "Remanufacturing in Circular Economy: } \\
\text { A gearbox Example. A Comparative Life Cycle and Cost } \\
\text { Assessment"; Chalmers University of Technology Gothenburg; } \\
\text { Master's thesis in Sustainable Energy Systems; Report no. 2017:7; } \\
\text { 2017; } \\
\text { https://publications.lib.chalmers.se/records/fulltext/252053/252053.p } \\
\text { df; downloaded 08.09.2021 }\end{array}$ \\
\hline Gao et al., 2017 & $\begin{array}{l}\text { Gao, W.; Li, T.; Tanf, Z.; Peng, S.; Zhang, H.-C. "Investigation on } \\
\text { the Compartive Life Cycle Assessment between Manufacturing and } \\
\text { Remanufacturing Turbochargers"; Procedia CIRP 61; } 750 \text { - 755; } \\
\text { December 2017; DOI:10.1016/j.procir.2016.11.214; } 2017\end{array}$ \\
\hline $\begin{array}{l}\text { Gavidel and Rickli, } \\
2018\end{array}$ & $\begin{array}{l}\text { Gavidel, S.Z.; Rickli, J.L. "Remanufacturing cost analysis under } \\
\text { uncertain core quality and return conditions: extreme and non- } \\
\text { extreme scenarios"; Article; January } 2018 \text {; } \\
\text { https://www.researchgate.net/publication/322851535_Remanufacturi } \\
\text { ng_cost_analysis_under_uncertain_core_quality_and_return_conditio } \\
\text { ns_extreme_and_non-extreme_scenarios; downloaded 08.09.2021 }\end{array}$ \\
\hline German, 2015 & $\begin{array}{l}\text { German, B. "Turbochargers - Boom time ahead"; in: RAI } \\
\text { Amsterdam; Rematec News; Amsterdam; Number 5; Volume 15; } \\
\text { October } 2015\end{array}$ \\
\hline GMI, 2009 & $\begin{array}{l}\text { GMI - Gütegemeinschaft der Motoreninstandsetzungsbetriebe e.V. } \\
\text { "Guetesicherung RAL-GZ 797"; Jerichow; 2009; https://www.gmi- } \\
\text { ev.de/files/ral-gz797-motoreninstandsetzung.pdf; downloaded } \\
\text { 08.09.2021 }\end{array}$ \\
\hline GMI, 2015 & $\begin{array}{l}\text { GMI - Gütegemeinschaft der Motoreninstandsetzungsbetriebe e.V. } \\
\text { "Zehn Schritte der Motoreninstandsetzung; Jerichow; 2015; } \\
\text { https://www.gmi-ev.de/files/gmi_10-schritte_1.pdf; downloaded } \\
\text { 08.09.2021 }\end{array}$ \\
\hline GMI, 2020a & $\begin{array}{l}\text { GMI - Gütegemeinschaft der Motoreninstandsetzungsbetriebe e.V. } \\
\text { "Motoreninstandsetzer mit höchstem Qualitätsanspruch"; } \\
\text { https://www.gmi-ev.de/1-0-Home.html; downloaded 01.10.2020 }\end{array}$ \\
\hline
\end{tabular}




\begin{tabular}{|c|c|}
\hline GMI, 2020b & $\begin{array}{l}\text { GMI - Gütegemeinschaft der Motoreninstandsetzungsbetriebe e.V. } \\
\text { "Motorenrecycling durch Instandsetzung"; https://www.gmi- } \\
\text { ev.de/files/folie_motorrecycling_1.pdf; downloaded 26.04.2020 }\end{array}$ \\
\hline Golafshani, 2003 & $\begin{array}{l}\text { Golafshani, N. "Understanding Reliability and Validity in Qualitative } \\
\text { Research";The Qualitative Report; 8(4); 597-606. Retrieved from } \\
\text { http://nsuworks.nova.edu/tqr/vol8/iss4; } 2003\end{array}$ \\
\hline $\begin{array}{l}\text { Golinska and Kawa, } \\
2011\end{array}$ & $\begin{array}{l}\text { Golinska, P.; Kawa, A. "Remanufacturing in automotive industry: } \\
\text { Challenges and limitations"; Journal of Industrial Engineering and } \\
\text { Management; JIEM, 2011 - 4(3):453-466 - Online ISSN: 2013-0953 } \\
\text { - Print ISSN: 2013-8423; } \\
\text { http://dx.doi.org/10.3926/jiem.2011.v4n3.p453-466; } 2011\end{array}$ \\
\hline Gomm et al., 2011 & $\begin{array}{l}\text { Gomm, R.; Hammersley, M.; Foster, P. "Case Study and } \\
\text { Generalization"; in: Case Study Method; Print pages: 98-115; } \\
\text { Publishing Company: SAGE Publications Ltd; ISBN: } \\
\text { 9780761964148; DOI: http://dx.doi.org/10.4135/9780857024367; } \\
2011\end{array}$ \\
\hline Graef et al., 2002 & $\begin{array}{l}\text { Graef,B.; Grieger, M.; Gutzmann, U.; Schlinker, D.; Schumacher,M.; } \\
\text { Grieger, M. "Wasser, Boden, Luft - Beiträge zur Umweltgeschichte } \\
\text { des Volkswagenwerks Wolfsburg"; ISBN 3-935112-09-2; } \\
\text { Wolfsburg; } 2002\end{array}$ \\
\hline $\begin{array}{l}\text { Gray and Charter, } \\
2008\end{array}$ & $\begin{array}{l}\text { Gray, C.; Charter, M. "Remanufacturing and Product Design - } \\
\text { Designing for the 7th Generation"; January 2008, International } \\
\text { Journal of Product Development 6(34); } \\
\text { DOI:10.1504/IJPD.2008.020406; } 2008\end{array}$ \\
\hline Gregorius, 2006 & $\begin{array}{l}\text { Gregorius, H. "Verzahnungsschäden an Getrieben - Ursachen, } \\
\text { Schadensbilder, Abhilfe"; TZN - Technologiezentrum Niederrhein; } \\
\text { Duisburg; 2006; http://www.ib24.de/images/ib- } \\
\text { gregorius_PDFs/Vortraege/Verzahnungsschaeden_an_Getrieben.pdf; } \\
\text { downloaded 08.09.2021 }\end{array}$ \\
\hline $\begin{array}{l}\text { Groenewald and } \\
\text { Barai, } 2016\end{array}$ & $\begin{array}{l}\text { Groenewald, J.; Barai, A. "In-Service EV Battery Life Extension } \\
\text { Through Feasible Remanufacturing"; published 2016; 10.4271/2016- } \\
\text { 01-1290, https://www.researchgate.net/publication/299640622_In- } \\
\text { Service_EV_Battery_Life_Extension_Through_Feasible_Remanufac } \\
\text { turing; downloaded 18.10.2020 }\end{array}$ \\
\hline
\end{tabular}




\begin{tabular}{|c|c|}
\hline $\begin{array}{l}\text { Gruening and Witte, } \\
2011\end{array}$ & $\begin{array}{l}\text { Grüning, M.; Witte, M. "An overview of Electric Vehicles on the } \\
\text { market and in development"; published 2011; } \\
\text { https://www.ecologic.eu/13510; downloaded 18.10.2020 }\end{array}$ \\
\hline $\begin{array}{l}\text { Guide and van } \\
\text { Wassenhove, } 2009\end{array}$ & $\begin{array}{l}\text { Guide, V.D.R.; Wassenhove, L. N. van "The Evolution of Closed- } \\
\text { Loop Supply Chain Research"; Operations Reseach; Vol. 57; No.1.; } \\
\text { February 2009; pp. 10-18; DOI:10.1287/opre.1080.0628; } 2009\end{array}$ \\
\hline $\begin{array}{l}\text { Gustafsson et al., } \\
1984\end{array}$ & $\begin{array}{l}\text { Gustafsson, B., Rydén, L., Tibell, G., \& Wallensteen, P. "The } \\
\text { Uppsala Code of Ethics for Scientists"; Journal of Peace Research; } \\
\text { 21(4); 311-316; Retrieved November 28, 2020; from } \\
\text { http://www.jstor.org/stable/423746; } 1984\end{array}$ \\
\hline Нао, 2019 & $\begin{array}{l}\text { Hao, G. "Research on Electric Shock Prevention and First Aid for } \\
\text { Electric Vehicles"; International Journal of Engineering Research \& } \\
\text { Technology (IJERT); ISSN: 2278-0181; Vol. } 8 \text { Issue 01; January- } \\
\text { 2019; DOI:10.17577/IJERTV8IS010003; } 2019\end{array}$ \\
\hline Harkness et al., 2016 & $\begin{array}{l}\text { Harkness, J.; Bilgen, I.; Cazar, A.C.; Huang, L.; Miller, D.; Stange, } \\
\text { M.; Villar, A. "Questionnaire Design"; 2010; Updated 2016; } \\
\text { https://www.academia.edu/33445029/Cross_Cultural_Survey_Guidel } \\
\text { ines_Questionnaire_Design; downloaded 08.09.2021 }\end{array}$ \\
\hline Hatcher et al., 2011 & $\begin{array}{l}\text { Hatcher, G.D.; Ijomaha, W.L.; Windmill, J.F.C. "Design for } \\
\text { remanufacture: a literature review and future research needs"; Journal } \\
\text { of Cleaner Production; Volume 19, Issues 17-18, November-- } \\
\text { December 2011, Pages 2004-2014; } \\
\text { https://doi.org/10.1016/j.jclepro.2011.06.019; } 2011\end{array}$ \\
\hline $\begin{array}{l}\text { Hilger and } \\
\text { Beauducel, } 2017\end{array}$ & $\begin{array}{l}\text { Hilger N., Beauducel A. "Parallel-Forms Reliability" in: } \\
\text { Encyclopaedia of Personality and Individual Differences; Springer; } \\
\text { https://doi.org/10.1007/978-3-319-28099-8_1337-1; } 2017\end{array}$ \\
\hline Hinkelmann, 2020 & $\begin{array}{l}\text { Hinkelmann, K. "BPMN - Business Process Modelling Notation"; } \\
\text { University of Applied Scienes Northwestern Switzerland; } \\
\text { http://knut.hinkelmann.ch/lectures/ISA2009/ISA-7-2-BPMN.pdf; } \\
\text { downloaded 25.04.2020 }\end{array}$ \\
\hline Hollah et al., 2016 & $\begin{array}{l}\text { Hollah, A.M.; Kreisköther, K.D.; Kampker, A.; Lienemann, C. } \\
\text { "Electromobile Remanufacturing - Nutzenpotenziale für } \\
\text { batterieelektrische Fahrzeuge"; in: 5th Conference on Future } \\
\text { Automotive Technology Focus Electromobility; COFAT; 2016-10-12 } \\
\text { - 2016-10-13; Fürstenfeld; http://publications.rwth- } \\
\text { aachen.de/record/673766; } 2016\end{array}$ \\
\hline
\end{tabular}




\begin{tabular}{|c|c|}
\hline Honeywell, 2020 & $\begin{array}{l}\text { Honeywell International Inc "By 2020, It's Predicted That 70\% Of } \\
\text { The Light Vehicles Worldwide Will Be Boosted By Turbo } \\
\text { Technology"; http://www51.honeywell.com/honeywell/news- } \\
\text { events/case-studies-n3n4/turbochargers.html?c=36; downloaded } \\
\text { 22.05.2020 }\end{array}$ \\
\hline Hossain et al., 2003 & $\begin{array}{l}\text { Hossain, L.; Patrick, J.D.; Rashid, M.A. "Enterprise Resource } \\
\text { Planning: Global Opportunities and Challenges"; The Electronic } \\
\text { Library; 21(2); 169-169.; ISBN 1-930708-36-X; January 2003; } \\
\text { DOI:10.1108/02640470310470543; } 2003\end{array}$ \\
\hline Huber, 2001 & $\begin{array}{l}\text { Huber, A. "Demontageplanung und -steuerung Planung und } \\
\text { Steuerung industrieller Demontageprozesse mit PPS-Systemen"; } \\
\text { Dissertation Thesis; ISBN-13 : 978-3826593413; 2001; } \\
\text { https://prof.beuth- } \\
\text { hochschule.de/fileadmin/prof/ahuber/Dokumente/Demontageplanung } \\
\text { _und_-steuerung.pdf; downloaded 08.09.2021 }\end{array}$ \\
\hline Idaho, 2016 & $\begin{array}{l}\text { Idaho National Laboratory "History of Electric Cars, Idaho Falls"; } \\
\text { published 2016; } \\
\text { https://avt.inl.gov/sites/default/files/pdf/fsev/HistoryOfElectricCars.p } \\
\text { df; downloaded 18.10.2020 }\end{array}$ \\
\hline $\begin{array}{l}\text { Ijomah and Danis, } \\
2012\end{array}$ & $\begin{array}{l}\text { Ijomah, W.L.; Danis, M. "Refurbishment and reuse of WEEE" in } \\
\text { Waste Electrical and Electronic Equipment (WEEE) Handbook; } \\
\text { Woodhead Publishing Series in Electronic and Optical Materials; } \\
\text { Pages 145-162; December 2012; } \\
\text { DOI:10.1533/9780857096333.2.145; } 2012\end{array}$ \\
\hline ILO, 2005 & $\begin{array}{l}\text { International Labour Organization "Automotive industry trends } \\
\text { affecting component suppliers"; Sectoral Activities Programme; } \\
\text { ISBN Print: 92-2-116442-X; First published 2005; } \\
\text { http://www.ilo.org/global/docs/WCMS_161675/lang--en/index.htm; } \\
\text { downloaded 08.09.2021 }\end{array}$ \\
\hline $\begin{array}{l}\text { Intg.Engineering, } \\
2019\end{array}$ & $\begin{array}{l}\text { Interesting Engineering, Inc. "The Interesting History of Electric } \\
\text { Cars"; published May 19, 2019; } \\
\text { https://interestingengineering.com/the-interesting-history-of-electric- } \\
\text { cars; downloaded 03.09.2021 }\end{array}$ \\
\hline ISO, 2015 & $\begin{array}{l}\text { ISO - International Organization for Standardization "THE } \\
\text { PROCESS APPROACH" in ISO 9001:2015; 2015; }\end{array}$ \\
\hline
\end{tabular}




\begin{tabular}{|c|c|}
\hline & $\begin{array}{l}\text { https://www.iso.org/files/live/sites/isoorg/files/archive/pdf/en/iso900 } \\
\text { 1-2015-process-appr.pdf; downloaded 08.09.2021 }\end{array}$ \\
\hline Jacobs, 2021 & $\begin{array}{l}\text { Jacobs, F. "How Europe will beat China on batteries" in BIG THINK; } \\
\text { published 23.04.2021; https://bigthink.com/the-present/gigafactories- } \\
\text { in-europe/; downloaded 03.09.2021 }\end{array}$ \\
\hline JHG, 2021 & $\begin{array}{l}\text { John Hughes Group "Common car troubles, their causes and } \\
\text { solutions", first published May 2018; } \\
\text { https://www.johnhughes.com.au/blog/common-car-troubles-their- } \\
\text { causes-and-solutions; downloaded 15.05.2021 }\end{array}$ \\
\hline Jukun et al., 2014 & $\begin{array}{l}\text { Jukun, Y.; Sheng, Z.; Xiaoming, W.; Peizhi, C. "Remanufacturing } \\
\text { Upgrade Theory and Technology System Facing Product Multi-Life } \\
\text { Cycle"; Conference: Proceedings of the } 2014 \text { Sixth International } \\
\text { Conference on Measuring Technology and Mechatronics } \\
\text { Automation; 472-475. 10.1109/ICMTMA.2014.116. ; DOI: } \\
\text { 10.1109/ICMTMA.2014.116; } 2014\end{array}$ \\
\hline Jung et al., 2011 & $\begin{array}{l}\text { Jung, D.H.; Gafurov, A.; Seo, Y.K.; Sung, C.H. "Remanufacturing } \\
\text { Process Issues of Fuel Injectors for Diesel Engines"; Advances in } \\
\text { Sustainable Manufacturing: Proceedings of the 8th Global } \\
\text { Conference } 221 \text { on Sustainable Manufacturing; DOI 10.1007/978-3- } \\
\text { 642-20183-7_33; } 2011\end{array}$ \\
\hline Kabir, 2016 & $\begin{array}{l}\text { Kabir, S. "Methods of Data Collection"; in book: Basic Guidelines } \\
\text { for Research: An Introductory Approach for All Disciplines (pp.201- } \\
\text { 275); Edition: FirstChapter: 9; Publisher: Book Zone Publication; } \\
\text { Chittagong-4203; Bangladesh; 2016; } \\
\text { https://www.researchgate.net/publication/325846997_METHODS_O } \\
\text { F_DATA_COLLECTION; downloaded 11.09.2021 }\end{array}$ \\
\hline Kajornboon, 2005 & $\begin{array}{l}\text { Kajornboon, A.B. "Using interviews as research instruments"; } \\
\text { Article; Chulalongkorn University; Language Institute; Bangkok; } \\
\text { 2005; } \\
\text { https://www.researchgate.net/publication/252161886_Using_intervie } \\
\text { ws_as_research_instruments; downloaded 08.09.2021 }\end{array}$ \\
\hline Kampker et al., 2016 & $\begin{array}{l}\text { Kampker, A.; Heimes, H.H.; Ordung, M.; Lienemann, C.; Hollah, A.; } \\
\text { Sarovic, N. "Evaluation of a Remanufacturing for Lithium Ion } \\
\text { Batteries from Electric Cars" World Academy of Science, } \\
\text { Engineering and Technology; International Journal of Mechanical }\end{array}$ \\
\hline
\end{tabular}




\begin{tabular}{|c|c|}
\hline & $\begin{array}{l}\text { and Mechatronics Engineering; Vol:10; No:12; DOI: } \\
\text { doi.org/10.5281/zenodo.1128215; } 2016\end{array}$ \\
\hline Kampker et al., 2017 & $\begin{array}{l}\text { Kamper, A.; Triebs, J.; Hollah, A.; Lienemann, C. "Remanufacturing } \\
\text { of electric vehicles: Challenges in production planning and control"; } \\
\text { 16th Global Conference on Sustainable Manufacturing - Sustainable } \\
\text { Manufacturing for Global Circular Economy; Procedia } \\
\text { Manufacturing } 00 \text { (2017) 000-000; } \\
\text { https://doi.org/10.1016/j.promfg.2019.04.034; } 2017\end{array}$ \\
\hline Kampker et al., 2020 & $\begin{array}{l}\text { Kampker, A.; Triebs, J.; Hollah, A.; Unruh, A. "Remanufacturing of } \\
\text { electric vehicles: Challenges in production management"; MATEC } \\
\text { Web of Conferences 312; } 02012 \text { (2020); EPPM2018; } \\
\text { https://doi.org/10.1051/matecconf/202031202012; } 2020\end{array}$ \\
\hline Kara, 2008 & $\begin{array}{l}\text { Kara, H. "Carbon Impact of Remanufactured Products"; Article; } \\
\text { Centre for Remanufacturing \& Reuse; } 2008\end{array}$ \\
\hline KBC, 2017 & $\begin{array}{l}\text { KBC - Kemény Boehme \& Company GmbH } \\
\text { "REMANUFACTURING STUDY 2017"; } \\
\text { https://company.rematec.com/Image/Download?docid=68038\&dl=M } \\
\text { IJNRAI_TOP_LIBRARY\&ltc=MIJNRAI_LOGIN_PRIVATEFILE; } \\
\text { downloaded 27.07.2021 }\end{array}$ \\
\hline KIA, 2021 & $\begin{array}{l}\text { Kia Motors Corp. "Are electric cars cheaper to maintain?"; } \\
\text { https://www.kia.com/dm/discover-kia/ask/are-electric-cars-cheaper- } \\
\text { to-maintain.html; downloaded } 01.06 .2021\end{array}$ \\
\hline Kin et al., 2014 & $\begin{array}{l}\text { Kin, S.T.M.; Ong, S.K.; Nee, A.Y.C. "Remanufacturing Process } \\
\text { Planning"; 21st CIRP Conference on Life Cycle Engineering; } \\
\text { Procedia CIRP } 15 \text { ( } 2014 \text { ) } 189-194 ; \\
\text { DOI:10.1016/j.procir.2014.06.087; } 2014\end{array}$ \\
\hline $\begin{array}{l}\text { Kleylein-Feuerstein } \\
\text { et al., } 2015\end{array}$ & $\begin{array}{l}\text { Kleylein-Feuerstein, J.; Joas, F.; Steinhilper, R. "Remanufacturing of } \\
\text { electronic control units: An RFID based (service) interface"; Procedia } \\
\text { CIRP } 29 \text { ( } 2015 \text { ) } 168 \text { - 172; } \\
\text { https://pdf.sciencedirectassets.com/282173; } 2015\end{array}$ \\
\hline Kluza et al., 2017 & $\begin{array}{l}\text { Kluza, K.; Wisniewski, P.; Jobczyk, K.; Lige, A. "Comparison of } \\
\text { Selected Modeling Notations for Process, Decision and System } \\
\text { Modeling"; Proceedings of the Federated Conference on Computer } \\
\text { Science and Information Systems; ACSIS; Vol. 11; pp. 1095-1098; } \\
\text { ISSN 2300-5963; DOI: 10.15439/2017F454; } 2017\end{array}$ \\
\hline
\end{tabular}




\begin{tabular}{|c|c|}
\hline Knackstedt, 2017 & $\begin{array}{l}\text { Knackstedt, S. A. "A Case Study on Part Engineering Change } \\
\text { Management from a Development and Production Perspective at a } \\
\text { Major Automotive OEM"; All Theses; 2646; } \\
\text { https://tigerprints.clemson.edu/all_theses/2646; } 2017\end{array}$ \\
\hline Koehler, 2017 & $\begin{array}{l}\text { Koehler, M. "Turbochargers in the workshop - Technology, variants, } \\
\text { troubleshooting"; Krafthand Medien GmbH; ISBN: 978-3-87441- } \\
\text { 158-5; September 2017; https://cdn.borgwarner.com/docs/default- } \\
\text { source/default-document- } \\
\text { library/extract_krafthand_turbocharger_en.pdf?sfvrsn=ec4eb73c_8; } \\
\text { downloaded 11.09.2021 }\end{array}$ \\
\hline Köhler, 2019 & $\begin{array}{l}\text { Köhler, C. "Technische Produktänderungen : Analyse und } \\
\text { Beurteilung von Lösungsmöglichkeiten auf Basis einer Erweiterung } \\
\text { des CPM/PDD-Ansatzes"; UNIVERSITÄT DES SAARLANDES } \\
\text { SCHRIFTENREIHE PRODUKTIONSTECHNIK; Herausgeber: D. } \\
\text { Bähre und H. Bley; Dissertation September 2009; } \\
\text { https://www.researchgate.net/publication/277171419_Technische_Pr } \\
\text { oduktanderungen_Analyse_und_Beurteilung_von_Losungsmoglichk } \\
\text { eiten_auf_Basis_einer_Erweiterung_des_CPMPDD-Ansatzes; } \\
\text { downloaded 11.09.2021 }\end{array}$ \\
\hline $\begin{array}{l}\text { Koskela and } \\
\text { Haajanen, } 2007\end{array}$ & $\begin{array}{l}\text { Koskela, M.; Haajanen, J. "Business Process Modeling and } \\
\text { Execution"; VTT Technical Research Centre of Finland; } \\
\text { RESEARCH NOTES 2407; ISBN 978-951-38-6958-8; 2007; } \\
\text { https://www.vttresearch.com/sites/default/files/pdf/tiedotteet/2007/T2 } \\
\text { 407.pdf; downloaded 09.09.2021 }\end{array}$ \\
\hline KPMG, 2018 & $\begin{array}{l}\text { KPMG International Cooperative "Global Automotive Executive } \\
\text { Survey 2018"; 19th consecutive Global Automotive Executive } \\
\text { Survey; 2018; } \\
\text { https://assets.kpmg/content/dam/kpmg/id/pdf/2018/03/2018-global- } \\
\text { automotive-executive-summary.pdf; downloaded 09.09.2021 }\end{array}$ \\
\hline Krafthand, 2013 & $\begin{array}{l}\text { Krafthand Medien GmbH "Immer unter Druck - der Aufbau von } \\
\text { Common-Rail-Systemen"; Bad Woerishofen; } 2013\end{array}$ \\
\hline Krafthand, 2016 & $\begin{array}{l}\text { Krafthand Medien GmbH "Common-Rail-Systeme in der } \\
\text { Werkstattpraxis"; Leseprobe / Extraction ; Bad Woerishofen; ISBN } \\
\text { 978-3-87441-136-3; 2016; https://www.krafthand- } \\
\text { shop.de/out/media/Common_Rail_5_Leseprobe.pdf; downloaded } \\
\text { 09.09.2021 }\end{array}$ \\
\hline
\end{tabular}




\begin{tabular}{|c|c|}
\hline $\begin{array}{l}\text { Kroon and Vrijens, } \\
1995\end{array}$ & $\begin{array}{l}\text { Kroon, L.; Vrijens, G. "Returnable containers: an example of reverse } \\
\text { logistics"; International Journal of Physical Distribution \& Logistics } \\
\text { Management; Vol. } 25 \text { Iss: 2; pp.56 - 68; } \\
\text { https://www.emerald.com/insight/content/doi/10.1108/096000395100 } \\
\text { 83934/full/html; } 1995\end{array}$ \\
\hline Kumar et al., 2013 & $\begin{array}{l}\text { Kumar, P.; Dias, A.S. \& Zhang, H.-C. \& Kim, H.; \& Liu, Z.-C. } \\
\text { (2013). "Life Cycle Assessment: A Comparison of Manufacturing } \\
\text { and Remanufacturing Processes of a Diesel Engine"; April 2013; In } \\
\text { book: Re-engineering Manufacturing for Sustainability; pp.pp 675- } \\
\text { 678; Edition: 2013; Publisher: Springer Singapore; Editors: Andrew } \\
\text { Y. C. Nee, Bin Song, Soh-Khim Ong; DOI:10.1007/978-981-4451- } \\
\text { 48-2_110; } 2013\end{array}$ \\
\hline $\begin{array}{l}\text { Kurilova- } \\
\text { Palisaitiene, } 2018\end{array}$ & $\begin{array}{l}\text { Kurilova-Palisaitiene, J. "Lean Remanufacturing: Reducing Process } \\
\text { Lead Time" Linköping Studies in Science and Technology; } \\
\text { Dissertation No. 1938; Department of Management and Engineering; } \\
\text { Linköping University; } 2018\end{array}$ \\
\hline Laketa et al., 2015 & $\begin{array}{l}\text { Laketa, M.; Sanader, D.; Laketa, L.; Misic, Z. "Customer } \\
\text { Relationship Management: Concept and Importance for Banking } \\
\text { Sector"; UTMS Journal of Economics 6 (2): 241-254; 2015; } \\
\text { https://www.utmsjoe.mk/files/Vol.\%206\%20No.\%202/UTMSJOE- } \\
\text { 2015-0602-006-Laketa-Sanader-Laketa-Misic.pdf; downloaded } \\
\text { 09.09.2021 }\end{array}$ \\
\hline Liu et al., 2013 & $\begin{array}{l}\text { Liu, W.; Li, M.Z.; Zhang, H.-C. "Study on Remanufacturing } \\
\text { Cleaning Technology in Mechanical Equipment Remanufacturing } \\
\text { Process"; In book: Re-engineering Manufacturing for Sustainability; } \\
\text { pp.643-648; Publisher: Springer Singapore; Editors: Andrew Y. C. } \\
\text { Nee, Bin Song, Soh-Khim Ong; January 2013; DOI:10.1007/978- } \\
\text { 981-4451-48-2_105 ; } 2013 \text { DOI:10.1007/978-981-4451-48-2_105; } \\
2013\end{array}$ \\
\hline $\begin{array}{l}\text { Lucky and Takim, } \\
2015\end{array}$ & $\begin{array}{l}\text { Lucky, B. O.; Takim, S. "Manufacturing defects in the automobile } \\
\text { industry, a case study of the remote causes and effects of Toyota's } \\
\text { transmission malfunctions in cars"; International Journal of } \\
\text { Engineering and Applied Sciences (IJEAS); ISSN: 2394-3661, } \\
\text { Volume-2, Issue-8; August 2015; } \\
\text { https://media.neliti.com/media/publications/257854-manufacturing- } \\
\text { defects-in-the-automobile-ad97b6af.pdf; downloaded 11.09.2021 }\end{array}$ \\
\hline Mahle, 2020a & $\begin{array}{l}\text { MAHLE GmbH "MOTORENTEILE UND } \\
\text { FILTER:SCHADENSBILDER, URSACHEN UND }\end{array}$ \\
\hline
\end{tabular}




\begin{tabular}{|c|c|}
\hline & $\begin{array}{l}\text { VERMEIDUNG"; https://www.mahle- } \\
\text { aftermarket.com/media/homepage/facelift/media-center/workshop/e- } \\
\text { paper-schadensbroschuere-de.pdf; downloaded } 28.04 .2020\end{array}$ \\
\hline Mahle, 2020b & $\begin{array}{l}\text { MAHLE Clevite Inc. "Turbocharger: Damage PROFILES, causes, } \\
\text { and PREVENTION"; https://www.mahle- } \\
\text { aftermarket.com/media/local-media-north-america/pdfs-\&- } \\
\text { thumbnails/catalogs-and-literature/turbochargers/turbo-damage- } \\
\text { brochure-mo-2-612.pdf; downloaded } 01.06 .2020\end{array}$ \\
\hline Mahle, 2020c & $\begin{array}{l}\text { MAHLE Aftermarket "TURBOLADER: SCHADENSBILDER, } \\
\text { URSACHEN UND VERMEIDUNG"; https://www.mahle- } \\
\text { aftermarket.com/media/homepage/facelift/media-center/workshop/e- } \\
\text { paper-turbolader-schaden_de.pdf; downloaded 01.06.2020 }\end{array}$ \\
\hline $\begin{array}{l}\text { Mahmood and } \\
\text { Gutteridge, } 2019\end{array}$ & $\begin{array}{l}\text { Mahmood, K.; Gutteridge, F. "EV Batteries Remanufacturing - } \\
\text { BORG Automotive Challenge-Team 33"; University of Strathclyde; } \\
\text { published: } 29 \text { May } 2019 \\
\text { https://strathprints.strath.ac.uk/69631/1/Mahmood_Gutteridge_BOR } \\
\text { G_2019_EV_batteries_remanufacturing_BORG_automotive.pdf; } \\
\text { downloaded 30.05.2021 }\end{array}$ \\
\hline $\begin{array}{l}\text { Mahmoudi et al., } \\
2014\end{array}$ & $\begin{array}{l}\text { Mahmoudi, C.; Flah, A.; Sbita, L. "An Overview of Electric Vehicle } \\
\text { Concept and Power Management Strategies", published 2014; } 2014 \\
\text { International Conference on Electrical Sciences and Technologies in } \\
\text { Maghreb; CISTEM 2014; DOI:10.1109/CISTEM.2014.7077026; } \\
2014\end{array}$ \\
\hline Mancha, 2016 & $\begin{array}{l}\text { Mancha, A. "A Look at Some International Lithium-Ion Battery } \\
\text { Recycling Initiatives"; published 2016; The Journal of Undergraduate } \\
\text { Research at the University of Illinois at Chicago 9, 1-5; ; Corpus ID: } \\
\text { 113794676; DOI:10.5210/JUR.V9I1.7546; } 2016\end{array}$ \\
\hline Manufacturing, 2021 & $\begin{array}{l}\text { Manufacturing Global "Remanufacturing: recycling materials, } \\
\text { recouping costs, refining designs"; BizClik Media Limited; } \\
\text { published: } 18.03 .2021 ; \\
\text { https://www.manufacturingglobal.com/smart- } \\
\text { manufacturing/remanufacturing-recycling-materials-recouping-costs- } \\
\text { refining-designs; downloaded } 11.05 .2021\end{array}$ \\
\hline $\begin{array}{l}\text { Matsumoto and } \\
\text { Ijomah, } 2013\end{array}$ & $\begin{array}{l}\text { Matsumoto, M.; Ijomah, Dr. W. "Remanufacturing"; in: Kauffman J., } \\
\text { Lee KM. (eds) Handbook of Sustainable Engineering. Springer; } \\
\text { Dordrecht; https://doi.org/10.1007/978-1-4020-8939-8_93; } 2013\end{array}$ \\
\hline
\end{tabular}




\begin{tabular}{|c|c|}
\hline $\begin{array}{l}\text { Matsumoto and } \\
\text { Ikeda, } 2015\end{array}$ & $\begin{array}{l}\text { Matsumoto, M.; Ikeda, A. "Examination of demand forecasting by } \\
\text { time series analysis for auto parts remanufacturing"; Journal of } \\
\text { Remanufacturing; 5(1); December 2015; DOI: 10.1186/s13243-015- } \\
\text { 0010-y; } 2015\end{array}$ \\
\hline Mayring, 2007 & $\begin{array}{l}\text { Mayring, P. "On Generalization in Qualitatively Oriented Research"; } \\
23 \text { paragraphs in: Forum Qualitative Sozialforschung / Forum: } \\
\text { Qualitative Social Research; 8(3); Art. 26; http://nbn- } \\
\text { resolving.de/urn:nbn:de:0114-fqs0703262; } 2007\end{array}$ \\
\hline McHugh, 2012 & $\begin{array}{l}\text { McHugh, M. "Interrater reliability: the kappa statistic"; Biochemia } \\
\text { Medica 2012; 22(3):276-82; October 2012; } \\
\text { DOI:10.11613/BM.2012.031; } 2012\end{array}$ \\
\hline McKinsey, 2017 & $\begin{array}{l}\text { McKinsey \& Company "The changing aftermarket game - and how } \\
\text { automotive suppliers can benefit from arising opportunities"; June } \\
2017 \text {, } \\
\text { https://www.mckinsey.com/ /media/mckinsey/industries/automotive } \\
\% 20 \text { and\%20assembly/our\%20insights/the\%20changing\%20aftermar } \\
\text { ket\%20game\%20and\%20how\%20automotive\%20suppliers\%20can\% } \\
\text { 20benefit\%20from\%20arising\%20opportunities/the-changing- } \\
\text { aftermarket-game.pdf; downloaded 09.09.2021 }\end{array}$ \\
\hline McKinsey, 2020 & $\begin{array}{l}\text { McKinsey \& Company "McKinsey Electric Vehicle Index: Europe } \\
\text { cushions a global plunge in EV sales"; online article published July } \\
\text { 17, 2020; https://www.mckinsey.com/industries/automotive-and- } \\
\text { assembly/our-insights/mckinsey-electric-vehicle-index-europe- } \\
\text { cushions-a-global-plunge-in-ev-sales; downloaded 07.10.2021 }\end{array}$ \\
\hline McKinsey, 2021a & $\begin{array}{l}\text { McKinsey \& Company "Electromobility’s impact on powertrain } \\
\text { machinery"; } \\
\text { https://www.mckinsey.com/ /media/mckinsey/industries/automotive } \\
\% 20 \text { and\%20assembly/our\%20insights/electromobilitys\%20impact\% } \\
\text { 20on\%20powertrain\%20machinery/electromobilitys-impact-on- } \\
\text { powertrain-machinery-vf.pdf; downloaded 19.07.2021 }\end{array}$ \\
\hline McKinsey, 2021b & $\begin{array}{l}\text { McKinsey \& Company "Global Oil Outlook to 2040"; } \\
\text { https://www.mckinsey.com/ /media/mckinsey/industries/oil\%20and } \\
\% 20 \text { gas/our\%20insights/global\%20oil\%20supply\%20and\%20deman } \\
\text { d\%20outlook\%20to\%202040/global-oil-supply-and-demand-outlook- } \\
\text { to-2040-online-summary.pdf; downloaded 26.07.2021 }\end{array}$ \\
\hline Melett, 2020 & $\begin{array}{l}\text { Melett Ltd. "Difference Between Remanufactured \& Repaired } \\
\text { Turbos"; https://www.melett.com/technical/turbo-repair-types/the- }\end{array}$ \\
\hline
\end{tabular}




\begin{tabular}{|c|c|}
\hline & $\begin{array}{l}\text { difference-between-remanufactured-repaired-turbo-components/; } \\
\text { downloaded 05.06.2020 }\end{array}$ \\
\hline Meti, 2020 & $\begin{array}{l}\text { Meti, A.C. "Automotive Transmission Systems"; Lecture at M.S } \\
\text { Ramaiah School of Advanced Studies Bangalore; document without } \\
\text { date; https://anajibi.profile.semnan.ac.ir/downloads/file/465; } \\
\text { downloaded 09.09.2021 }\end{array}$ \\
\hline MHI, 2021 & $\begin{array}{l}\text { MHI "The } 2021 \text { MHI Annual Industry Report - Innovation Driven } \\
\text { Resilience"; https://www.mhi.org/publications/report\#download8; } \\
\text { downloaded 17.10.2021 }\end{array}$ \\
\hline $\begin{array}{l}\text { Milling and Jürging, } \\
2008\end{array}$ & $\begin{array}{l}\text { Milling, P.; Jürging, J. "Der Serienanlauf in der Automobilindustrie: } \\
\text { Technische Änderungen als Ursache oder Symptom von } \\
\text { Anlaufschwierigkeiten?"; in: Himpel F., Kaluza B., Wittmann J. (eds) } \\
\text { Spektrum des Produktions- und Innovationsmanagements; Gabler; } \\
\text { https://doi.org/10.1007/978-3-8350-5583-4_5; } 2008\end{array}$ \\
\hline Mills et al., 2012 & $\begin{array}{l}\text { Mills, A.; Durepos, G.; Wiebe, E. "Encyclopedia of Case Study } \\
\text { Research"; Print ISBN: 9781412956703; Online ISBN: } \\
\text { 9781412957397; Online Publication Date: December 27, 2012; } \\
\text { https://dx.doi.org/10.4135/9781412957397.n328; downloaded } \\
\text { 17.10.2021 }\end{array}$ \\
\hline Mingchuan, 2014 & $\begin{array}{l}\text { Mingchuan, M. "Automobile Transmission Design"; Thesis at } \\
\text { Saimaa University of Applied Sciences; 2014; } \\
\text { https://www.theseus.fi/bitstream/handle/10024/75701/Automobile\%2 } \\
\text { 0Transmission\%20Design.pdf?sequence=1\&isAllowed=y; } \\
\text { downloaded 11.09.2021 }\end{array}$ \\
\hline Mogre, 2012 & $\begin{array}{l}\text { Mogre, M.R. "Comparative Study between Automatic and Manual } \\
\text { Transmission Car"; International Conference on Mechanical, } \\
\text { Automobile and Biodiesel Engineering 2012; Dubai; 2012; } \\
\text { http://psrcentre.org/images/extraimages/6\%201012137.pdf; } \\
\text { downloaded 09.09.2021 }\end{array}$ \\
\hline Mohammadia, 2018 & $\begin{array}{l}\text { Mohammadia F. "Design, Analysis, and Electrification of a Solar- } \\
\text { Powered Electric Vehicle"; Journal of Solar Energy Research (JSER); } \\
\text { Vol 3; No 4; 293-299; 2018; } \\
\text { https://jser.ut.ac.ir/article_68813_c52cc5ab93afa490c2c02ac009e7d4 } \\
\text { 39.pdf; downloaded 09.09.2021 }\end{array}$ \\
\hline Morse, 2021 & $\begin{array}{l}\text { Morse, I. "Millions of electric cars are coming. What happens to all } \\
\text { the dead batteries?"; in ScienceMag; published May. 20, 2021; }\end{array}$ \\
\hline
\end{tabular}




\begin{tabular}{|c|c|}
\hline & $\begin{array}{l}\text { https://www.sciencemag.org/news/2021/05/millions-electric-cars-are- } \\
\text { coming-what-happens-all-dead-batteries; downloaded 01.08.2021 }\end{array}$ \\
\hline Moulin, 2010 & $\begin{array}{l}\text { Moulin, P. "AIR SYSTEMS MODELING AND CONTROL } \\
\text { FORTURBOCHARGED ENGINES"; Automatic; École Nationale } \\
\text { Supérieure des Mines de Paris; HAL Id: tel-00506475; 2010; } \\
\text { https://tel.archives-ouvertes.fr/tel-00506475; downloaded 09.09.2021 }\end{array}$ \\
\hline MSD, 2018 & $\begin{array}{l}\text { MS MOTORSERVICE DEUTSCHLAND GMBH "TEAMPLAYER } \\
\text { AM MOTOR - TURBOLADER UND PIERBURG PRODUKTE"; } \\
\text { Handout; March 2018; https://www.ms- } \\
\text { motorservice.de/fileadmin/media/MAM/PDF_Assets/Teamplayer- } \\
\text { am-Motor-Turbolader-und-Pierburg_55976.pdf; downloaded } \\
\text { 09.09.2021 }\end{array}$ \\
\hline MSI, 2006 & $\begin{array}{l}\text { MSI Motor Service International GmbH; "Ueberholung von } \\
\text { Aluminium-Motorbloecken"; August 2006; https://cdn2.ms- } \\
\text { motorservice.com/fileadmin/media/MAM/PDF_Assets/\%C3\%9Cber } \\
\text { holung-von-Aluminium-Motorb1\%C3\%B6cken_51703.pdf; } \\
\text { downloaded 09.09.2021 }\end{array}$ \\
\hline MSI, 2015 & $\begin{array}{l}\text { MSI Motor Service International GmbH; "WISSENSWERK - } \\
\text { KOLBENSCHÄDEN - ERKENNEN UND BEHEBEN"; May 2015; } \\
\text { https://cdn2.ms- } \\
\text { motorservice.com/fileadmin/media/MAM/PDF_Assets/Kolbensch\% } \\
\text { C3\%A4den-erkennen-und-beheben_51711.pdf; downloaded } \\
\text { 09.09.2021 }\end{array}$ \\
\hline Muenster, 2015 & $\begin{array}{l}\text { Muenster, V.; "Technologieentwicklung für die Refabrikation von } \\
\text { Einspritzsystemen"; Dissertation Thesis; Universität Bayreuth; } \\
\text { Lehrstuhl für Umweltgerechte Produktionstechnik; 2015; } \\
\text { https://epub.uni-bayreuth.de/2540/1/M\%C3\%BCnster_Injection.pdf; } \\
\text { downloaded 09.09.2021 }\end{array}$ \\
\hline Murphy, 2017 & $\begin{array}{l}\text { Murphy, L. "THE ELECTRIFYING PROBLEM OF USED } \\
\text { LITHIUM ION BATTERIES: RECOMMENDATIONS FOR } \\
\text { LITHIUM-ION BATTERY RECYCLING AND DISPOSAL"; } \\
\text { 01.12.2017; University of California, Davis, School of Law; } \\
\text { https://law.ucdavis.edu/centers/environmental/files/2018-Spring- } \\
\text { papers/The-Electrifying-Problem-of-Used-Lithium-Ion- } \\
\text { Batteries_Murphy.pdf; downloaded 23.09.2021 }\end{array}$ \\
\hline Nandhini et al., 2014 & $\begin{array}{l}\text { Nandhini, D.; Nandhini, G.; Nandhini, M.; Vidhya, R. "ON-BOARD } \\
\text { DIAGNOSTIC SYSTEM FOR VEHICLES"; International Journal of }\end{array}$ \\
\hline
\end{tabular}




\begin{tabular}{|c|c|}
\hline & $\begin{array}{l}\text { Advanced Research in Computer Engineering \& Technology } \\
\text { (IJARCET); Volume 3; Issue 3; March 2014; http://ijarcet.org/wp- } \\
\text { content/uploads/IJARCET-VOL-3-ISSUE-3-860-865.pdf; } 2014\end{array}$ \\
\hline NAPA, 2020 & $\begin{array}{l}\text { NAPA Echlin "MORE DIESEL, MORE POWER - THOUSANDS } \\
\text { OF DIESEL PARTS, HUNDREDS OF DIESEL CATEGORIES"; } \\
\text { https://www.napaechlin.com/media/6315/ne11389- } \\
\text { ned_dieselbrochure_sep19-web.pdf; downloaded 20.05.2020 }\end{array}$ \\
\hline Nasr, 2010 & $\begin{array}{l}\text { Nasr, N. Z. "Reman for Success"; in: Industrial Engineer; 06-2010; } \\
\text { https://www.iise.org/Archives.aspx?View=ArchivesAbstract\&ID=83 } \\
\text { 7\&Title=Reman\%20for\%20success; downloaded 09.09.2021 }\end{array}$ \\
\hline $\begin{array}{l}\text { Naunheimer et al., } \\
2011\end{array}$ & $\begin{array}{l}\text { Naunheimer, H.; Bertsche, B.; Ryborz, J.; Novak, W. "Vehicle } \\
\text { Transmission Systems: Basic Design Principles"; in: Automotive } \\
\text { Transmissions; ISBN 978-3-642-16213-8; Springer; Berlin; } \\
\text { Heidelberg; DOI:10.1007/978-3-642-16214-5_6; } 2011\end{array}$ \\
\hline NGD, 2011 & $\begin{array}{l}\text { National Geographic Deutschland, "Geschichte: Frühes Recycling"; ; } \\
\text { Heft 10-2011; http://www.nationalgeographic.de/wissen/geschichte- } \\
\text { fruehes-recycling; downloaded 26.08.2013 }\end{array}$ \\
\hline Ngo, 2012 & $\begin{array}{l}\text { Ngo, D. V. "Gear shift strategies for automotive transmissions"; } \\
\text { Technische Universiteit Eindhoven; } \\
\text { https://doi.org/10.6100/IR735458; } 2012\end{array}$ \\
\hline Niir, 2021 & $\begin{array}{l}\text { Niir Project Consultancy Services (NPCS) "Electric Motor } \\
\text { Rewinding Business. Emerging Investment Opportunities in } \\
\text { Rewinding of Burnt Electric Motors" } \\
\text { https://www.entrepreneurindia.co/Document/Download/Electric\%20 } \\
\text { Motor\%20Rewinding\%20Business.\%20Emerging\%20Investment\%2 } \\
\text { 0Opportunities\%20in\%20Rewinding\%20of\%20Burnt\%20Electric\%2 } \\
\text { 0Motors\%20Industry-721996-.pdf; downloaded 13.07.2021 }\end{array}$ \\
\hline Nikkei, 2021 & $\begin{array}{l}\text { Nikkei Inc. "Toyota to recycle hybrid and EV batteries for renewable } \\
\text { energy use"; published 30.05.2021; } \\
\text { https://asia.nikkei.com/Business/Automobiles/Toyota-to-recycle- } \\
\text { hybrid-and-EV-batteries-for-renewable-energy-use; downloaded } \\
\text { 04.09.2021 }\end{array}$ \\
\hline Nikolaidis, 2013 & $\begin{array}{l}\text { Nikolaidis, Y. "Quality Management in Reverse Logistics: A Broad } \\
\text { Look on Quality Issues and Their Interaction with Closed-Loop } \\
\text { Supply Chains"; Publisher: Springer; ISBN: 978-1-4471-4536-3; }\end{array}$ \\
\hline
\end{tabular}




\begin{tabular}{|c|c|}
\hline & $\begin{array}{l}\text { 2013th edition; November 2013; DOI:10.1007/978-1-4471-4537-0; } \\
2013\end{array}$ \\
\hline Ning et al., 2017 & $\begin{array}{l}\text { Ning, D.; Prasad, K.; Lie, T.T. "The electric vehicle: a review"; Int. J. } \\
\text { Electric and Hybrid Vehicles; Vol. 9; No. 1; } \\
\text { DOI:10.1504/IJEHV.2017.10003709; } 2017\end{array}$ \\
\hline OECD, 2011 & $\begin{array}{l}\text { OECD "THE ECONOMIC SIGNIFICANCE OF NATURAL } \\
\text { RESOURCES: KEY POINTS FOR REFORMERS IN EASTERN } \\
\text { EUROPE, CAUCASUS AND CENTRAL ASIA"; 2011; } \\
\text { https://www.oecd.org/env/outreach/2011_AB_Economic\%20signific } \\
\text { ance\%20of\%20NR\%20in\%20EECCA_ENG.pdf; downloaded } \\
09.09 .2021\end{array}$ \\
\hline Oertel, 2015 & $\begin{array}{l}\text { Oertel, K. (Hrsg.) "Loesungen entwickleln und nicht nur ein Produkt } \\
\text { verkaufen"; in "OEM Supplier 2015"; p.6-8; ISSN 1860-5699; } 2015\end{array}$ \\
\hline Oestlin, 2008 & $\begin{array}{l}\text { Östlin J. "On Remanufacturing Systems: Analysing and Managing } \\
\text { Material Flows and Remanufacturing Processes"; Dissertation; } \\
\text { Linköping University; Department of Management and Engineering, } \\
\text { Assembly technology; Linköping University; The Institute of } \\
\text { Technology; } 2008\end{array}$ \\
\hline OFI, 2020 & $\begin{array}{l}\text { OFI - Oregon FuelInjection, Inc. "Stanadyne Pump Diagnostic } \\
\text { Troubleshooting"; } \\
\text { https://oregonfuelinjection.com/content/uploads/2016/08/stanadyne- } \\
\text { pump-diagnostic-troubleshooting.pdf; downloaded 20.05.2020 }\end{array}$ \\
\hline Optimat, 2013 & $\begin{array}{l}\text { Optimat "Remanufacture, refurbishment, reuse and recycling of } \\
\text { vehicles: Trends and opportunities"; Final Report; June 2013; } \\
\text { Reference No J2432/OPT/001/12; ISBN: 9781784121136; 2013; } \\
\text { https://www.gov.scot/publications/remanufacture-refurbishment- } \\
\text { reuse-recycling-vehicles-trends-opportunities/; downloaded } \\
\text { 12.09.2021 }\end{array}$ \\
\hline Oxfam, 2020 & $\begin{array}{l}\text { Oxfam International "Global Megatrends: Mapping the Forces that } \\
\text { Affect Us All"; January 2020; ISBN 978-1-78748-564-8; } \\
\text { https://policy-practice.oxfam.org/resources/global-megatrends- } \\
\text { mapping-the-forces-that-affect-us-all-620942/; downloaded } \\
\text { 12.09.2021 }\end{array}$ \\
\hline Parker et al., 2015 & $\begin{array}{l}\text { Parker, D.; Riley, K.; Robinson, S.; Symington, H.; Tewson, J.; } \\
\text { Jansson, K.; Ramkumar, S.; Peck, D. "ERN-European } \\
\text { Remanufacturing Network, Remanufacturing Market Study. Delft, }\end{array}$ \\
\hline
\end{tabular}




\begin{tabular}{|c|c|}
\hline & $\begin{array}{l}\text { The Netherlands: European Remanufacturing Council"; published } \\
\text { 2015; www.remanufacturing.eu/assets/pdfs/remanufacturing-market- } \\
\text { study.pdf; downloaded 26.07.2021 }\end{array}$ \\
\hline Partington, 2001 & $\begin{array}{l}\text { Partington, G. "Qualitative Research Interviews: Identifying } \\
\text { Problems in Technique Technique"; Issues in educational research; } \\
\text { Vol. 11; no 2; 2001; https://ro.ecu.edu.au/ecuworks/4368/; } \\
\text { downloaded 09.09.2021 }\end{array}$ \\
\hline Pham and Cao, 2019 & $\begin{array}{l}\text { Pham, V.V.; Cao, D.T. "A BRIEF REVIEW OF TECHNOLOGY } \\
\text { SOLUTIONS ON FUEL INJECTION SYSTEM OF DIESEL } \\
\text { ENGINE TO INCREASE THE POWER AND REDUCE } \\
\text { ENVIRONMENTAL POLLUTION"; Journal of Mechanical } \\
\text { Engineering Research \& Developments (JMERD) 42(1) (2019) 01- } \\
\text { 09; DOI : http://doi.org/10.26480/jmerd.01.2019.01.09; } 2019\end{array}$ \\
\hline Pillai, 2017 & $\begin{array}{l}\text { Pillai, P. "Forecasting of Core Returns for Remanufacture: A Time } \\
\text { Series Analysis"; Theses and Dissertations; 1525; published May } \\
\text { 2017; } \\
\text { https://dc.uwm.edu/cgi/viewcontent.cgi?article=2530\&context=etd; } \\
\text { downloaded 01.08.2021 }\end{array}$ \\
\hline $\begin{array}{l}\text { Polichronis et al., } \\
2013\end{array}$ & $\begin{array}{l}\text { Polichronis, D.; Evaggelos, R.; Alcibiades, G.; Elias, G.; Apostolos, } \\
\text { P. "Turbocharger Lubrication - Lubricant Behavior and Factors That } \\
\text { Cause Turbocharger Failure"; ISSN 2146-9067 International Journal } \\
\text { of Automotive Engineering and Technologies Vol. 2; Issue 1; pp. } 40 \\
\text { - 54; 2013; } \\
\text { https://www.researchgate.net/publication/271701360_Turbocharger_ } \\
\text { Lubrication_- } \\
\text { Lubricant_Behavior_and_Factors_That_Cause_Turbocharger_Failure } \\
\text {; downloaded 12.09.2021 }\end{array}$ \\
\hline Polit and Beck, 2010 & $\begin{array}{l}\text { Polit, D.;Beck, C. "Generalization in quantitative and qualitative } \\
\text { research: Myths and strategies"; International Journal of Nursing } \\
\text { Studies 47; 1451-1458; } \\
\text { https://doi.org/10.1016/j.ijnurstu.2010.06.004; } 2010\end{array}$ \\
\hline $\begin{array}{l}\text { Prasad and } \\
\text { Krishnanunni, } 2020\end{array}$ & $\begin{array}{l}\text { Prasad, S.K.V.; Krishnanunni, S. "Review on Analysis of Failures } \\
\text { Modes in the Electric Vehicles due to } \\
\text { Electric Bearings"; International Research Journal of Engineering and } \\
\text { Technology (IRJET); e-ISSN: 2395-0056; Volume: 07; Issue: 12; } \\
\text { December 2020; https://www.irjet.net/archives/V7/i12/IRJET- } \\
\text { V7I12315.pdf; 2020 }\end{array}$ \\
\hline
\end{tabular}




\begin{tabular}{|c|c|}
\hline Prolim, 2021 & $\begin{array}{l}\text { PROLIM Global Corporation "Engineering Change Management in } \\
\text { the Automotive Industry - When are you Finally Market Ready?"; } \\
\text { https://prolim.com/wp-content/uploads/2015/09/Engineering-change- } \\
\text { management-in-automotive-industry.pdf; downloaded 16.05.2021 }\end{array}$ \\
\hline Qasem, 2010 & $\begin{array}{l}\text { Qasem, I. "Resource scarcity in the 21st century: Conflict or } \\
\text { cooperation?" ; The Hague Centre for Strategic Studies and TNO ; } \\
\text { paper no 2010-03; ISBN: 978-94-91040-11-5; 2010; } \\
\text { https://repository.tudelft.nl/islandora/object/uuid:92893597-2433- } \\
\text { 4721-ac26-e0a6e5fec63a/datastream/URL/download; downloaded } \\
\text { 10.09.2021 }\end{array}$ \\
\hline $\begin{array}{l}\text { Ramoni and Zhang, } \\
2012\end{array}$ & $\begin{array}{l}\text { Ramoni, M.; Zhang, H.-C. "Remanufacturing Processes of Electric } \\
\text { Vehicle Battery"; Article May 2012; DOI: } \\
\text { 10.1109/ISSST.2012.6228014; } 2012\end{array}$ \\
\hline Rashid et al., 2020 & $\begin{array}{l}\text { Rashid, A.; Roci, M.; Asif, M.A.F. "Chapter 26: Circular } \\
\text { manufacturing systems"; in: Handbook of the Circular Economy; } \\
\text { Published:15 December 2020; Pages:343-357; } \\
\text { https://doi.org/10.4337/9781788972727.00036; downloaded } \\
\text { 12.09.2021 }\end{array}$ \\
\hline $\begin{array}{l}\text { Reddy and Yamini, } \\
2015\end{array}$ & $\begin{array}{l}\text { Reddy, A.V.S.K.; Yamini, P. "Fuel Injection System an } \\
\text { Advancement in Fuel Supply Systems"; Journal of Basic and Applied } \\
\text { Engineering Research; Print ISSN: 2350-0077; Online ISSN: 2350- } \\
\text { 0255; Volume 2, Number 6; April-June, } 2015 \text { pp. 496-501; } 2015\end{array}$ \\
\hline Reif, 2012 & $\begin{array}{l}\text { Reif, K. "Klassische Diesel-Einspritzsysteme"; Vieweg+Teubner } \\
\text { Verlag; Springer Fachmedien Wiesbaden GmbH; ISBN 978-3-8348- } \\
\text { 1596-5; 2012; https://link.springer.com/content/pdf/bbm\%3A978-3- } \\
\text { 8348-8664-4\%2F1.pdf; downloaded 09.09.2021 }\end{array}$ \\
\hline Renault, 2008 & $\begin{array}{l}\text { Renault Deutschland GmbH "Common rail"; Printed Handout; } \\
\text { Bruehl; December } 2008\end{array}$ \\
\hline Reuters, 2018 & $\begin{array}{l}\text { Thomson Reuters Holdings Inc. "China puts responsibility for battery } \\
\text { recycling on makers of electric vehicles"; published 2018; } \\
\text { https://br.reuters.com/article/us-china-batteries-recycling/china-puts- } \\
\text { responsibility-for-battery-recycling-on-makers-of-electric-vehicles- } \\
\text { idUSKCN1GA0MG; downloaded } 18.10 .2020\end{array}$ \\
\hline Reuters, 2021 & $\begin{array}{l}\text { Thomson Reuters Holdings Inc. "UK in talks with } 6 \text { firms to build } \\
\text { gigafactories for EV batteries -FT"; published 16.06.2021; } \\
\text { https://www.reuters.com/world/uk/britain-talks-with-6-firms-about- }\end{array}$ \\
\hline
\end{tabular}




\begin{tabular}{|c|c|}
\hline & $\begin{array}{l}\text { building-gigafactories-ev-batteries-ft-2021-06-16/; downloaded } \\
\text { 03.09.2021 }\end{array}$ \\
\hline Revicki, 2014 & $\begin{array}{l}\text { Revicki D. "Internal Consistency Reliability"; in: Michalos A.C. } \\
\text { (eds); Encyclopedia of Quality of Life and Well-Being Research; } \\
\text { Springer; Dordrecht; ISBN } \\
\text { 978-94-007-0752-8; https://doi.org/10.1007/978-94-007-0753- } \\
\text { 5_102076; } 2014\end{array}$ \\
\hline Reynolds, 1995 & $\begin{array}{l}\text { Reynolds, S. P. "The German Recycling Experiment and Its Lessons } \\
\text { for United States Policy"; } 6 \text { Vill. Envtl. L.J. 43; 1995; } \\
\text { https://digitalcommons.law.villanova.edu/elj/vol6/iss 1/2; downloaded } \\
\text { 09.09.2021 }\end{array}$ \\
\hline $\begin{array}{l}\text { Ridley and Ijomah, } \\
2021\end{array}$ & $\begin{array}{l}\text { Ridley, S.J.; Ijomah, W.L. "Improving the Efficiency of the } \\
\text { Remanufacture of Complex Mechanical Assemblies with Robust } \\
\text { Inspection of Core Units"; } \\
\text { https://strathprints.strath.ac.uk/57750/1/Ridley_Ijomah_ICoR_2011_I } \\
\text { mproving_the_efficiency_of_the_remanufacture_of_complex_mecha } \\
\text { nical.pdf; downloaded 20.07.2021 }\end{array}$ \\
\hline $\begin{array}{l}\text { Riza and Purba, } \\
2018\end{array}$ & $\begin{array}{l}\text { Riza, M.; Purba, H. H. "THE IMPLEMENTATION OF ECONOMIC } \\
\text { ORDER QUANTITY FOR REDUCING INVENTORY COST: A } \\
\text { CASE STUDY IN AUTOMOTIVE INDUSTRY"; Article; October } \\
\text { 2018; DOI:10.21008/j.2083-4950.2018.8.4.1; } 2018\end{array}$ \\
\hline $\begin{array}{l}\text { Rosa and Schaeffer, } \\
1995\end{array}$ & $\begin{array}{l}\text { Rosa, L.P.; Schaeffer, R. "Global warming potentials: The case of } \\
\text { emissions from dams"; Energy Policy; Volume 23, Issue 2, Pages } \\
\text { 149-158; February 1995; https://doi.org/10.1016/0301- } \\
\text { 4215(95)91418-C; } 1995\end{array}$ \\
\hline Rothgang, 2015 & $\begin{array}{l}\text { Rothgang, S. "Mehr Fahrspaß und Effizienz: Der elektrische } \\
\text { Verdichter von Pierburg" in "OEM Supplier 2015"; p.89; ISSN 1860- } \\
5699 ; 2015\end{array}$ \\
\hline RRC, 2020 & $\begin{array}{l}\text { Renewable Resources Coalition "Top 11 Natural Resources"; last } \\
\text { updated 27.11.2016; } \\
\text { https://www.renewableresourcescoalition.org/top-natural-resources/; } \\
\text { downloaded 17.04.2020 }\end{array}$ \\
\hline Saberi, 2018 & $\begin{array}{l}\text { Saberi, B. "The role of the automobile industry in the economy of } \\
\text { developed countries"; International Robotics \& Automation Journal; } \\
\text { Volume 4; Issue 3; DOI:10.15406/iratj.2018.04.00119; } 2018\end{array}$ \\
\hline
\end{tabular}




\begin{tabular}{|c|c|}
\hline Sahni et al., 2010 & $\begin{array}{l}\text { Sahni, S.; Boustani, A.; Gutowski, T.; Graves, S. "Electric Motor } \\
\text { Remanufacturing and Energy Savings"; Environmentally Benign } \\
\text { Laboratory Laboratory for Manufacturing and Productivity Sloan } \\
\text { School of Management; Publication MITEI-1-d-2010; 2010; } \\
\text { http://web.mit.edu/ebm/www/Publications/MITEI-1-d-2010.pdf; } \\
\text { downloaded 12.09.2021 }\end{array}$ \\
\hline Sanderson, 2017 & $\begin{array}{l}\text { Sanderson, H. "Rise of electric cars poses battery recycling } \\
\text { challenge"; Financial Times; published 03. September 2017; } \\
\text { https://www.ft.com/content/c489382e-6b06-11e7-bfeb- } \\
\text { 33fe0c5b7eaa; downloaded 18.10.2020 }\end{array}$ \\
\hline Sanguesa et al., 2021 & $\begin{array}{l}\text { Sanguesa, J.A.; Torres-Sanz, V.; Garrido, P.; Martinez, F.J.; } \\
\text { Marquez-Barja, J.M "A Review on Electric Vehicles: Technologies } \\
\text { and Challenges"; Smart Cities 2021, 4, 372-404; } \\
\text { https://doi.org/10.3390/smartcities4010022; } 2021\end{array}$ \\
\hline Sansoni, 2011 & $\begin{array}{l}\text { Sansoni, J.E. "Questionnaire design and systematic literature } \\
\text { reviews"; University of Wollongong; presentation at the University of } \\
\text { Canberra; 2011; } \\
\text { https://ro.uow.edu.au/cgi/viewcontent.cgi?article=1124\&context=ahs } \\
\text { ri; downloaded 09.09.2021 }\end{array}$ \\
\hline Sauer, 2016 & $\begin{array}{l}\text { Peter Sauer \& Sohn KG Motorentechnik "MOTORENSERVICE"; } \\
\text { Dieburg; September 2016; } \\
\text { https://www.sauerundsohn.de/fileadmin/user_upload/SA- } \\
\text { 119_Service-Broschuere_2016_Web.pdf; downloaded 09.09.2021 }\end{array}$ \\
\hline Scherner, 2018 & $\begin{array}{l}\text { Scherner, J. "Lernen und Lernversagen - Die 'Metallmobilisierung' im } \\
\text { Deutschen Reich } 1939 \text { bis 1945"; Vierteljahrshefte für } \\
\text { Zeitgeschichte, vol. 66, no. 2, 2018, pp. 233-266. } \\
\text { https://doi.org/10.1515/vfzg-2018-0013; } 2018\end{array}$ \\
\hline $\begin{array}{l}\text { Schneider et al., } \\
2009\end{array}$ & $\begin{array}{l}\text { Schneider, E. I.; Kindlein, W.; Souza, S.; Malfatti, C. F. "Assessment } \\
\text { and reuse of secondary batteries cells"; published 2009; Journal of } \\
\text { Power Sources - J POWER SOURCES. 189; 1264-1269; DOI } \\
\text { 10.1016/j.jpowsour.2008.12.154; } 2009\end{array}$ \\
\hline Seitz, 2005 & $\begin{array}{l}\text { Seitz, M. A. "Closed-Lopp Supply Chain Management and } \\
\text { Remanufacturing in the Automotive Sector"; 2005; } \\
\text { https://core.ac.uk/download/pdf/19397605.pdf; downloaded } \\
\text { 09.09.2021 }\end{array}$ \\
\hline
\end{tabular}




\begin{tabular}{|c|c|}
\hline Sileyew, 2019 & $\begin{array}{l}\text { Sileyew, K. "Research Design and Methodology"; } 2019 \text {; DOI: } \\
\text { 10.5772/intechopen.85731; downloaded 12.09.2021 }\end{array}$ \\
\hline SIR, 2017 & $\begin{array}{l}\text { SIR - Scottish Institute for Remanufacture; University of Strathclyde; } \\
\text { "Scaling Remanufacturing Processes by improving efficiency and } \\
\text { productivity Mackie Automatic Transmissions Ltd \& University of } \\
\text { Strathclyde - A Scottish Institute for Remanufacture Case Study"; } \\
\text { January 2017; https://www.scot-reman.ac.uk/wp- } \\
\text { content/uploads/2017/01/Scaling-Remanufacturing-Processes-by- } \\
\text { improving-efficiency-productivity.-Mackies-Automatic- } \\
\text { Transmissions-Ltd-University-of-Strathclyde.pdf; downloaded } \\
\text { 09.09.2021 }\end{array}$ \\
\hline Slimstock, 2019 & $\begin{array}{l}\text { Slimstock Sverige "MINIMUM ORDER QUANTITY (MOQ) } \\
\text { EXPLAINED"; } 22 \text { JULY 2019 PUBLISHED IN BLOG; } \\
\text { https://www.slimstock.com/se/minimum-order-quantity/; } \\
\text { downloaded: } 21.09 .2021\end{array}$ \\
\hline Snyder, 2019 & $\begin{array}{l}\text { Snyder, H. "Literature review as a research methodology: An } \\
\text { overview and guidelines"; Journal of Business Research 104: p. 333- } \\
\text { 339; August 2019; https://doi.org/10.1016/j.jbusres.2019.07.039; } \\
2019\end{array}$ \\
\hline Spiegel, 2017 & $\begin{array}{l}\text { SPIEGEL Online "Autokrise - Merkel halt Ende von } \\
\text { Verbrennungsmotoren für richtig"; published 14.08.2017; } \\
\text { https://www.spiegel.de/auto/aktuell/merkel-haelt-ende-von- } \\
\text { verbrennungsmotoren-fuer-richtigen-ansatz-a-1162820.html; } \\
\text { downloaded 18.10.2020 }\end{array}$ \\
\hline Springer, 2013 & $\begin{array}{l}\text { Springer (Herausgeber) "Ersatzteillogistik im Automobilbau"; Berlin } \\
\text { / Heidelberg; } 2013\end{array}$ \\
\hline Springer, 2021 & $\begin{array}{l}\text { Springer; Die Welt "PS Welt - Leser fragen - Experten antworten - } \\
\text { Welche Teile zählen eigentlich zu den Verschleißteilen?"; published } \\
\text { 09.06.2016; } \\
\text { https://www.welt.de/motor/news/article156102397/Leser-fragen- } \\
\text { Experten-antworten.html; downloaded 14.05.2021 }\end{array}$ \\
\hline $\begin{array}{l}\text { Standridge and } \\
\text { Lindsay, } 2014\end{array}$ & $\begin{array}{l}\text { Standridge, C. R.; Lindsay, C. "Remanufacturing, Repurposing and } \\
\text { Recycling of Post-Vehicle-Application Lithium-Ion Batteries"; } \\
\text { Report 12-20, A publication of Mineta National Transit Research } \\
\text { Consortium, } \\
\text { https://www.google.com/url?sa=t\&rct=j\&q=\&esrc=s\&source=web\& } \\
\text { cd=\&ved=2ahUKEwj10YXmqb7sAhXK6nMBHQwSAfUQFjAAeg }\end{array}$ \\
\hline
\end{tabular}




\begin{tabular}{|c|c|}
\hline & $\begin{array}{l}\text { QIBBAC\&url=https\%3A\%2F\%2Frosap.ntl.bts.gov\%2Fview\%2Fdot } \\
\text { \%2F27425\%2Fdot_27425_DS1.pdf\%3F\&usg=AOvVaw0n4AU2grar } \\
\text { 1axbYbqNR-7E; downloaded 18.10.2020 }\end{array}$ \\
\hline $\begin{array}{l}\text { Standridge and } \\
\text { Mehedi, } 2015\end{array}$ & $\begin{array}{l}\text { Standridge, C. R.; Mehedi, H. "Post-vehicleapplication lithium-ion } \\
\text { battery remanufacturing, repurposing and recycling capacity: } \\
\text { Modeling and analysis" ; Journal of Industrial Engineering and } \\
\text { Management (JIEM); ISSN 2013-0953; OmniaScience; Barcelona; } \\
\text { Vol. 8, Iss. 3, pp. 823-839, http://dx.doi.org/10.3926/jiem.1418; } 2015\end{array}$ \\
\hline STANDS4, 2021 & $\begin{array}{l}\text { STANDS4 LLC "Mark Twain Quotes"; Quotes.net; 2021; } \\
\text { https://www.quotes.net/quote/69095; downloaded 28.10.2021 }\end{array}$ \\
\hline Starman, 2013 & $\begin{array}{l}\text { Starman, A. "The case study as a type of qualitative research"; } 28 . \\
\text { JOURNAL OF CONTEMPORARY EDUCATIONAL STUDIES } \\
\text { 1/2013; 2013; } \\
\text { https://www.researchgate.net/publication/265682891_The_case_stud } \\
\text { y_as_a_type_of_qualitative_research; downloaded 09.09.2021 }\end{array}$ \\
\hline Statista, 2020 & $\begin{array}{l}\text { Statista, Inc. "Estimated worldwide automobile production from } 2000 \\
\text { to 2019"; https://www.statista.com/statistics/262747/worldwide- } \\
\text { automobile-production-since-2000/; downloaded 17.03.2020 }\end{array}$ \\
\hline Statista, 2021a & $\begin{array}{l}\text { Statista, Inc. "Daily demand for crude oil worldwide from } 2006 \text { to } \\
\text { 2020, with a forecast until 2026"; } \\
\text { https://www.statista.com/statistics/271823/daily-global-crude-oil- } \\
\text { demand-since-2006/; downloaded 26.07.2021 }\end{array}$ \\
\hline Statista, 2021b & $\begin{array}{l}\text { Statista, Inc. "Projected electric vehicle production in } 2027 \text {, by } \\
\text { region"; https://www.statista.com/statistics/974263/electric-vehicle- } \\
\text { production-by-region/; downloaded } 21.09 .2021\end{array}$ \\
\hline $\begin{array}{l}\text { Steinhilper and } \\
\text { Nagel, } 2017\end{array}$ & $\begin{array}{l}\text { Steinhilper, R.; Nagel, A. "New Opportunities and Incentives for } \\
\text { Remanufacturing by 2020`s Car Service Trends"; The 24th CIRP } \\
\text { Conference on Life Cycle Engineering; Procedia CIRP } 61 \text { (2017); } \\
183 \text { - 188; DOI:10.1016/j.procir.2016.11.233; } 2017\end{array}$ \\
\hline $\begin{array}{l}\text { Steinhilper et al., } \\
2006\end{array}$ & $\begin{array}{l}\text { Steinhilper, R.; Rosemann,B.; Freiberger, S. "Product and Process } \\
\text { Assessment for Remanufacturing of Computer Controlled } \\
\text { Automotive Components"; Conference: 13th CIRP International } \\
\text { Conference on Life Cycle Engineering January 2006; } \\
\text { https://www.researchgate.net/publication/337472134_Product_and_p } \\
\text { rocess_assessment_for_remanufacturing_of_computer_controlles_aut } \\
\text { omative_components; downloaded 18.10.2020 }\end{array}$ \\
\hline
\end{tabular}




\begin{tabular}{|c|c|}
\hline Steinhilper, 1998 & $\begin{array}{l}\text { Steinhilper, R. "Remanufacturing - The Ultimate Form of } \\
\text { Recycling"; Fraunhofer IRB Verlag; ISBN: } 3816752160 \\
\text { 9783816752165; OCLC Number: 56138196 Stuttgart; } 1998\end{array}$ \\
\hline Stroehmer, 2009 & $\begin{array}{l}\text { Ströhmer, M. "Verpackungen in der Logistik"; Fraunhofer IML; } \\
\text { Presentation handout of presentation on 30th September } 2009 \text { at } \\
\text { Fachpark 2009 / bdvi Seminar Verpackung 2009; 2009; } \\
\text { https://www.bdvi.org/fileadmin/pool/Seminar_Verpackung/Verpacku } \\
\text { ng_und_Logistik_Marcel_Stroehmer_FhG_IML.pdf; downloaded } \\
\text { 10.09.2021 }\end{array}$ \\
\hline $\begin{array}{l}\text { Subramoniam et al., } \\
2009\end{array}$ & $\begin{array}{l}\text { Subramoniam, R.; Huisingh, D.; Chinnam, R. B. "Remanufacturing } \\
\text { for the automotive aftermarket- strategic factors: literature review and } \\
\text { future research needs"; Journal of Cleaner Production; September } \\
2009,17.1163-1174 \text {, DOI: 10.1016/j.jclepro.2009.03.004; } 2009\end{array}$ \\
\hline $\begin{array}{l}\text { Subramoniam et al., } \\
2021\end{array}$ & $\begin{array}{l}\text { Subramoniam, R.; Sundin, E.; Subramoniam, S.; Huisingh, D. } \\
\text { "Riding the Digital Product Life Cycle Waves towards a Circular } \\
\text { Economy"; Sustainability 2021; 13; 8960; } \\
\text { https://doi.org/10.3390/su13168960; } 2021\end{array}$ \\
\hline Subramoniam, 2012 & $\begin{array}{l}\text { Subramoniam, R. "Remanufacturing for the Aftermarket: Strategic } \\
\text { Planning and Decision-making Framework for the Automotive } \\
\text { Industry"; docor thesis; Erasmus University; Rotterdam; 2012; } \\
\text { https://www.eur.nl/sites/corporate/files/FINALFINALThesisSubramo } \\
\text { niam_april_0.pdf; downloaded 12.09.2021 }\end{array}$ \\
\hline $\begin{array}{l}\text { Sundin and } \\
\text { Dunbäck, } 2013\end{array}$ & $\begin{array}{l}\text { Sundin, E.; Dunbäck, O. "Reverse Logistics Challenges in } \\
\text { Remanufacturing of Automotive Mechatronics and Electronic } \\
\text { Systems"; Journal of Remanufacturing, (3)2.; } \\
\text { http://dx.doi.org/10.1186/2210-4690-3-2; } 2013\end{array}$ \\
\hline Sundin et al., 2012 & $\begin{array}{l}\text { Sundin, E.; Elo, K; Lee, H.M. "Design for automatic end-of-life } \\
\text { processes"; Assembly Automation, Vol. } 32 \text { Iss: } 4 \text { pp. } 389 \text { - 398; } \\
\text { ISSN: 0144-5154; http://dx.doi.org/10.1108/01445151211262447; } \\
2012\end{array}$ \\
\hline Sundin, 2004 & $\begin{array}{l}\text { Sundin, E. "Product and process design for successful } \\
\text { remanufacturing"; Linköpings Universitet; Dissertation No. 906; } \\
\text { ISBN 9185295736; ISSN: 0345-7524; 2004; https://www.diva- } \\
\text { portal.org/smash/get/diva2:20932/FULLTEXT01.pdf; downloaded } \\
\text { 10.09.2021 }\end{array}$ \\
\hline
\end{tabular}




\begin{tabular}{|c|c|}
\hline $\begin{array}{l}\text { Svensson et al., } \\
2007 \mathrm{a}\end{array}$ & $\begin{array}{l}\text { Svensson, L., Eklund, J., Randle, H., Aronsson, G. "Interactive } \\
\text { Research - an Attempt to Analyse two Change Programmes"; } \\
\text { International Journal of Action Research 3(3):250-277; https://nbn- } \\
\text { resolving.org/urn:nbn:de:0168-ssoar-356386; } 2007\end{array}$ \\
\hline $\begin{array}{l}\text { Svensson et al., } \\
2007 \mathrm{~b}\end{array}$ & $\begin{array}{l}\text { Svensson, L; Ellström, P.; Brulin, G. "Introduction - on interactive } \\
\text { research"; International Journal of ActionResearch; 3(3); 233-249; } \\
\text { https://nbn-resolving.org/urn:nbn:de:0168-ssoar-356352; } 2007\end{array}$ \\
\hline $\begin{array}{l}\text { Svensson et al., } \\
2007 \mathrm{c}\end{array}$ & $\begin{array}{l}\text { Svensson, L.; Ellström, P.-E.; Brulin, G. "Introduction - on } \\
\text { interactive research"; International Journal of Action Research, 3(3), } \\
\text { 233-249. https://nbn-resolving.org/urn:nbn:de:0168-ssoar-356352; } \\
2007\end{array}$ \\
\hline Szmelter, 2016 & $\begin{array}{l}\text { Szmelter, A. "Specifics of Closed Loop Supply Chain Management } \\
\text { in the food sector"; Journal of Reverse Logistics; 1/2016 (2) p. 14-19; } \\
\text { 2016; } \\
\text { https://www.academia.edu/31575443/Specifics_od_Closed_Loop_Su } \\
\text { pply_Chain_Management_in_the_food_sector; downloaded } \\
\text { 12.09.2021 }\end{array}$ \\
\hline Taherdoost, 2016 & $\begin{array}{l}\text { Taherdoost, H. "Validity and Reliability of the Research Instrument - } \\
\text { How to Test the Validation of a Questionnaire/Survey in a } \\
\text { Research"; International Journal of Academic Research in } \\
\text { Management (IJARM); Vol. 5; No. 3; 2016; Page: 28-36; ISSN: } \\
\text { 2296-1747; } 2016\end{array}$ \\
\hline $\begin{array}{l}\text { Tangkawarow and } \\
\text { Waworuntu, } 2016\end{array}$ & $\begin{array}{l}\text { Tangkawarow, I.; Waworuntu, J. "A Comparative of business process } \\
\text { modelling techniques"; } 2016 \text { IOP Conf. Ser.: Mater. Sci. Eng.128 } \\
\text { 012010; DOI } \\
\text { https://doi.org/10.1088/1757-899X/128/1/012010; } 2016\end{array}$ \\
\hline TBR, 2010 & $\begin{array}{l}\text { Technische Betriebe Remscheid; Remscheider Entsorgungsbetriebe } \\
\text { "Die Industrialisierung des Muells"; Handout; 2010; https://www.tbr- } \\
\text { info.de/files/daten/entsorgung/download/201006_abfall_02.pdf; } \\
\text { downloaded 10.09.2021 }\end{array}$ \\
\hline $\begin{array}{l}\text { Tchertchian et al., } \\
2012\end{array}$ & $\begin{array}{l}\text { Tchertchian, N.; Millet, D.; El Korchi, A. "Design for } \\
\text { remanufacturing: What performances can be expected?"; } \\
\text { International Journal of Environmental Technology and } \\
\text { Management; } 15 \text { (1); pp.28 - 49.; January 2012; } \\
\text { DOI:10.1504/IJETM.2012.045151; } 2012\end{array}$ \\
\hline
\end{tabular}




\begin{tabular}{|c|c|}
\hline TDS, 2020 & $\begin{array}{l}\text { TDS - Total Diesel Service "Instandsetzung der Diesel } \\
\text { Einspritzdüsen und Pumpen"; } \\
\text { http://www.totaldiesel.eu/Instandsetzung_Diesel_Einspritzdusen_und } \\
\% 20 \_P u m p e n . p d f ; \text { downloaded 21.05.2020 }\end{array}$ \\
\hline TH, 2020 & $\begin{array}{l}\text { TH Group "Turbo remanufacturing according to the latest } \\
\text { manufacturers' specifications"; https://www.th- } \\
\text { group.eu/en/turbochargers/remanufacturing; downloaded } 05.06 .2020\end{array}$ \\
\hline TRC, 2014 & $\begin{array}{l}\text { TRC Reman "On-Highway Remanufactured Products"; Handout; } \\
\text { January 2014; http://www.trcreman.com/files/11635\%20- } \\
\text { \%20Brochure\%20for\%20Web.pdf; downloaded 11.09.2021 }\end{array}$ \\
\hline TT, 2020 & $\begin{array}{l}\text { Turbo Technics "Turbo Reman Process"; } \\
\text { https://www.turbotechnics.com/turbo-reman-process/; downloaded } \\
\text { 05.06.2020 }\end{array}$ \\
\hline U.S.Energy, 2020a & $\begin{array}{l}\text { U.S. Department of Energy "Alternative Fuels Data Center; Energy } \\
\text { Efficiency and Renewable Energy" } \\
\text { https://afdc.energy.gov/vehicles/how-do-all-electric-cars-work; } \\
\text { downloaded } 18.10 .2020\end{array}$ \\
\hline U.S.Energy, 2020b & $\begin{array}{l}\text { U.S. Department of Energy "The History of the Electric Car"; } \\
\text { https://www.energy.gov/articles/history-electric-car; downloaded } \\
18.10 .2020\end{array}$ \\
\hline UN, 2011 & $\begin{array}{l}\text { United Nations; Centre for Regional Development; CSD-19 Learning } \\
\text { Centre "Synergizing Resource Efficiency with Informal Sector } \\
\text { towards Sustainable Waste Management" - Reduce, Reuse and } \\
\text { Recycle (the 3Rs) and Resource Efficiency as the basis for } \\
\text { Sustainable Waste Management; Presentation Slides of Presentation } \\
\text { 9th May 2011; New York; } 2011\end{array}$ \\
\hline UN, 2019 & $\begin{array}{l}\text { United Nations "United Nations Environment Programme 2019; } \\
\text { GLOBAL RESOURCES OUTLOOK 2019 - NATURAL } \\
\text { RESOURCES FOR THE FUTURE WE WANT"; 2019; } \\
\text { https://www.resourcepanel.org/reports/global-resources-outlook; } \\
\text { downloaded 11.09.2021 }\end{array}$ \\
\hline UniBayreuth, 2012 & $\begin{array}{l}\text { Universität Bayreuth; "Reverse Supply Chains within Automotive } \\
\text { Remanufacturing CAN-Reman - Public Results"; Chair } \\
\text { Manufacturing and Remanufacturing Technology; Bayreuth; } 2012\end{array}$ \\
\hline
\end{tabular}




\begin{tabular}{|c|c|}
\hline $\begin{array}{l}\text { UniRegensburg, } \\
2010\end{array}$ & $\begin{array}{l}\text { Universität Regensburg "Teil 2: Der Nationalsozialismus } 1933 \text { - } 1945 \\
\text { - Autarkie und Außenwirtschaft"; Fachbereich } \\
\text { Wirtschaftswissenschaften; Lecturing Script Winter Semester } 2009 \text { / } \\
\text { 2010; Regensburg; } 2010\end{array}$ \\
\hline UniSussex, 2017 & $\begin{array}{l}\text { University of Sussex "Engine Testing and Modelling"; School of } \\
\text { Engineering and Informatics; Sussex; 2017; } \\
\text { https://users.sussex.ac.uk/ tafb8/eti/eti_03_EngineTestingOverview. } \\
\text { pdf; download 11.09.2021 }\end{array}$ \\
\hline Un-Noor et al., 2017 & $\begin{array}{l}\text { Un-Noor, F.; Padmanaban, S.; Mihet-Popa, L.; Mollah, M. N.; } \\
\text { Hossain, E. "A Comprehensive Study of Key Electric Vehicle (EV) } \\
\text { Components, Technologies, Challenges, Impacts, and Future } \\
\text { Direction of Development. Energies"; 2017; 10. } \\
\text { 10.3390/en10081217; GM Media Online (2018) } \\
\text { https://media.gm.com/media/us/en/gm/news.html; downloaded } \\
\text { 12.10.2018 }\end{array}$ \\
\hline USA, 2020 & $\begin{array}{l}\text { United States of America, U.S. Embassy Seoul "Theodore Roosevelt } \\
\text { : The Conservation Of Natural Resources (1907)"; } \\
\text { https://kr.usembassy.gov/education-culture/infopedia-usa/living- } \\
\text { documents-american-history-democracy/theodore-roosevelt- } \\
\text { conservation-natural-resources-1907/; downloaded 17.04.2020 }\end{array}$ \\
\hline $\begin{array}{l}\text { VanWynsberghe, } \\
2007\end{array}$ & $\begin{array}{l}\text { VanWynsberghe, R. "Redefining Case Study"; International Journal } \\
\text { of Qualitative Methods 2007; 6(2); } \\
\text { https://doi.org/10.1177/160940690700600208; } 2007\end{array}$ \\
\hline Vege, 2012 & $\begin{array}{l}\text { Vege Moteurs S.A. "Turbochargers Remanufactured \& New"; Vege } \\
\text { UK; Handout; } 2012\end{array}$ \\
\hline Vege, 2020 & $\begin{array}{l}\text { VEGE-Motoren GmbH "Generalueberholte Schaltgetriebe"; } \\
\text { document without date; https://www.vege- } \\
\text { motoren.de/userfiles/library/germany/german_gearboxes.pdf; } \\
\text { downloaded 15.05.2020 }\end{array}$ \\
\hline Vergidis et al., 2008 & $\begin{array}{l}\text { Vergidis, K., Majeed, B., Tiwari, A. "Business Process Analysis and } \\
\text { Optimization: Beyond Reengineering"; article in IEEE Transactions } \\
\text { on Systems Man and Cybernetics Part C (Applications and Reviews); } \\
\text { DOI:10.1109/TSMCC.2007.905812; February } 2008\end{array}$ \\
\hline $\begin{array}{l}\text { Voelkner and } \\
\text { Robkhob, } 2010\end{array}$ & $\begin{array}{l}\text { Voelkner, D.; Robkhob, A. "Zerlegung eines PKW- Fünf- } \\
\text { Ganggetriebe" im Rahmen der Vorlesung „Konstruktionselemente }\end{array}$ \\
\hline
\end{tabular}




\begin{tabular}{|c|c|}
\hline & $\begin{array}{l}\text { 2“; Fachhochschule Suedwestfalen; Semester Work Semester } \\
\text { 2009/2010 in the Seminar of Prof.Dr.-Ing. W. Hannibal; } 2010\end{array}$ \\
\hline Vogel, 2014 & $\begin{array}{l}\text { Vogel Communications Group "Laderhemmung?"; kfz-betrieb; Heft } \\
\text { 29/2014; Würzburg; } 2014\end{array}$ \\
\hline VW, 2004 & $\begin{array}{l}\text { Volkswagen AG "Neuwertig durch industrielle Aufbereitung - } \\
\text { Volkswagen Original Austausch Teile"; Printed Handout; Wolfsburg; } \\
\text { September } 2004\end{array}$ \\
\hline VW, 2011 & $\begin{array}{l}\text { Volkswagen AG; "Volkswagen Kassel in Baunatal"; } \\
\text { Geschichtswerkstatt Volkswagen Kassel; Herausgeber : Sutton; } 1 . \\
\text { Edition (1. Juli 2011); ISBN-10 : 3866808275; } 2011\end{array}$ \\
\hline VW, 2013 & $\begin{array}{l}\text { Volkswagen AG "Wiedersehen macht Freude - Volkswagen Original } \\
\text { Teile"; Printed Handout; Wolfsburg; } 2016\end{array}$ \\
\hline VW, 2016 & $\begin{array}{l}\text { Volkswagen AG "Original Austausch Teile - Altteile- } \\
\text { Ruecknahmekriterien"; no date printed on document; Received 2016; } \\
\text { Printed Handout; Wolfsburg; } 2016\end{array}$ \\
\hline VW, 2021a & $\begin{array}{l}\text { Volkswagen Bank GmbH "Verschleißteile am Auto"; } \\
\text { https://www.vwfs.de/auto-mobilitaet-services/wartung- } \\
\text { inspektion/verschleiss.html; downloaded 14.05.2021 }\end{array}$ \\
\hline VW, 2021b & $\begin{array}{l}\text { Volkswagen AG "Lithium to lithium, manganese to manganese"; } \\
\text { https://www.volkswagenag.com/en/news/stories/2019/02/lithium-to- } \\
\text { lithium-manganese-to-manganese.html\#; downloaded 04.09.2021 }\end{array}$ \\
\hline Wagner et al., 2017b & $\begin{array}{l}\text { Wagner, S.M.; Joenke, R.; Eisingerich, A.B. "A Strategic Framework } \\
\text { for Spare Parts Logistics"; California Management Review, Vol. 54, } \\
\text { No. 4, pp. 69-92. ISSN 0008-1256, eISSN 2162-8564.; } \\
\text { DOI:10.1525/cmr.2012.54.4.69; } 2012\end{array}$ \\
\hline Wagner, 2017a & $\begin{array}{l}\text { Wagner, R. "Production Phase-Out - Process Modelling Including } \\
\text { Adaptions for Production Planning and Control"; Publisher: Josef Eul } \\
\text { Verlag Gmbh; ISBN-13: 978-3844105209; August } 2017\end{array}$ \\
\hline $\begin{array}{l}\text { Walsham and } \\
\text { Winterbone, } 1990\end{array}$ & $\begin{array}{l}\text { Walsham, B.E.; Winterbone, D.E. "The Turbocharger"; in: Weaving } \\
\text { J.H. (eds) Internal Combustion Engineering: Science \& Technology; } \\
\text { Springer; Print ISBN } \\
\text { 978-94-010-6822-2; DOI https://doi.org/10.1007/978-94-009-0749- } \\
\text { 2_14; } 1990\end{array}$ \\
\hline
\end{tabular}




\begin{tabular}{|c|c|}
\hline Walton, 2021 & $\begin{array}{l}\text { Walton, E. "Short Block vs. Long Block Engine - What's the } \\
\text { Difference?"; published July 13, } 2021 \text { at Autolist, Inc.; } \\
\text { https://www.autolist.com/guides/short-block-vs-long-block-engine; } \\
\text { downloaded 20.07.2021 }\end{array}$ \\
\hline Warsen et al., 2011 & $\begin{array}{l}\text { Warsen, J.; Laumer, M.; Momberg, W. "Comparative Life Cycle } \\
\text { Assessment of Remanufacturing and New Manufacturing of a } \\
\text { Manual Transmission"; In: Hesselbach J., Herrmann C. (eds) } \\
\text { Globalized Solutions for Sustainability in Manufacturing. Springer; } \\
\text { Berlin; Heidelberg; ISBN 978-3-642-19691-1; } 2011\end{array}$ \\
\hline Wei et al., 2015 & $\begin{array}{l}\text { Wei, S.; Tang, O.; Sundin, E. "Core (product) Acquisition } \\
\text { Management for remanufacturing: a review", Journal of } \\
\text { Remanufacturing volume 5; Article number: 4; DOI } \\
\text { https://doi.org/10.1186/s13243-015-0014-7; } 2015\end{array}$ \\
\hline Wei, 2014 & $\begin{array}{l}\text { Wei, S. "Core Acquisition Management in Remanufacturing - } \\
\text { Current Status and Modeling Techniques"; Linköping Studies in } \\
\text { Science and Technology; Dissertation No. 1637; ISBN 978-91-7519- } \\
\text { 167-6; December } 2014\end{array}$ \\
\hline Weiland, 2012 & $\begin{array}{l}\text { Weiland, F.J. "European Automotive Remanufacturing - Technical } \\
\text { Trends \& Market Development", Cologne, Editions FJW Consulting; } \\
2012\end{array}$ \\
\hline Weiland, 2020 & $\begin{array}{l}\text { Weiland, F.J. "Electric Vehicle Challenges \& Opportunities for } \\
\text { European Remanufacturers" published } 07 \text { April } 2020 \text { in REMATEC; } \\
\text { https://www.rematec.com/news/strategy-and-concept/electric- } \\
\text { vehicle-challenges/; downloaded 03.06.2021 }\end{array}$ \\
\hline Weissler, 2014 & $\begin{array}{l}\text { Weissler, R. "'Reman' engine market steady, but complexity } \\
\text { challenges production efficiency"; Article in: SAE International; } \\
\text { published 26.11.2014; https://www.sae.org/news/2014/11/reman- } \\
\text { engine-market-steady-but-complexity-challenges-production- } \\
\text { efficiency; downloaded 21.09.2021 }\end{array}$ \\
\hline Westermann, 2012 & $\begin{array}{l}\text { Westermann, H.-H. "Managing Complexity in Remanufacturing } \\
\text { Companies"; Fraunhofer Projektgruppe Prozessinnovation; Bayreuth; } \\
\text { Presentation slides as part of presentation during WorldReman } \\
\text { Summit 2012; } 2012\end{array}$ \\
\hline Wiesinger, 2021 & $\begin{array}{l}\text { Kfz-Technik Wiesinger "Motorschaden - wie kommt es dazu? - Die } \\
7 \text { häufigsten Ursachen für kapitale Motorschäden / Zu hohe } \\
\text { Drehzahlen"; }\end{array}$ \\
\hline
\end{tabular}




\begin{tabular}{|c|c|}
\hline & $\begin{array}{l}\text { https://www.kfztech.de/kfztechnik/motor/motorschaden.htm; } \\
\text { downloaded 15.05.2021 }\end{array}$ \\
\hline Wikfeldt, 2017 & $\begin{array}{l}\text { Wikfeldt, E. "Generalising from Case Studies"; Halmstad University } \\
\text { Halmstad; Sweden; DOI: 10.13140/RG.2.2.25554.76480; } 2017\end{array}$ \\
\hline Woollacott, 2021 & $\begin{array}{l}\text { Woollacott, E. "Electric cars: What will happen to all the dead } \\
\text { batteries?" in BBC; first published 27.04.2021; } \\
\text { https://www.bbc.com/news/business-56574779; downloaded } \\
04.09 .2021\end{array}$ \\
\hline $\begin{array}{l}\text { Woongkul et al., } \\
2017\end{array}$ & $\begin{array}{l}\text { Woongkul, L.; Schubert, E.; Li, Y.; Li, S.; Bobba, D.; Sarlioglu, B. } \\
\text { "Overview of Electric Turbocharger and Supercharger } \\
\text { for Downsized Internal Combustion Engines"; IEEE Transactions on } \\
\text { Transportation Electrification; 3(1):36-47; March 2017; DOI: } \\
\text { 10.1109/TTE.2016.2620172; } 2017\end{array}$ \\
\hline WSA, 2016 & $\begin{array}{l}\text { World Steel Association "STEEL - THE PERMANENT MATERIAL } \\
\text { IN THE CIRCULAR ECONOMY"; ISBN 978-2-930069-86-9; } \\
\text { Brussels; 2016; https://www.worldsteel.org/en/dam/jcr:7e0dc90a- } \\
\text { 3efe-41bc-9fb4-85f9e873dfc7/Steel\%2520- } \\
\text { \%2520The\%2520Permanent\%2520Material\%2520in\%2520the\%252 } \\
\text { 0Circular\%2520Economy.pdf; downloaded 11.09.2021 }\end{array}$ \\
\hline WTO, 2011 & $\begin{array}{l}\text { World Trade Organization "Word Trade Report 2010"; ISBN: } \\
\text { 9789287043160; https://doi.org/10.30875/65678d0b-en; } 2011\end{array}$ \\
\hline Xia et al., 2011 & $\begin{array}{l}\text { Xia, W.; Jia, D.; He, Y. "The remanufacturing reverse logistics } \\
\text { management based on Closed-loop supply chain management } \\
\text { processes"; Procedia Environmental Sciences } 11 \text { (2011) } 351-354 \text {; } \\
\text { DOI https://doi.org/10.1016/j.proenv.2011.12.056; } 2011\end{array}$ \\
\hline $\begin{array}{l}\text { Yatheesha et al., } \\
2014\end{array}$ & $\begin{array}{l}\text { Yatheesha, R. B.; Anarghya, A.; Ranjith, B. S.; Rao, N. "Extended } \\
\text { Range Electric Vehicle (EREV)"; International Journal of } \\
\text { Engineering and Advanced Technology (IJEAT) ISSN: } 2249 \text { - 8958; } \\
\text { Volume-4 Issue-1; https://www.ijeat.org/wp- } \\
\text { content/uploads/papers/v4i1/A3459104114.pdf; October } 2014\end{array}$ \\
\hline Yoda et al., 2020 & $\begin{array}{l}\text { Yoda, K.; Irie, H.; Kinoshita, Y.; Yamada, T.; Yamada, S.; Inoue, M. } \\
\text { "Remanufacturing Option Selection with Disassembly for Recovery } \\
\text { Rate and Profit"; paper Received March 29, 2020; accepted } \\
\text { September 11, 2020; } \\
\text { https://www.jstage.jst.go.jp/article/ijat/14/6/14_930/_pdf/-char/ja; } \\
\text { downloaded: 01.08.2021 }\end{array}$ \\
\hline
\end{tabular}




\begin{tabular}{|c|c|}
\hline $\begin{array}{l}\text { Zawacki-Richter et } \\
\text { al., } 2020\end{array}$ & $\begin{array}{l}\text { Zawacki-Richter, O., Kerres, M., Bedenlier, S., Bond, M., Buntins, } \\
\text { K. "Systematic Reviews in Educational Research Methodology, } \\
\text { Perspectives and Application"; Springer VS; ISBN 978-3-658-27601- } \\
\text { 0; ISBN 978-3-658-27602-7; https://doi.org/10.1007/978-3-658- } \\
\text { 27602-7; } 2020\end{array}$ \\
\hline ZDK, 2021 & $\begin{array}{l}\text { Zentralverband Deutsches Kraftfahrzeuggewerbe e. V. "Falsches } \\
\text { Motoröl kann teuer werden"; } \\
\text { https://www.kfzgewerbe.de/presse/publikationen/promotor/archiv/fal } \\
\text { sches-motoroel-kann-teuer-werden.html; downloaded 15.05.2021 }\end{array}$ \\
\hline Zero, 2014a & $\begin{array}{l}\text { Zero Waste Scotland Limited "Mackie Automatic \& Manual } \\
\text { Transmissions"; October 2014; https://www.scot-reman.ac.uk/wp- } \\
\text { content/uploads/2015/10/Mackie-Transmissions-case-study- } \\
\text { approved.pdf; downloaded 11.09.2021 }\end{array}$ \\
\hline Zero, 2014b & $\begin{array}{l}\text { Zero Waste Scotland Limited "Diesel ReCon a subsidiary of } \\
\text { Cummins"; November 2015; https://www.scot-reman.ac.uk/wp- } \\
\text { content/uploads/2015/10/Diesel-ReCon-case-study-approved.pdf; } \\
\text { downloaded 11.09.2021 }\end{array}$ \\
\hline ZF, 2012 & $\begin{array}{l}\text { ZF Friedrichshafen AG "Remanufacturing at ZF"; } \\
\text { https://www.zf.com/mobile/en/stories_7289.html; downloaded } \\
\text { 16.05.2021 }\end{array}$ \\
\hline $\mathrm{ZF}, 2013 \mathrm{a}$ & $\begin{array}{l}\text { ZF Getriebe GmbH "Getriebetechnik der ZF"; Symposium } \\
\text { Kraftfahrzeugtechnik by Heribert Scherer; } 2013\end{array}$ \\
\hline $\mathrm{ZF}, 2013 \mathrm{~b}$ & $\begin{array}{l}\text { ZF Services, LLC "ZF Remanufactured Transmissions for Passenger } \\
\text { Cars"; Hill Drive; 2013; https://ci- } \\
\text { portal.zf.com/gc_content/document/int_print_catalogs_documents/us } \\
\text { a_4/ZF_Remanufactured_Transmissions.pdf; downloaded } \\
\text { 11.09.2021 }\end{array}$ \\
\hline ZF, 2016 & $\begin{array}{l}\text { ZF Services "Remanufacturing ohne Grenzen"; in: "Up2DATE - Das } \\
\text { Aftermarket Magazin von ZF Services" the company newspaper for } \\
\text { the aftersales division of ZF; issue April 2016; Schweinfurt; } 2016\end{array}$ \\
\hline $\begin{array}{l}\text { Zhang and Chen, } \\
2018\end{array}$ & $\begin{array}{l}\text { Zhang, J.: Chen, M. "After-Sale Data Based Common Rail Injector } \\
\text { Remanufacturability Analysis"; Journal of Shanghai Jiaotong } \\
\text { University (Science); 23, 337-344(2018); DOI } \\
\text { https://doi.org/10.1007/s12204-018-1948-3; } 2018\end{array}$ \\
\hline Zhang et al., 2011 & $\begin{array}{l}\text { Zhang, Y.; Wanga, C.-Y.; Tang, X. "Cycling degradation of an } \\
\text { automotive LiFePO4lithium-ion battery"; Journal of Power }\end{array}$ \\
\hline
\end{tabular}




\begin{tabular}{|l|l|}
\hline & $\begin{array}{l}\text { Sources196 (2011); 1513-1520; DOI } \\
\text { https://doi.org/10.1016/j.jpowsour.2010.08.070; } 2011\end{array}$ \\
\hline Zhang et al., 2014a & $\begin{array}{l}\text { Zhang, H.C.; Li, T.; Liu, Z.; Jiang, Q. "Diesel Engine Block } \\
\text { Remanufacturing: Life Cycle Assessment"; in: Handbook of } \\
\text { Manufacturing Engineering and Technology; Print ISBN: 978-1- } \\
\text { 4471-4669-8; pp 1-22; } \\
\text { https://link.springer.com/referenceworkentry/10.1007\%2F978-1- } \\
\text { 4471-4670-4_111; March 2014 }\end{array}$ \\
\hline Zhang et al., 2014b & $\begin{array}{l}\text { Zhang, H.; Liu, W.; Dong, Y.; Zhang, H.; Chen,H. "A method for } \\
\text { pre-determining the optimal remanufacturing point of lithium } \\
\text { ion batteries"; 21st CIRP Conference on Life Cycle Engineering; } \\
\text { Procedia CIRP 15 (2014) 218 - 222; DOI: } \\
\text { https://doi.org/10.1016/j.procir.2014.06.064; 2014 }\end{array}$ \\
\hline ZKR, 2013 & $\begin{array}{l}\text { Zweckverband der Kehrichtverwertung Rheintal "Geschichte des } \\
\text { Recyclings"; http://www.kvr-rheintal.com/umwelt/recycling.html; } \\
\text { downloaded 26.08.2013 }\end{array}$ \\
\hline
\end{tabular}



in a Changing Market 


\section{Papers}

The papers associated with this thesis have been removed for copyright reasons. For more details about these see:

http://urn.kb.se/resolve?urn=urn:nbn:se:liu:diva-180947 


\section{FACULTY OF SCIENCE AND ENGINEERING}

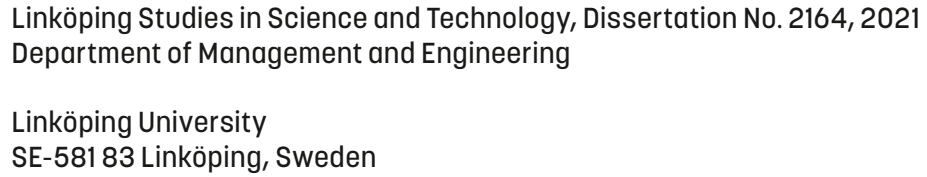

www.liu.se 